\title{
El volcanismo tipo intraplaca del Cenozoico tardío en el centro y norte de México: una revisión
}

\author{
José Jorge Aranda-Gómez 1,*, James F. Luhr², Todd B. Housh³, Gabriel Valdez-Moreno ${ }^{4}$, \\ Gabriel Chávez-Cabello ${ }^{4}$
}

${ }^{1}$ Departamento de Geología Económica, Instituto Potosino de Investigación Científica y Tecnológica, Apartado postal 3-74, San Luis Potosí, S. L. P., 78216, México. Domicilio actual: Centro de Geociencias, UNAM, Campus Juriquilla, Querétaro, Qro. 76230, México

${ }^{2}$ Department of Mineral Sciences, Smithsonian Institution, Washington, D. C. 20560, USA

${ }^{3}$ Department of Geological Sciences, University of Texas at Austin, Austin, Texas 78712, USA

${ }^{4}$ Posgrado en Ciencias de la Tierra, Centro de Geociencias, Universidad Nacional Autónoma de México, Campus Juriquilla, Apartado postal 1-742, Querétaro, Qro., 76001, México

* jaranda@ipicyt.edu.mx, jjag@geociencias.unam.mx

\section{Resumen}

El volcanismo tipo intraplaca (Oligoceno tardío-Cuaternario) ocurre en México tanto en regiones pertenecientes a la placa de América del Norte como sobre corteza oceánica de la placa del Pacífico. Los magmas extravasados a través de corteza oceánica formaron volcanes escudo voluminosos (Socorro: 2 $400 \mathrm{~km}^{3}$ ) ubicados sobre o cerca de dorsales abandonadas. Las rocas en las porciones subaéreas de los volcanes forman series contínuas y coherentes (Guadalupe) o conjuntos bimodales (Socorro). La cristalización fraccionada en cámaras magmáticas someras, a partir de magmas basálticos alcalinos, así como la asimilación de rocas alteradas por sistemas hidrotermales determinaron la composición elemental e isotópica de las rocas máficas e intermedias de Socorro. Las traquitas de Socorro al parecer fueron formadas por fusión parcial (5-10\%) de un basalto alcalino. Fraccionamiento a partir de magmas traquíticos originó a las riolitas. Las rocas félsicas de Socorro también muestran evidencias de asimilación de rocas alteradas hidrotermalmente.

En la región continental existen numerosas localidades al norte de la Faja Volcánica Transmexicana (FVTM). Este fenómeno es independiente de provincias volcánicas más antiguas, de límites entre provincias geológica/tectónicas actuales y de fronteras entre terrenos tectonoestratigráficos. Muchas rocas volcánicas de tipo intraplaca son alcalinas [i.e., grafican arriba de la línea $\mathrm{FeO} / \mathrm{MgO}=\left(0.156 \times \mathrm{SiO}_{2}\right)-6.69$ en el diagrama $\mathrm{SiO}_{2}$ vs. $\mathrm{FeO} / \mathrm{MgO}$ de Miyashiro (1974) y con valores elevados de $\mathrm{TiO}_{2}, \mathrm{Nb}$ y Ta] y contienen xenolitos de peridotita provenientes del manto superior, y/o conjuntos de megacristales, y/o de granulitas feldespáticas provenientes de partes profundas de la corteza. La mayoría de los campos con xenolitos del manto se localizan en la porción meridional de la provincia Cuencas y Sierras, pero hay localidades que yacen en donde las fallas normales no son obvias o cuantitativamente importantes en la geología expuesta en la superficie. Algunos de los campos volcánicos de tipo intraplaca más voluminosos y extensos del norte de México fueron en parte simultáneos a fallamiento normal. En otros sitios los volcanes se encuentran alineados a lo largo de fallas normales regionales y/o sus productos están intercalados con gravas de relleno de graben. Sin embargo, en la mayoría de los casos, la relación entre extensión y magmatismo de tipo intraplaca es tenue. La ubicación de algunos campos sugiere que el ascenso de magmas de tipo intraplaca fue influenciado por fallas que delimitan dominios tectónicos regionales en el basamento y que tienen historias complejas.

Los procesos petrogenéticos dominantes en los magmas continentales asociados a extensión temprana (Oligoceno temprano-Mioceno), es decir aquella que sucedió inmediatamente después de un cambio de acortamiento ENE a extensión ENE a NE, difieren de aquellos en el Plioceno-Cuaternario. En las rocas de tipo intraplaca tempranas hay muestras similares en composición a las rocas más primitivas del Plioceno-Cuaternario. Sin embargo, es más común que las rocas antiguas 
sean más diferenciadas y muestren evidencias claras de contaminación significativa con material cortical, mientras que en las rocas volcánicas jóvenes los vestigios de asimilación son sutiles o ausentes. Se cree que esto se debe a un cambio progresivo en las condiciones tectónicas y a la evolución térmica de la litósfera en la región. Al inicio de la extensión, la corteza estaba caliente debido a la etapa paroxísmica del volcanismo terciario asociado a subducción. Bajo estas circunstancias la transición frágil-dúctil en la corteza debió ascender, disminuyendo la posibilidad de que las estructuras frágiles (i. e., fallas normales) penetraran profundamente y formaran conductos adecuados para el ascenso rápido del magma. El movimiento lento de los magmas favoreció al proceso de asimilación y cristalización fraccionada y la segregación de los xenolitos de peridotita. Conforme se enfrió la corteza, las estructuras frágiles causadas por extensión ENE a NE penetraron más profundamente y los magmas sin contaminar llegaron rápidamente a la superficie con xenolitos del manto.

Las rocas de tipo intraplaca más subsaturadas en sílice en México son las nefelinitas del sur de San Luis Potosí. Asumiendo fuentes similares, compuestas por lherzolita de granate, la diferencia entre la composición de las nefelinitas y hawaiitas expuestas un poco más al norte ha sido explicada por un grado de fusión mayor para las segundas. Las rocas más evolucionadas en la región estudiada son las panteleritas y comenditas de Sonora, así como traquitas provenientes de Sonora, Chihuahua y Tamaulipas. Desgraciadamente se sabe poco de ellas. Cabe señalarse que en la región Oriental/Alcalina son relativamente comunes los ejemplos de rocas altamente diferenciadas. Las evidencias de extensión contemporánea al volcanismo en esta región son escasas o aun ausentes en comparación con el centro y noroeste de México.

Algunas de las rocas primitivas de San Quintín, B. C. tienen características geoquímicas que sugieren fusión parcial progresiva a presiones relativamente bajas dentro del manto (i. e., a partir de peridotitas de espinela). La geotermometría/geobarometría en los xenolitos de San Quintín indica temperaturas y presiones de equilibración significativamente más bajas que en el centro de México.

En muchos campos volcánicos de tipo intraplaca hay rocas máficas sin alterar con hiperstena en la norma que, aparentemente, son contemporáneas a rocas máficas alcalinas. Hasta ahora, este fenómeno no ha sido analizado en la literatura y solo para la región de Durango se ha argumentado que en las rocas máficas de tipo intraplaca con hiperstena hay componentes heredados de la subducción del Terciario medio que pudieron persistir en el manto y contribuir periódicamente a la formación de los magmas de tipo intraplaca.

En el área de estudio no se ha demostrado un cambio temporal en la fuente de los magmas de tipo intraplaca, de una porción relativamente somera del manto litosférico a una más profunda en la astenósfera, similar al propuesto en la porción norteamericana de Cuencas y Sierras. Al parecer el proceso de asimilación y cristalización fraccionada en los magmas de tipo intraplaca tempranos en México fue de tal magnitud que enmascara los rasgos geoquímicos heredados de las fuentes en el manto.

Palabras Clave: Rocas alcalinas, extensión, Cuencas y Sierras, xenolitos del manto, xenolitos corticales.

\section{Abstract}

Intraplate-type volcanism (late Oligocene-Quaternary) occurs in Mexico in regions that belong to the North American and Pacific plates. Magmas erupted through oceanic crust formed voluminous shield volcanoes (Socorro: $2400 \mathrm{~km}^{3}$ ) located on or near fossil spreading ridges. Rocks in the subaerial part of the volcanoes form continuous and coherent rock series (Guadalupe) or bimodal sets (Socorro). Crystall fractionation of alkali basalt in shallow magma chambers and assimilation of hydrothermally altered rocks determined the elemental and isotopic composition of the mafic and intermediate rocks of Socorro. Trachytes from Socorro were originated by 5-10\% partial melting of alkali basalt. Crystal fractionation of a parental trachytic magma originated the rhyolites. Felsic rocks also show the evidence of assimilation of hydrothermally altered rocks.

Continental mafic intraplate-type volcanism (late Oligocene - Quaternary) is scattered throughout the region located north of the Mexican Volcanic Belt. This phenomenon is independent of older volcanic provinces, boundaries between today's geologic/tectonic provinces, and limits among tectonostratigraphic terranes. Most intraplate-type volcanic rocks are alkalic [i. e. they plot above the $\mathrm{FeO}^{t} / \mathrm{MgO}=\left(0.156 \times \mathrm{SiO}_{2}\right)$ - 6.69 line in the $\mathrm{SiO}_{2}$ vs. FeOt/MgO diagram of Miyashiro (1974) and have high $\mathrm{TiO}_{2}, \mathrm{Nb}$, and $\left.\mathrm{Ta}\right]$ and host peridotite xenoliths from the upper mantle, and/or megacrysts, and/or feldspathic granulite xenoliths from deep portions of the crust. Most volcanic fields with mantle xenolith are in the southern part of the Basin and Range Province, but there are localities in regions where normal faulting is minor or absent in the geology exposed at the surface. Some of the most extensive and voluminous intraplate-type volcanic fields in northern México were contemporaneous with normal faulting. In some areas volcanoes are aligned along regional normal faults and/or their products are interlayered with graben-fill gravel deposits. However, in most areas the tie between extension and volcanism is not evident. The locations of some volcanic fields suggest that magma ascent was influenced by regional faults. These basement structures have complex evolutions and they separate large tectonic domains. 
Dominant petrogenetic processes in magmas associated to the first pulses of extension (early Oligocene - Miocene), those immediately after the change from ENE compression to ENE extension, are different from those manifested in PlioQuaternary magmas. Volcanic fields associated with the earlier extension may contain primitive rocks, similar to those erupted by Plio-Quaternary volcanoes. However, older rocks are commonly more evolved and show clear geochemical evidence for assimilation of crustal material, whereas contamination is subtle or absent in younger intraplate-type suites. This is attributed to a gradual change in tectonic and thermal conditions in the crust in the region. During the early stages of extension ( $\leq 33-30 \mathrm{Ma}$ ) the crust was hot as a consequence of the subduction-related mid-Tertiary ignimbrite flare up. This thermal condition raised the brittle-ductile transition and brittle structures (i. e., normal faults) were not able to propagate to deeper parts of the crust, preventing the formation of conduits for rapid magma ascent. The resulting slow magma ascent favored AFC processes and gravitational settling of dense xenoliths. As the crust cooled down, brittle structures caused by ENE to NE extension were able to propagate deeper and xenolith-bearing magmas reached the surface.

Nephelinites exposed in the southern part of San Luis Potosí are the most silica-undersaturated intraplate-type rocks in Mexico. Assuming a similar garnet-lherzolite mantle source, the difference between the nephelinites and hawaiites found a short distance north has been attributed to a larger degree of partial melting in the hawaiites. The most evolved samples in the studied area are pantellerites and comendites from Sonora, as well as trachytes from isolated occurrencees in Sonora, Chihuahua and Tamaulipas. Unfortunately, little is known about them. It is worth mentioning that highly evolved rocks are relatively common in the Eastern/Alkalic region. Compared to central and northwestern México, evidence of synvolcanic extension in this region is scarce or absent.

The chemical composition of some of the primitive rocks from San Quintin, B. C., suggests progressive fusion at relatively low pressures in the mantle (i. e., from spinel peridotite). Compared with samples from central México, the xenoliths from San Quintín yield significantly lower temperatures and pressures.

Hypersthene-bearing, unaltered mafic rocks occur in many intraplate type volcanic fields and apparently were coeval with mafic alkalic volcanic products. This phenomenon has not been analyzed and only for hyperstene-normative mafic rocks of Durango, it has been argued that they inherited some components from the mid Tertiary, subduction-related activity. This mantle component may be occasionally melted and contribute to the intraplate type-magmas.

The temporal change in mantle sources, from shallow lithospheric mantle to deeper asthenospheric mantle, proposed for the United States portion of the Basin and Range has not been demonstrated in central México. It seems that the $A F C$ processes in the early magmas of México mask some of the geochemical characteristics inherited from the mantle sources.

Key words: Alkalic rocks, extension, Basin and Range, xenolith.

\section{Introducción}

Con base en el tipo de corteza sobre la que fueron extravasadas, las localidades de rocas volcánicas de tipo intraplaca en México pueden dividirse en dos grupos: oceánicas y continentales. Las localidades oceánicas son cinco islas desarrolladas en o cerca de dorsales abandonadas, en lo que ahora es la placa del Pacífico. Con la excepción de San Quintín, todas las localidades formadas sobre corteza continental se encuentran en la placa de América del Norte. Aunque San Quintín yace sobre corteza continental, este sitio ahora forma parte de la placa del Pacífico.

En la literatura, tradicionalmente se ha considerado la existencia de cuatro provincias magmáticas del Cenozoico en la parte continental del centro y norte de México. Estas son la provincia Oriental/Alcalina, la Sierra Madre Occidental, la provincia Californiana y la Faja Volcánica Transmexicana FVTM (véase recuadro en Figura 1). En los últimos 20 años se han estudiado campos volcánicos del Terciario tardío y Cuaternario distribuidos por toda la región continental al norte de la FVTM (Figura 1) que aquí proponemos como una quinta provincia magmática, sobrepuesta sobre aquéllas consideradas por autores previos (e. g., Demant y Robin, 1975; Ortega-Gutiérrez et al., 1992; Morán-Zenteno, 1994) y que llamamos la Provincia Extensional del Norte de México (PENM). Para facilitar y sistematizar la descripción de los datos incluidos en este artículo, dividimos a la PENM en las regiones Occidental/ Baja California, Cuencas y Sierras meridional y Oriental/ Alcalina (Figura 1).

En este artículo revisamos la información referente a los campos volcánicos de tipo intraplaca tanto oceánicos como continentales. Las islas son volcanes alcalinos de menos de 15 Ma de edad, formados sobre tholeiitas del piso oceánico. Con la excepción del Bernal de Horcasitas (K-Ar: $\sim 28 \mathrm{Ma}$ ), las localidades continentales son del Mioceno o más jóvenes $(<24 \mathrm{Ma})$, y están esparcidas en la PENM. Las rocas en estas localidades generalmente son máficas y en el diagrama $\mathrm{SiO}_{2}$ vs. $\mathrm{FeO}^{\mathrm{t}} / \mathrm{MgO}$ de Miyashiro (1974) grafican arriba de la línea $\mathrm{FeO}^{\mathrm{t}} / \mathrm{MgO}=\left(0.156 \times \mathrm{SiO}_{2}\right)-6.69$ 
(i.e., afuera del campo calcialcalino). Usualmente tienen afinidad alcalina (i.e., con $[\mathrm{Ne}]$, aunque en muchos campos volcánicos es común encontrar algunas rocas contemporáneas, sin alteración evidente, con algo de $[H y]$ o aún $[Q t z]$; nótese que las abreviaturas de minerales entre corchetes y en itálicas son componentes normativos, véase Tabla 1) y por sus características geoquímicas (contenidos elevados de $\mathrm{TiO}_{2}, \mathrm{Nb}$ y Ta) y entorno geológico alejado de una margen convergente cuando se formaron, se les considera como productos de actividad magmática de tipo intraplaca. Este volcanismo generalmente es monogenético, fue extravasado por conductos centrales (conos de ceniza con derrames de lavas asociados, escudos de lava continentales y algunos maares aislados) y en ocasiones por erupciones fisurales pequeñas. En comparación con las provincias volcánicas de Demant y Robin (1975), la actividad de tipo intraplaca cubrió áreas pequeñas y discontinuas y los volúmenes extravasados fueron considerablemente menores.
Originalmente nuestro interés en el volcanismo de tipo intraplaca continental se derivó del hecho que en muchos sitios los magmas transportaron xenolitos del manto y/o de la parte profunda de la corteza (Aranda-Gómez y OrtegaGutiérrez, 1987) y/o conjuntos complejos de megacristales (Aranda-Gómez y Luhr, 1993) que pueden o no ser accidentales respecto al magma huésped. Así mismo, un análisis casual de la distribución de estos campos volcánicos y de las fallas normales cenozoicas sugiere que la mayor parte de ellos se encuentran en una región que fue extendida en el Cenozoico medio y tardío y que Henry y Aranda-Gómez (1992, 2000) consideran como la porción meridional de la provincia de Cuencas y Sierras de América del Norte (Figura 1). Excepciones notables son San Quintín, las localidades en la región Oriental/Alcalina y dos localidades con xenolitos del manto en la FVTM (Figura 1).

En este artículo hacemos la revisión ordenando primero las localidades en función de si sobreyacen la corteza

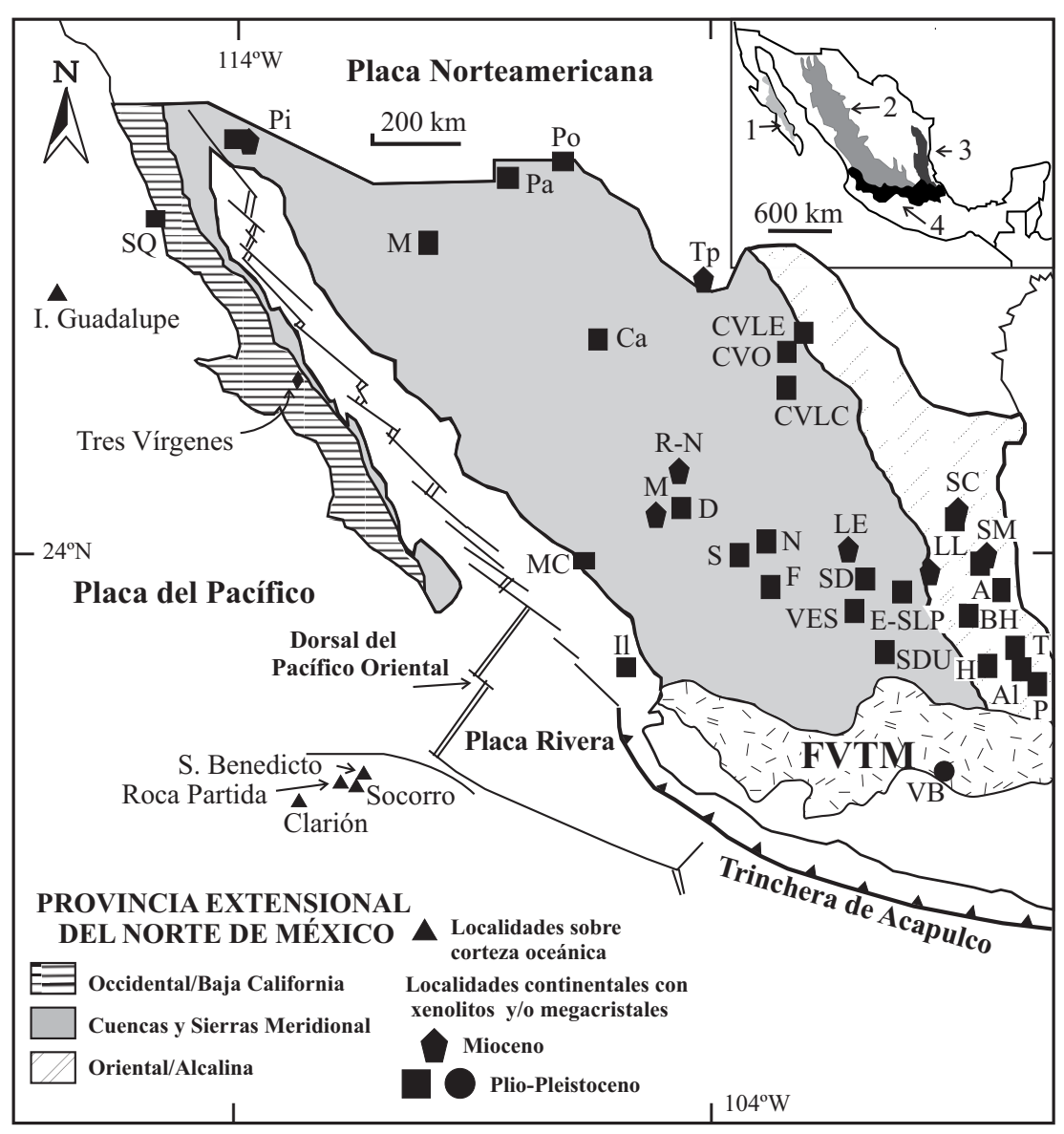

\author{
Cuaternario - Mioceno tardío \\ SQ: San Quintín $(165-22 \mathrm{Ka})$ \\ Pi: Pinacate $(1.7-\leq 0.17 \mathrm{Ma})$ \\ M: Moctezuma (1.7- $0.53 \mathrm{Ma})$ \\ MC: Mesa Cacaxta (3.2 - 2-1 Ma) \\ II: Isla Isabel (¿Holoceno?) \\ Pa: Palomas (¿Plioceno?) \\ Po: Potrillo (1.23 - $1.18 \mathrm{Ma})$ \\ Ca: Camargo (4.7-0.09 Ma) \\ D: Durango $(\leq 0.8 \mathrm{Ma})$ \\ $\mathrm{N}$ : Nieves \\ $\mathrm{S}$ : Sombrerete \\ F: Fresnillo \\ SDU: San Diego de la Unión \\ VES: Ventura-Espíritu Santo (1.1 - 1.4 Ma) \\ SD: Santo Domingo (0.35 - $0.45 \mathrm{Ma}$ ) \\ E-SLP: Este de San Luis Potosí \\ SC: San Carlos-Cruillas (?) \\ CVLE: Las Esperanzas ( $2.8 \mathrm{Ma})$ \\ CVO: Ocampo (3.4 - 1.8 Ma) \\ CVLC: Las Coloradas \\ SM: Sierra Maratínez (1.4 - $0.2 \mathrm{Ma})$ \\ A: Aldama (2.6 - $1.4 \mathrm{Ma})$ \\ LL: Llera ( $\sim 5 \mathrm{Ma}-2.4 \mathrm{Ma})$ \\ T: Tlanchinol (7.4 - 5.2 Ma) \\ $\mathrm{Al}$ : Álamo (7.5 - 6.6 Ma) \\ P: Poza Rica (1.6 - 1.3 Ma)
}

Oligoceno tardío - Mioceno medio

SM: Sierra Maratínez (24-8 Ma)

Pi: Pinacate $(\sim 10 \mathrm{Ma} ?)$

M: Metates (12.7-12.0)

LE: Los Encinos (13.6-10.6 Ma)

R-N: Rodeo-Nazas (24-20 Ma)

Tp: Transpecos (24-17 Ma)

SC: San Carlos-Cruillas

BH: Bernal de Horcasitas,

Auza (?), Nopal (?) y Murciélago (?)

Figura 1. Localización de los campos volcánicos con rocas de tipo intraplaca en la Provincia Extensional del Norte de México (PENM) y ubicación de las islas mencionadas en el texto. Las localidades continentales discutidas en este artículo están al norte de la FVTM y muchas de ellas tienen xenolitos del manto, de partes profundas de la corteza y/o megacristales. Las localidades con xenolitos del manto ubicadas en la FVTM son Valle de Bravo (VB) y Palma Sola (afuera del área cubierta por el mapa). La roca huésped en VB es una andesita (Blatter y Carmichael, 1998). También se muestra la localización del volcán Tres Vírgenes que es mencionado en el texto. FVTM=Faja Volcánica Transmexicana. Nótese que si se compara esta Figura con la Figura 1 en Aranda-Gómez y Ortega-Gutiérrez (1987), en aquélla hay varias localidades con xenolitos afuera de la FVTM que aquí no se incluyen. Los motivos son discutidos en el texto. Recuadro: Las cuatro provincias volcánicas propuestas por Demant y Robin (1975). Clave: 1=Californiana, 2=Sierra Madre Occidental, 3=Oriental y 4=Faja Volcánica Transmexicana. 
Tabla 1. Símbolos para minerales (modales y normativos ${ }^{1}$ )

\begin{tabular}{|c|c|c|c|c|c|}
\hline $\mathrm{Ab}$ & Albita & Eni & Enigmatita & Ns & Metasilicato de sodio \\
\hline $\mathrm{Acm}$ & Acmita & $\mathrm{Fa}$ & Fayalita & $\mathrm{Ol}$ & Olivino \\
\hline An & Anortita & FHd* & Ferrohedenbergita & OFT & Óxidos de Fe y Ti \\
\hline Anf* & Anfíbol & Fo & Forsterita & Pgt & Pigeonita \\
\hline Anor** & Anortoclasa & Grt & Granate & $\mathrm{Pl}$ & Plagioclasa \\
\hline Ap & Apatito & $\mathrm{Hbl}$ & Hornblenda & Po & Pirrotita \\
\hline Aug & Augita & Hy & Hiperstena & Qtz & Cuarzo \\
\hline Bri* & Britholita & $\mathrm{Ilm}$ & Ilmenita & $\mathrm{Sa}$ & Sanidino \\
\hline $\mathrm{Bt}$ & Biotita & Krs & Kaersutita & Sil & Silimanita \\
\hline Calc & Calcedonia & Kspar* & Feldespato potásico & Spl & Espinela \\
\hline $\mathrm{Cpx}$ & Clinopiroxeno & Let & Leucita & TAug* & Titanaugita \\
\hline Di & Diópsida & Mt & Magnetita & TMt* & Titanomagnetita \\
\hline Egi & Egirina & $\mathrm{Ne}$ & Nefelina & & \\
\hline
\end{tabular}

T: Se emplean los símbolos recomendados por Kretz (1983), excepto en aquellos marcados con * (porque no son incluidos en la tabla de dicho autor). Los componentes normativos se citan en el texto del artículo con los mismos símbolos, con itálicas y entre paréntesis rectangulares.

oceánica o continental. Después se considera su edad, ya que entre las localidades continentales hay diferencias significativas en la petrología de los magmas de tipo intraplaca emitidos al inicio de la extensión (Oligoceno tardío-Mioceno). Las localidades plio-cuaternarias continentales $(\leq 5 \mathrm{Ma})$ son ordenadas en función de su ubicación en las regiones de la PENM (Figura 1). En algunos sitios existen estudios sistemáticos de rocas de tipo intraplaca colectadas a través de todo el campo volcánico (e. g., Ventura-Espíritu Santo); en otros sólo hay investigaciones detalladas de uno o varios de los volcanes (e. g., Durango) y en otras regiones sólo se sabe que los magmas probablemente son de tipo intraplaca por su entorno regional, análisis químicos de muestras aisladas (Camargo) y/o por la presencia de xenolitos (Fresnillo) y/o megacristales (Metates).

\section{Magmatismo oceánico}

\subsection{Isla Guadalupe}

La petrología de esta localidad fue investigada por Batiza (1977), de donde resumimos la mayor parte de la información presentada. En Medina et al. (1989) y Siebert et al. (2002) se proporcionan algunos datos acerca de su actividad más reciente. Guadalupe está ubicada a aproximadamente $300 \mathrm{~km}$ al $\mathrm{W}$ de la costa de Baja California (Figura 1), cerca de la latitud $29^{\circ} \mathrm{N}$ y longitud $118^{\circ} \mathrm{W}$ y tiene una elevación máxima de $1100 \mathrm{msnm}$. Su forma es alargada (N-S). La isla consiste de los vestigios erosionales de dos volcanes escudo que se traslapan parcialmente, siendo más joven el volcán ubicado al norte. En las cimas de los escudos existen calderas y sobre las laderas de los volcanes centrales están expuestos los productos de actividad lateral y fisural tardía, que también rellena parcialmente a las calderas. La isla yace sobre el eje de una dorsal fósil que es flanqueada por la anomalía 5B ( 15.5 Ma). La edad de la actividad inicial que dio origen a los escudos es desconocida, pero las rocas más antiguas que han sido fechadas (K-Ar) son de $7 \pm 2 \mathrm{Ma}$. La actividad más reciente es considerada del Holoceno por Medina et al. (1989). Las lavas formadoras de los escudos, junto con los productos de la actividad tardía, forman una serie basalto alcalino-traquita, completa y coherente (Figura 2a). Todos los miembros intermedios -incluyendo hawaiita, mugearita y benmoreita - están presentes (Figura 2a). En general, las rocas de Guadalupe son pobres en fenocristales $(<10 \%)$, pero hay algunas afíricas y otras fuertemente porfídicas. La mineralogía varía dependiendo de la composición de la roca. La paragénesis en los basaltos es: $\mathrm{Ol}+\mathrm{Pl}+\mathrm{Aug}+\mathrm{OFT}$ (Tabla 1). En las hawaiitas, mugearitas y benmoreitas es similar: $\mathrm{Ol}+\mathrm{Pl}+\mathrm{Aug}+\mathrm{Ap}+\mathrm{OFT} \pm \mathrm{Krs}$ (ausente en las lavas que originaron los escudos), sólo que los minerales tienen composiciones distintas, siendo la Pl más sódica y los minerales ferromagnesianos más ricos en Fe. La mineralogía en las traquitas es: $\mathrm{Pl}+\mathrm{Ol}+\mathrm{Cpx}+\mathrm{Bt}+\mathrm{OFT} \pm \mathrm{Anf} \pm \mathrm{K}$ spar. Las rocas máficas alcalinas (Figura 3a) tienen aproximadamente entre 5 y $10 \%$ de $[\mathrm{Ne}]$ y la abundancia de Ti, K, Na, P, Rb, Sr, Zr y Tierras Raras ligeras (LREE por sus siglas en inglés) es comparable a aquella encontrada en otros muchos volcanes centrales ubicados en los flancos de dorsales activas. Las variaciones en composición química en la serie pueden modelarse con éxito mediante cristalización fraccionada de conjuntos de minerales similares a las paragénesis observadas en las rocas, a presiones entre 2 y $10 \mathrm{kbar}$, a partir de basalto alcalino como magma madre. Esta interpretación es apoyada por: la continuidad química dentro de la serie, las proporciones estimadas y sucesión temporal de los distintos tipos de roca en el sistema y por los valores relativamente 

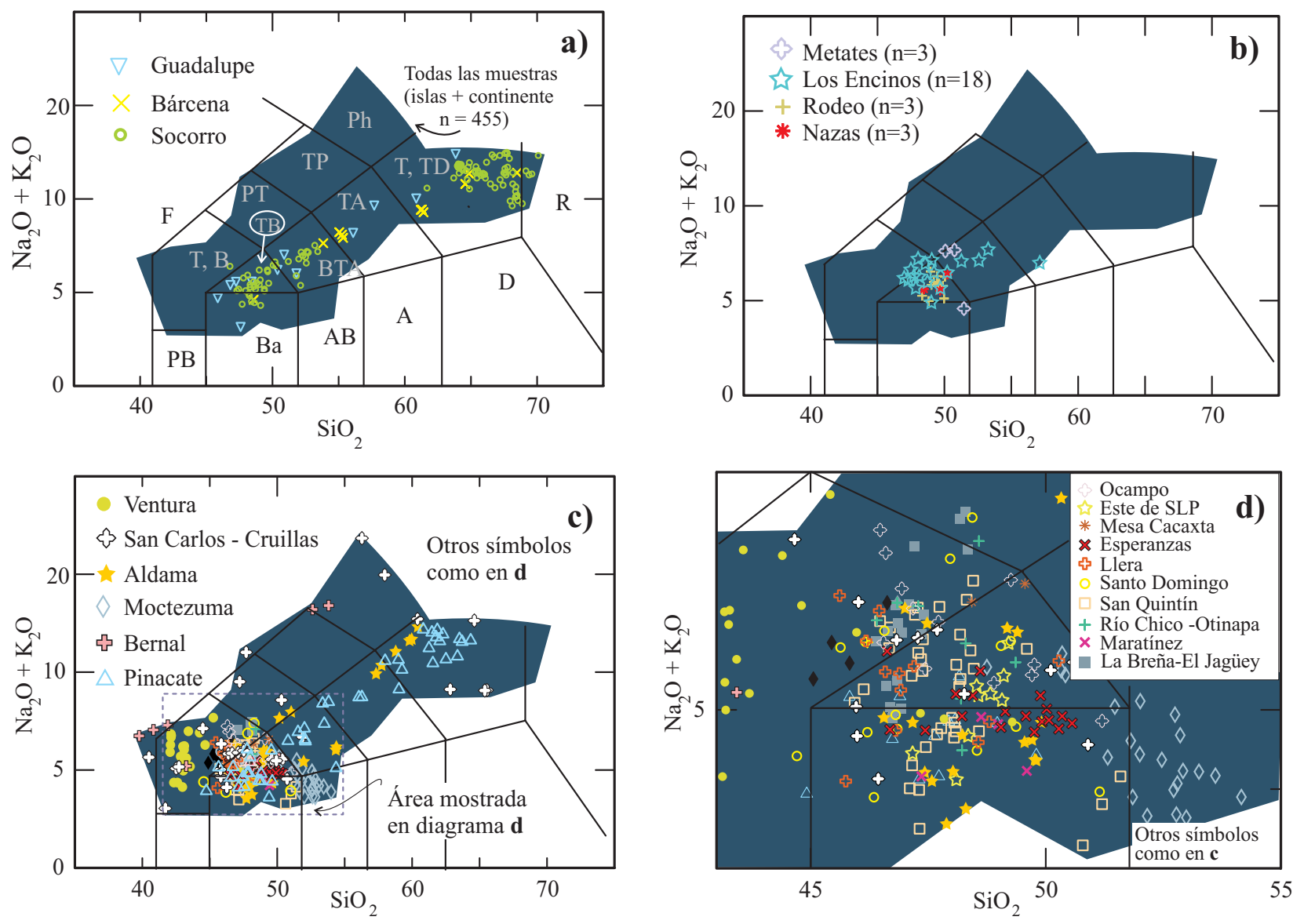

Figura 2. Clasificación de las rocas ígneas de tipo intraplaca de México de acuerdo con los criterios propuestos por Le Maitre et al. (2002). Los valores de $\mathrm{SiO}_{2}$ y $\mathrm{Na}_{2} \mathrm{O}+\mathrm{K}_{2} \mathrm{O}$ se dan en peso por ciento. El campo gris en todas las gráficas cubre el área en donde grafican todas las muestras mexicanas de tipo intraplaca $(\mathrm{n}=455)$ hasta ahora reportadas, tanto en corteza oceánica como en corteza contiental. a) Muestras colectadas en localidades ubicadas sobre corteza oceánica $(n=124)$. Los ejemplares provenientes de Socorro $(n=90)$ tienen un arreglo claramente bimodal. El hueco composicional entre estos grupos es cubierto por algunas de las rocas provenientes de Guadalupe $(\mathrm{n}=13)$ y Bárcena $(\mathrm{n}=13)$. b) Muestras correspondientes al volcanismo intraplaca temprano (Mioceno) en áreas continentales $(\mathrm{n}=35)$. La mayoría de los ejemplares grafican en el área en donde tienden a concentrarse un gran número de muestras del Plioceno-Cuaternario. c) Todas las localidades del Plioceno-Cuaternario extravasadas sobre corteza continental (n=296). Nótese que, con excepción de los campos volcánicos señalados en la leyenda, el resto de las muestras tiende a agruparse cerca del campo correspondiente a las hawaiitas. Las variaciones en composición más extremas se encuentran en los campos enlistados. d) A pesar del traslape entre los grupos, las muestras colectadas en varios campos volcánicos del Plioceno-Cuaternario tienden a concentrarse en áreas relativamente bien definidas (e.g., Ventura, Moctezuma, Esperanzas). Abreviaciones empleadas: $\mathrm{F}=$ foidita; $\mathrm{PB}=$ picrobasalto; $\mathrm{B}=$ basanita $(\mathrm{ol}>10 \%) ; \mathrm{T}=$ tefrita $(\mathrm{ol}<10 \%)$; $\mathrm{PT}=$ fonotefrita; $\mathrm{TP}=$ tefrifonolita; $\mathrm{Ph}=$ fonolita; $\mathrm{Ba}=$ basalto; $\mathrm{TB}=$ traquibasalto (hawaiita o traquibasalto potásico); $\mathrm{BTA}=$ traquiandesita basáltica (mugearita o shoshonita); $\mathrm{TA}=$ traquiandesita (benmoreita o latita); $\mathrm{T}=$ traquita $(\mathrm{Qtz}<20 \%)$ o $\mathrm{TD}=$ traquidacita $(\mathrm{Qtz}>20 \%) ; \mathrm{AB}=$ andesita basáltica; $\mathrm{A}=$ andesita; $\mathrm{D}=$ dacita; $\mathrm{R}=$ riolita. Los nombres entre paréntesis se modifican dependiendo de la relación $\mathrm{Na}_{2} \mathrm{O}-\mathrm{K}_{2} \mathrm{O}$ como lo explican Le Maitre et al., 2002 (p. 35).

homogéneos de ${ }^{87} \mathrm{Sr} /{ }^{86} \mathrm{Sr}(0.70321-0.70330)$. La posición tectónica de la isla Guadalupe, sobre el eje de una dorsal fósil, tiene implicaciones importantes en cuanto a la escala de las heterogeneidades químicas e isotópicas en el manto y la geometría de las fuentes que alimentan a los sistemas de dorsales y volcanes centrales en sus flancos.

\subsection{Archipiélago Revillagigedo}

Está formado por cuatro islas volcánicas -Socorro, San Benedicto, Clarión y Roca Partida (Figura 1)- ubicadas en el Pacífico oriental, en el extremo norte de la dorsal de los Matemáticos. Esta dorsal es un rasgo topográfico submarino que marca el sitio en donde hasta hace $\sim 3.5$ Ma hubo expansión del fondo oceánico (Mammerickx, et al., 1988). Las islas representan actividad alcalina posterior a que la dorsal fue abandonada. Con la excepción de Roca Partida, el volumen de estas islas está en el 1-2\% superior de los volúmenes de los montes submarinos e islas formadas sobre corteza oceánica del Plioceno (Batiza, 1982). La actividad volcánica más reciente en el archipiélago son las erupciones de 1952-1953 en la isla San Benedicto (Richards, 1959) y actividad submarina basáltica cerca de Socorro en 1993 (McClelland et al., 1993; Siebe et al., 1995). Heterogeneidad regional en el manto es evidente a partir de datos elementales (Figuras 4a y 5a) e isotópicos (Figuras 6a y 7a) derivados de los basaltos transicionales (ligeramente alcalinos) de Socorro, las mugearitas 

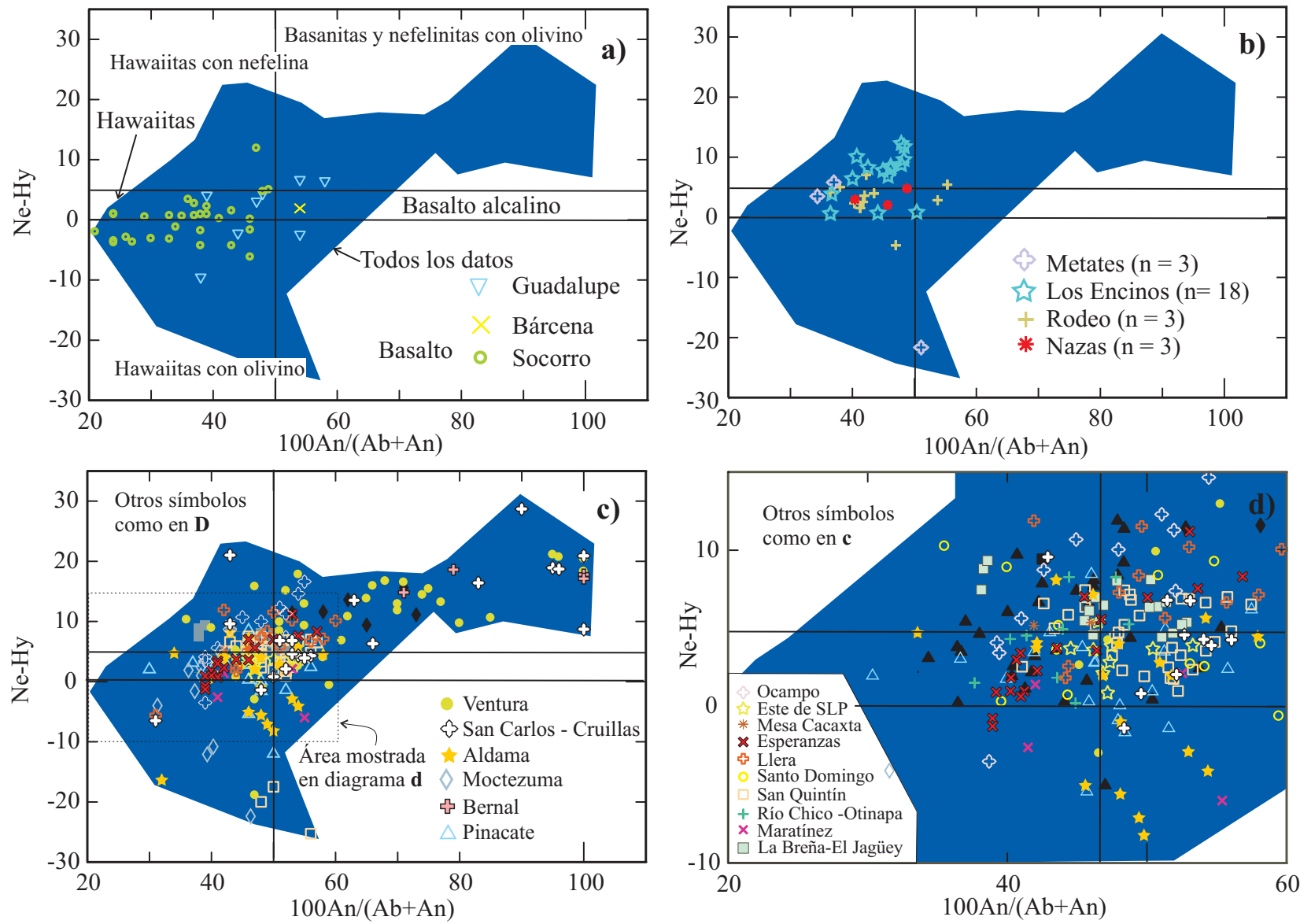

Figura 3. Clasificación normativa de las rocas máficas intraplaca de acuerdo con los criterios empleados por Luhr et al. (1995a). Se grafica la composición normativa de la plagioclasa (peso\%) versus el contenido normativo de nefelina o hiperstena en la roca en peso por ciento. En estos diagramas sólo grafican las muestras en que $\mathrm{SiO}_{2}($ peso\%) $\leq 52$. El campo gris en todos los dibujos cubre el área en donde grafican todas las muestras máficas mexicanas $(n=313)$ hasta ahora reportadas, tanto en corteza oceánica como en corteza continental. a) Localidades ubicadas sobre corteza oceánica $(n=40)$. b) Magmas extravasados sobre corteza continental durante el Mioceno $(n=27)$. c) Todas las localidades del Plioceno-Cuaternario ubicadas sobre corteza continental $(\mathrm{n}=246)$. Nótese que es común que en algunos campos se presenten rocas con [Hy]. El recuadro con línea punteada se muestra amplificado en la gráfica $\mathrm{d}$.

de San Benedicto y basaltos submarinos colectados cerca de Socorro (Bohrson y Reid, 1995).

\subsubsection{Isla Socorro}

El trabajo inicial en esta localidad fue realizado por Bryan (1959, 1966, 1976). Recientemente ha sido estudiada por Bohrson y Reid $(1995,1997)$ y Bohrson et al. (1996) de donde resumimos la mayor parte del material aquí asentado.

Socorro es un ejemplo único en la cuenca del Pacífico, ya que el volcanismo subaéreo ha sido dominado $(\sim 80 \%)$ por actividad silícica peralcalina, aunque se cree que el volcán es principalmente basáltico. El volumen total estimado del volcán es de $2400 \mathrm{~km}^{3}$, pero de éste solo menos del $2 \%\left(40 \mathrm{~km}^{3}\right)$ está sobre el nivel del mar. El volcán es coronado por una caldera $(\sim 4.5 \times 3.8 \mathrm{~km})$ que se encuentra casi totalmente cubierta por material volcánico posterior. La historia eruptiva de la porción subaérea del volcán se divide en las etapas pre-, sin- y postcaldera. Las rocas pre- y sincaldera son derrames de lava e ignimbritas traquíticas y riolíticas que dan edades ${ }^{40} \mathrm{Ar}-{ }^{39} \mathrm{Ar}$ entre 540 y $370 \mathrm{ka}$. La actividad postcaldera se desarrolló a partir de 180 ka y la roca más joven colectada en la isla es de $15 \mathrm{ka}$. La actividad postcaldera produjo principalmente domos y derrames de lava silícica. El Cerro Evermann es un cono de tefra con domos asociados y su cima es el punto más alto en la isla (1 $050 \mathrm{msnm}$ ). La Formación Evermann es postcaldera y está dominada por domos y lavas silícicas peralcalinas asociadas con material piroclástico y derrames de lava de composición basáltica alcalina. En el extremo sureste de la isla aflora la Formación Lomas Coloradas (180-15 ka) que también es postcaldera y está dominada por basalto alcalino con rocas silícicas peralcalinas subordinadas. Hasta ahora no se han encontrado rocas intermedias $\left(\mathrm{SiO}_{2}=54-61 \%\right)$ en la isla (Figura 2a). Este hueco en composición es observado también en algunos óxidos y elementos como $\mathrm{K}_{2} \mathrm{O}, \mathrm{TiO}_{2}$, $\mathrm{P}_{2} \mathrm{O}_{5}$ y Sr.

Génesis de los basaltos postcaldera. Las lavas máficas 

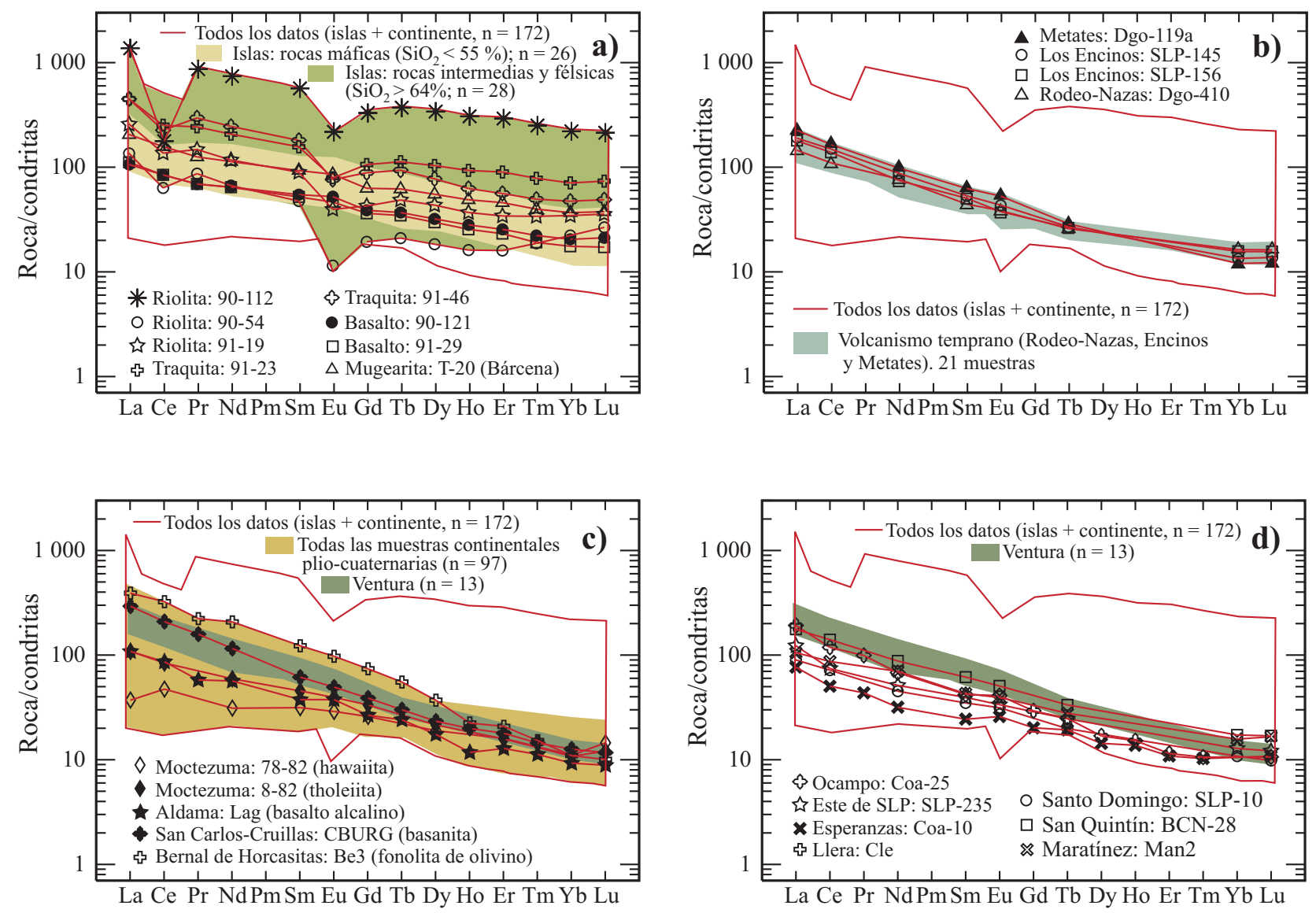

Figura 4. Diagramas de Tierras Raras normalizadas respecto a condritas (Sun y McDonough, 1989); en todas las gráficas la línea sólida continua bordea al área en donde grafican todas las muestras continentales y oceánicas hasta ahora estudiadas. En cada una de las gráficas se muestran algunos ejemplos característicos de varias localidades discutidas en el texto. a) Las muestras colectadas en las islas forman dos tendencias distintas dependiendo del contenido de $\mathrm{SiO}_{2}$. Nótese que las rocas máficas tienen patrones similares a los de las rocas de tipo intraplaca continentales. b) Patrones característicos de las rocas de tipo intraplaca del Mioceno. c) En el área verde claro grafican todas las muestras continentales del Plioceno-Cuaternario. El área verde oscuro corresponde a los ejemplares de Ventura, que aquí se consideran como características de los magmas intraplaca con xenolitos del manto. En la gráfica se incluye una muestra del Oligoceno (Bernal de Horcasitas) de la región Oriental/Alcalina. A diferencia de las localidades tempranas de Rodeo-Nazas, Los Encinos y Metates, en esta localidad no se han reportado megacristales ni xenolitos de granulitas corticales. d) Otros ejemplos de rocas del Plioceno-Cuaternario.

de Socorro son dominantemente afíricas o con un contenido bajo de fenocristales. Los conjuntos de fenocristales son $\mathrm{Pl}>>\mathrm{Ol} \sim \mathrm{Cpx}$ o $\mathrm{Pl}>>\mathrm{O}$. La matriz es pilotaxítica o intergranular y está compuesta por $\mathrm{Pl}+\mathrm{Ol}+\mathrm{Cpx}+\mathrm{OFT} \pm \mathrm{Ap}$. Las rocas estudiadas forman una serie compuesta principalmente por basalto alcalino, hawaiita y mugearita (Figuras 2a y $3 a$ ), con cantidades subordinadas de basaltos transicionales (suavemente alcalinos). Casi todas las variaciones en elementos mayores y elementos de alto potencial iónico (HFSE por sus siglas en inglés) pueden explicarse por cristalización fraccionada a presión baja de $\mathrm{Pl}+\mathrm{Cpx}+\mathrm{Ol}+\mathrm{OFT}$. Si se considera que en el conjunto de rocas de Socorro el magma madre fue un basalto alcalino, se requiere aproximadamente un fraccionamiento de $50 \%$ para llegar a mugearita. El rango limitado de $\mathrm{Zr} / \mathrm{Nb}$ (5.77.2) en el conjunto de muestras sugiere que los magmas madre son producto de aproximadamente el mismo grado de fusión a partir de un manto relativamente homogéneo. Las variaciones en las proporciones isotópicas de ${ }^{87} \mathrm{Sr} /{ }^{86} \mathrm{Sr}$
(Figura 6a) y ${ }^{143} \mathrm{Nd} /{ }^{144} \mathrm{Nd}$ son pequeñas $(0.7031-0.7032 \mathrm{y}$ $0.5128-0.5130$, respectivamente), pero significativas ya que exceden las incertidumbres analíticas. Las variaciones en los isótopos de $\mathrm{Pb}$ (Figura 7a) son ${ }^{206} \mathrm{~Pb} /{ }^{204} \mathrm{~Pb}=18.74$ $19.16,{ }^{207} \mathrm{~Pb} /{ }^{204} \mathrm{~Pb}=15.56-15.65 \mathrm{y}{ }^{208} \mathrm{~Pb} /{ }^{204} \mathrm{~Pb}=38.36-38.88$ y son similares a aquellas documentadas en los montes submarinos de la Dorsal del Pacífico Oriental. Muchas muestras presentan anomalías negativas de $\mathrm{Ce}$ (Figuras 4a y 5a) y enriquecimientos en $\mathrm{P}_{2} \mathrm{O}_{5}$, Ba y elementos de Tierras Raras (REE por sus siglas en inglés) intermedias que no pueden explicarse con el modelo de cristalización fraccionada. Estas características son atribuidas a asimilación de componentes provenientes de corteza oceánica somera, sedimentos metalíferos y/o Ap formado en etapas previas del sistema magmático de Socorro o, en el caso de Sr radiogénico (Figura 6a), por contaminación con agua de mar o con fluidos hidrotermales. La magnitud de las anomalías causadas por asimilación/contaminación varía de un sitio a otro y depende del material incorporado. 

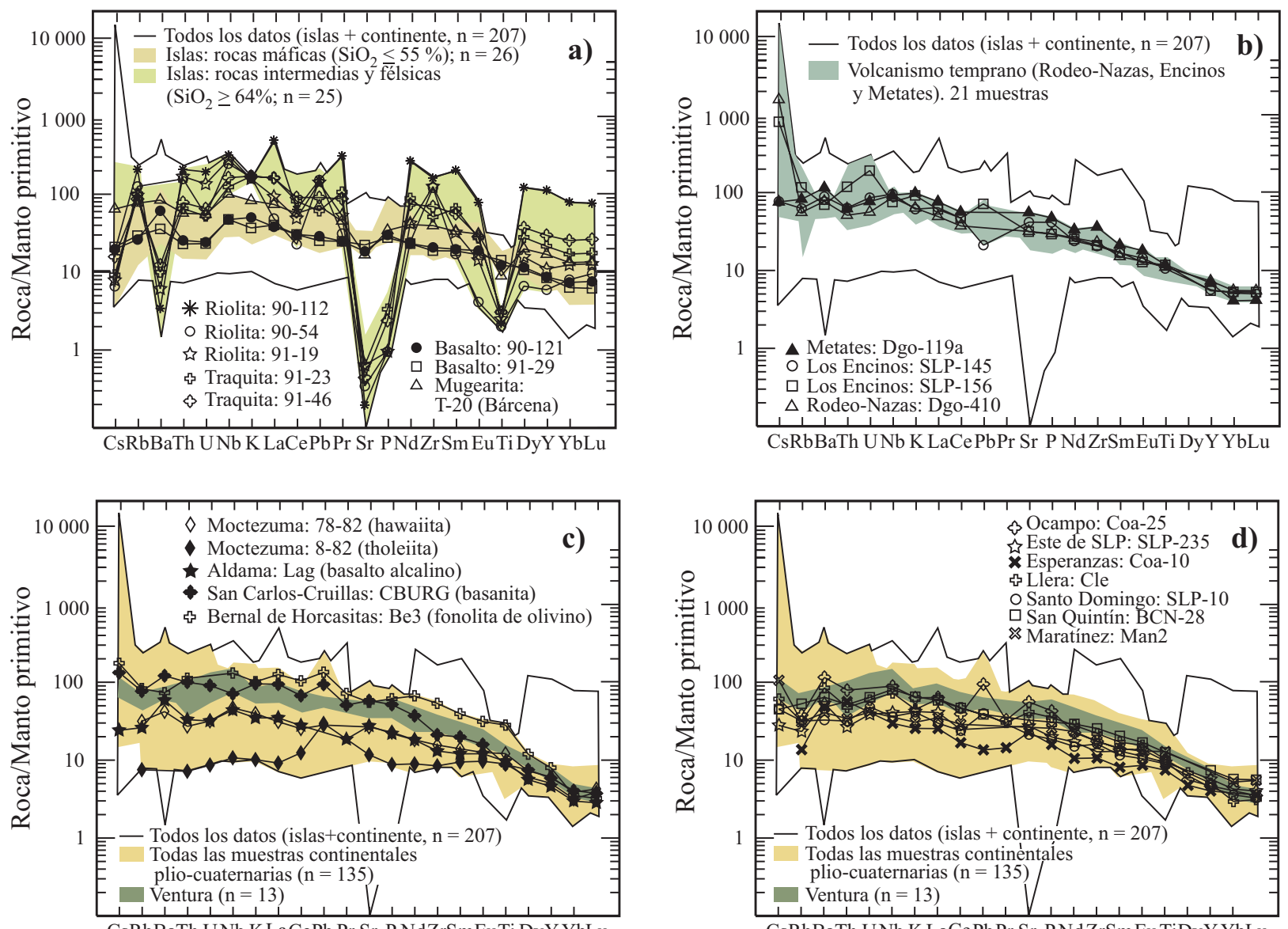

Figura 5. Diagramas multielementos normalizados respecto al manto primitivo (Sun y McDonough, 1989); en todas las gráficas la línea sólida continua bordea al área en donde grafican todas las muestras continentales y oceánicas hasta ahora estudiadas. En las gráficas se muestran algunos ejemplos característicos de varias localidades discutidas en el texto. a) Las muestras colectadas en las islas forman dos tendencias distintas dependiendo del contenido de $\mathrm{SiO}_{2}$. b) Patrones característicos de las rocas de tipo intraplaca del Mioceno. c) En el área verde claro grafican todas las muestras continentales del Plioceno-Cuaternario. El área verde oscuro corresponde a los ejemplares de Ventura, que aquí se consideran como representativas de los magmas intraplaca con xenolitos del manto. En la gráfica se incluye una muestra del Oligoceno (Bernal de Horcasitas) de la región Oriental/Alcalina. A diferencia de las localidades tempranas de Rodeo-Nazas, Los Encinos y Metates, en esta localidad no se han reportado megacristales. d) Otros ejemplos de rocas del Plioceno-Cuaternario.

Origen de las traquitas y riolitas peralcalinas. El conjunto de rocas estudiadas (51) por Bohrson y Reid (1997) incluye materiales de las etapas pre-, sin- y postcaldera, provenientes de derrames y domos de lava e ignimbritas. Las muestras de lavas y domos jóvenes son vitrófidos, mientras que las lavas más antiguas -al igual que las ignimbritas- son holocristalinas. El conjunto de fenocristales forma $0-15 \%$ (volumen) de las rocas y es: feldespato alcalino $\left(\mathrm{Ab}_{65} \mathrm{Or}_{35}-\mathrm{Ab}_{67} \mathrm{Or}_{33}\right)>>$ piroxeno sódico $\pm \mathrm{Fa} \pm \mathrm{OFT} \pm$ Eni. La mineralogía de la matriz es similar. Con la excepción de una única benmoreita en el conjunto, todas las rocas son traquitas o riolitas (Figura 2a) peralcalinas con $[\mathrm{Qtz}],[\mathrm{Acm}]$ y $[N s]$ en la norma y con enriquecimientos (respecto a rocas metaluminosas) en $\mathrm{Na}_{2} \mathrm{O}, \mathrm{K}_{2} \mathrm{O}, \mathrm{FeO}^{\mathrm{t}} \mathrm{y}$ algunos HFSE, y empobrecimiento en $\mathrm{Al}_{2} \mathrm{O}_{3}, \mathrm{Sr}$ y Ba. Todas las muestras son enriquecidas en LREE con $(\mathrm{La} / \mathrm{Yb})_{\mathrm{N}}$ entre 2.9 y 8.9 , la mayoría con anomalías negativas en Eu y una parte con anomalías de $\mathrm{Ce}$, siendo estas últimas casi siempre negativas (Figura 5a). Los valores de isótopos de $\mathrm{Nd}$ y $\mathrm{Pb}$ son
${ }^{143} \mathrm{Nd} /{ }^{144} \mathrm{Nd}=0.512869-0.512956,{ }^{206} \mathrm{~Pb} /{ }^{204} \mathrm{~Pb}=18.76-19.00$, ${ }^{207} \mathrm{~Pb} /{ }^{204} \mathrm{~Pb}=15.55-15.61,{ }^{208} \mathrm{~Pb} / 204 \mathrm{~Pb}=38.36-38.71$ y comparables con aquellos documentadas en los basaltos alcalinos de Socorro (Figuras 6a y 7a). Las relaciones ${ }^{87} \mathrm{Sr} /{ }^{86} \mathrm{Sr}$ en feldespatos son: $0.703086-0.704632$ y en roca total sin lixiviar con ácidos son considerablemente más variables (0.703431-0.708621), pero los valores altos se registran en rocas con contenidos muy bajos de $\mathrm{Sr}$, que son muy susceptibles a contaminación y, por tanto, son atribuidos a interacción con fluidos hidrotermales dominados por agua marina.

Con base en la semejanza en el contenido de isótopos de $\mathrm{Nd}$ y $\mathrm{Pb}$ entre las rocas máficas y félsicas de Socorro (Figura 7a), se ha planteado la hipótesis que las traquitas pudieron formarse por cristalización fraccionada a partir de un magma suavemente alcalino. El modelado mostró que no es posible conciliar el contenido de elementos mayores y traza medidos en las rocas con los valores calculados. Los modelos de fusión parcial de basalto alcalino y rocas 
cumulofíricas asociadas sugieren que 5-10\% de fusión parcial es una solución viable para reproducir a la vez los contenidos de $\mathrm{K}_{2} \mathrm{O}$ y algunos elementos incompatibles como $\mathrm{Zr}$ y $\mathrm{Nb}$ en las traquitas. Las riolitas sin desvitrificar (i. e. que no han experimentado pérdidas importantes de $\left.\mathrm{Na}_{2} \mathrm{O}\right)$ sí pueden derivarse por cristalización fraccionada (baja presión, hasta $80 \%$ ) a partir de un magma traquítico. El conjunto de fases empleadas en la modelación es principalmente feldespato alcalino y $\mathrm{Cpx}+\mathrm{Fa}+\mathrm{Ilm}+\mathrm{Ap}$. Las anomalías negativas de Ce y algunos REE (Figura 4a) se atribuyen a la asimilación de cantidades variables de sedimentos hidrotermales y la gran variación de los isótopos de $\mathrm{Sr}$ en rocas totales sin lixiviar con ácidos a interacción de magmas con contenidos bajos de $\mathrm{Sr}$ con un sistema hidrotermal dominado por agua marina.

Con base en el estudio de Socorro, Bohrson y Reid (1987) concluyeron que hay tres condiciones que conducen a la formación de magmas peralcalinos: 1) tasas moderadas de extensión, 2) cámaras magmáticas someras y 3) un magma madre de composición basáltica y suavemente alcalina.

\subsubsection{Isla San Benedicto}

El volcán Bárcena es el rasgo topográfico más prominente en la isla San Benedicto, que es la isla más septentrional en el archipiélago Revillagigedo. Bárcena está ubicado a $350 \mathrm{~km}$ al sur de la punta de Baja California (Figura 1) y fue formado por erupciones que ocurrieron en 1952-1953 (Richards, 1959, 1965, 1966). La isla San Benedicto es alargada en dirección NE-SW y contiene una serie de domos traquíticos cuaternarios en su extremo norte. En el extremo meridional de la isla están ubicados el volcán Bárcena y el Montículo Cinerítico que es un cono de tefra compuesto por mugearita y riolita sódica, posiblemente del Holoceno, que precedió a Bárcena y que fue casi completamente sepultado por los productos del segundo. Bárcena es un cono de toba de más de $300 \mathrm{~m}$ de alto, con un cráter de $700 \mathrm{~m}$ de diámetro, que contiene domos postmaar de lava traquítica. De su flanco sudoriental fue extravasado un derrame de lava traquítico que llegó hasta el mar y formó un delta que mide 700 x 1200 m (Siebert et al., 2002). La petrología de San Benedicto no ha sido estudiada en detalle. En el trabajo de Bohrson y Reid (1995)
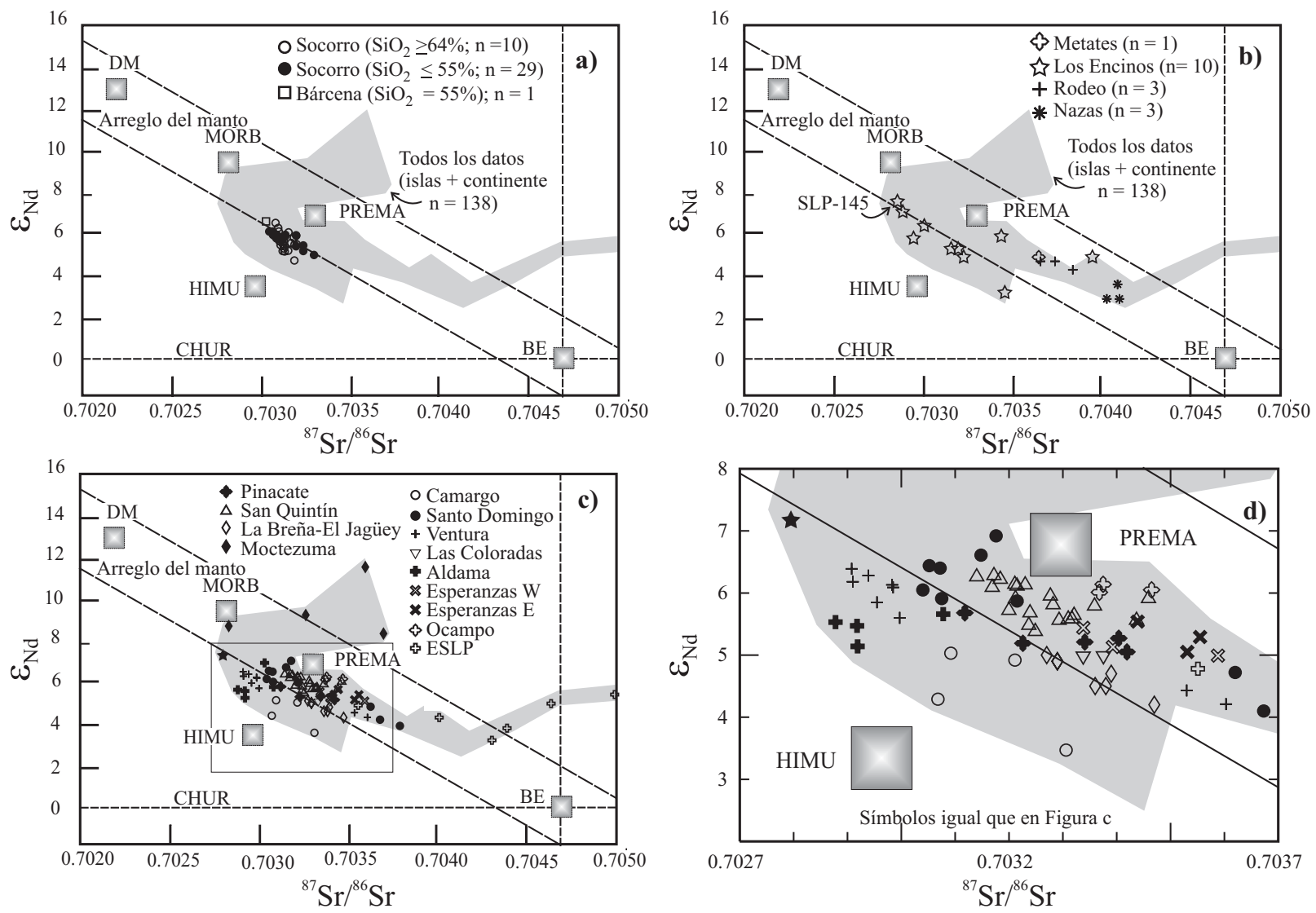

Figura 6. Diagramas que muestran los datos isotópicos de los campos volcánicos de tipo intraplaca y los distintos componentes del manto propuestos por Hart et al. (1986): HIMU (manto con una alta relación U/Pb), MORB (Mid Ocean Ridge Basalt), DM (Depleted Mantle), PREMA (PREvalent MAntle) y BE (Bulk Earth). CHUR=Chondrite Upper Reservoir. En todos los diagramas el área gris corresponde a las composiciones en donde grafican casi todos los datos en muestras provenientes de localidades continentales e islas. Sólo se omiten dos muestras con contenidos de ${ }^{87} \mathrm{Sr} /{ }^{86} \mathrm{Sr} \sim 0.706 \mathrm{y}$ $\varepsilon N d \sim 5$ provenientes del E de San Luis Potosí y Pinacate. En el caso de las muestras de Socorro se graficaron los valores obtenidos en feldespatos. a) Muestras provenientes de las islas. b) Magmas tempranos (valores iniciales). c) Muestras del Plioceno-Cuaternario ( $\mathrm{n}=81$ ). El rectángulo corresponde a la gráfica d), en donde puede notarse que las rocas de Ventura-Espíritu Santo y Santo Domingo tienen un arreglo claramente bimodal. 
se incluyen análisis de algunas muestras provenientes de esta isla (Figuras 2a y 6a).

\section{Magmatismo continental}

3.1. Actividad temprana: Oligoceno tardío-Mioceno, región Cuencas y Sierras meridional

\subsubsection{Campo volcánico El Pinacate}

Recientemente, en un resumen breve, Vidal-Solano et al. (2000) documentaron en El Pinacate (Figura 1) una fase volcánica temprana (¿Mioceno?) íntimamente relacionada a basaltos transicionales con tendencia alcalina. Esta actividad produjo rocas félsicas en que la relación $\left(\mathrm{Na}_{2} \mathrm{O}+\mathrm{K}_{2} \mathrm{O}\right) /$ $\mathrm{Al}_{2} \mathrm{O}_{3}$ es aproximadamente igual a 1.2. Estas panteleritas y comenditas contienen [Egi]. La mineralogía de las rocas es Sa, Anor, Fa, Anf, FHd, Eni y TMt. Los elementos traza muestran enriquecimientos en $\mathrm{Y}, \mathrm{Zr}, \mathrm{Zn}, \mathrm{Ta}, \mathrm{Nb}$ y Hf y un espectro de REE con una pendiente negativa pronunciada en las LREE, una anomalía negativa de Eu marcada y una tendencia casi horizontal en las HREE. Se cree que esta fase está relacionada a los primeros pulsos de extensión terciaria (i. e., Protogolfo de California). Otros sitios en donde se han encontrado rocas similares en composición y ubicación estratigráfica dentro de la Provincia Extensional del Golfo de California son en la región de Hermosillo y en el noroeste de Sonora (Paz-Moreno et al., 2000).

\subsubsection{Rodeo y Nazas, Durango}

La primera manifestación petrológica del inicio de la extensión en el norte de México y el suroeste de los Estados Unidos fue la expulsión del Southern Cordillera Basaltic Andesite (SCORBA), que posee contenidos similares de elementos traza e isótopos que la suite orogénica (i. e., asociada a subducción) basalto-andesita-riolita de la Sierra Madre Occidental, pero que en conjunto tiene menos $\mathrm{SiO}_{2}$ (Cameron et al., 1989). Aunque estas rocas no son consideradas aquí como de tipo intraplaca, sus características químicas fueron interpretadas por Cameron et al. (1989) como una consecuencia de un ascenso más rápido de este tipo de magma, en comparación con los magmas orogénicos, lo que implicó menor diferenciación. Las rocas tipo SCORBA (Aranda-Gómez et al., 1997) afloran inmediatamente al norte de la ciudad de Durango (Figura 8) y son conocidas como el basalto Caleras (K-Ar, roca total: 29-30 Ma).

Las rocas más antiguas (K-Ar: 24-20 Ma; Aguirre-Díaz y McDowell, 1993) con las características de magmas de tipo intraplaca que se han documentado en el norte de México son las hawaiitas de Rodeo y Nazas, Dgo. (Figuras 1 y 8). Las relaciones de campo y edades isotópicas fueron analizadas por Aguirre-Díaz y McDowell (1993) y por Aranda-Gómez et al. (1997). La petrogénesis de estas rocas fue discutida en detalle por Luhr et al. (2001). Las rocas volcánicas de Rodeo y Nazas son similares en edad y composición a algunas rocas de la región de Transpecos, Texas
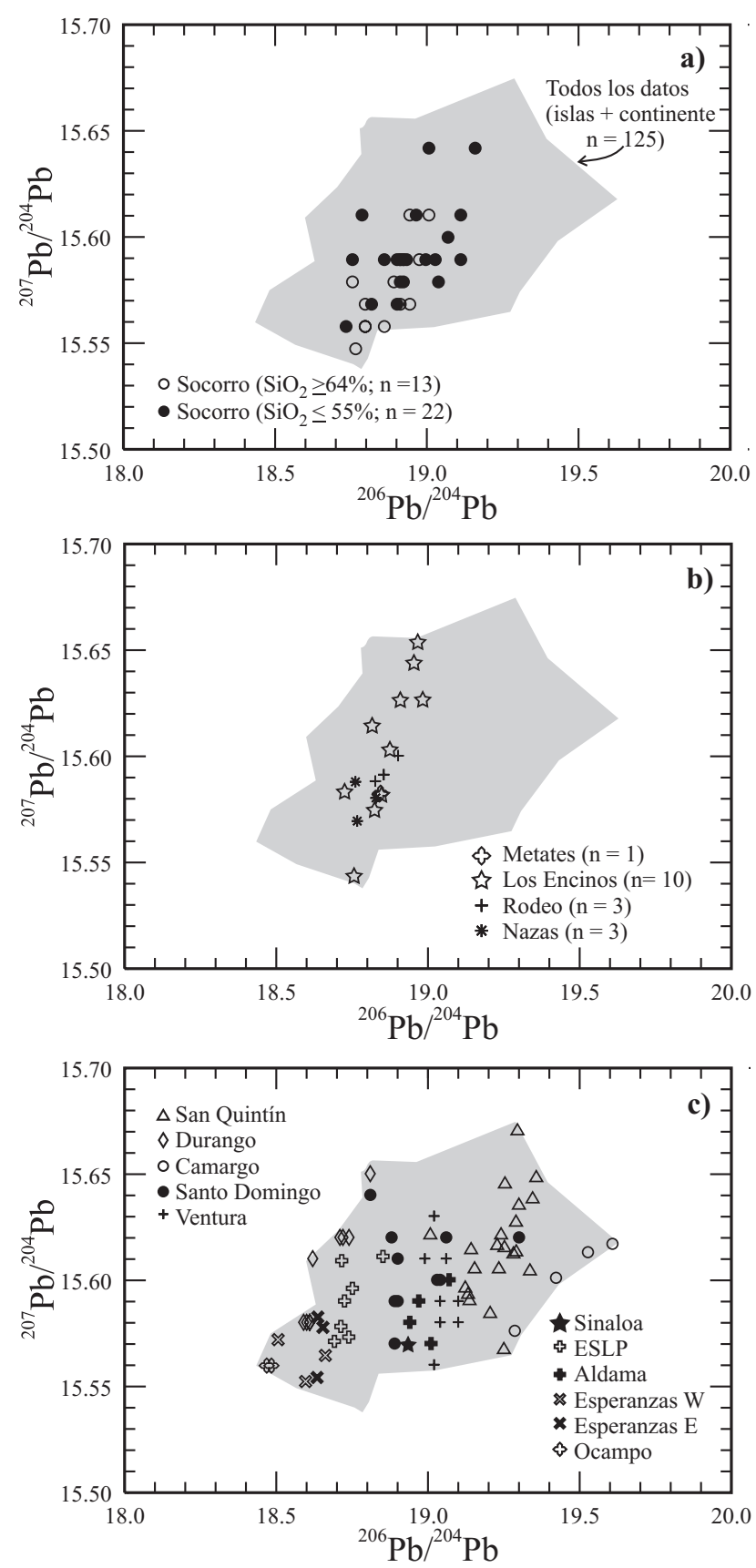

Figura 7. Gráficas ${ }^{206} \mathrm{~Pb} /{ }^{204} \mathrm{~Pb}$ vs. ${ }^{207} \mathrm{~Pb} /{ }^{204} \mathrm{~Pb}$. En todos los diagramas el área sombreada corresponde a las composiciones de las muestras provenientes de todas las localidades continentales e islas. a) Islas. b) Valores iniciales en los magmas tempranos (Mioceno). c) Muestras del Plioceno-Cuaternario $(n=73)$.

(James y Henry, 1991). Los volcanes de Rodeo hicieron erupción cerca de la falla maestra (breakaway fault zone) de un semigraben importante (Figura 8) y están intercaladas con depósitos clásticos de relleno del semigraben. Tanto las gravas como algunas hawaiitas fueron cortadas por fallas normales, infiriéndose de estas relaciones que el volcanismo de tipo intraplaca fue contemporáneo con un evento importante de extensión en la zona. Las hawaiitas 


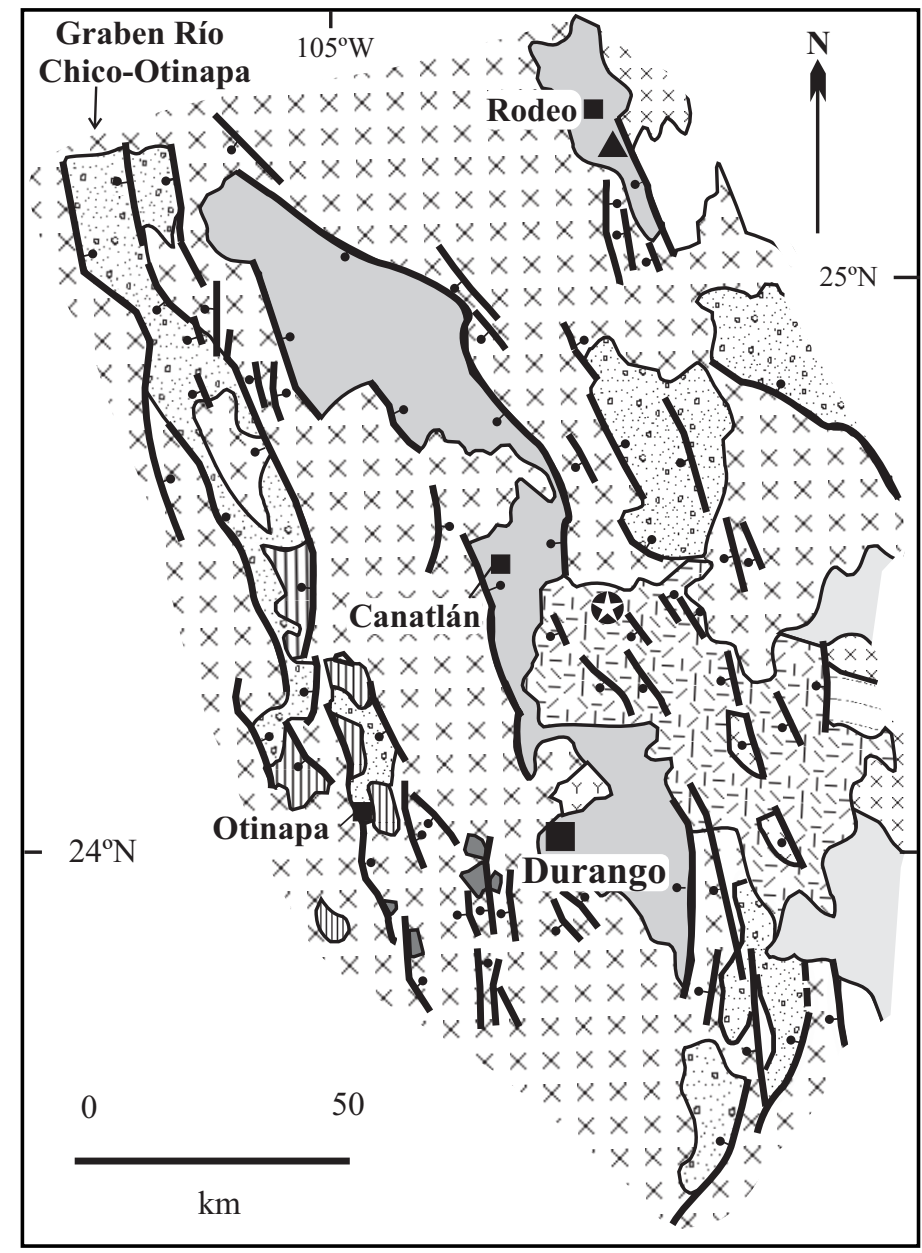

Aluvión

I-1. Rocas máficas intraplaca (Cuaternario)

Basalto alcalino $(\sim 2 \mathrm{Ma})$

a

Sedimentos continentales (Terciario)

Hawaiita Metates ( 12 Ma)

- Hawaiita (24-20 Ma)

$Y Y$
$Y y$ Basalto Caleras (SCORBA, 29-30 Ma)

$\times \times$ Rocas volcánicas félsicas (Terciario medio)

Rocas sedimentarias marinas (Mesozoico)

* Complejo de maares La Breña-El Jagüey

- Falla normal

- Poblado

Ciudad

Figura 8. Mapa geológico generalizado de los alrededores de la ciudad de Durango (Aranda-Gómez et al., 1997). Los afloramientos de Metates se encuentran al oeste de la ciudad en las cercanías del graben Río Chico-Otinapa.

de Nazas forman varios campos de lava sin deformar que sobreyacen a bloques de falla basculados formados por rocas volcánicas félsicas del Oligoceno y a conglomerados con capas horizontales, derivados de los bloques de falla cercanos. Algunos de los derrames de lava en Nazas pueden seguirse hasta sus fuentes, que son conos cineríticos profundamente erosionados y que yacen sobre o cerca de fallas normales.

Las hawaiitas de Rodeo y Nazas $\left(\mathrm{SiO}_{2}: 47.4-49.5 \%\right.$ peso) incluyen fenocristales y/o microfenocristales de $\mathrm{Pl}$, Ol, Cpx y TMt. Aproximadamente la mitad de las muestras estudiadas por Luhr et al. (2001) también contienen microfenocristales de Bt. La mayor parte de las rocas incluyen conjuntos de megacristales con feldespato sódico, $\mathrm{Ol}$ rico en $\mathrm{Fe}, \mathrm{Cpx}$ rico en $\mathrm{Al}$ y una variedad amplia de cristales de Spl. Las texturas y composiciones químicas observadas en los bordes de los megacristales sugieren desequilibrio con el magma huésped. Por ejemplo, los núcleos de los megacristales de feldespato tienen composiciones homogéneas entre $\mathrm{An}_{26-51}$, mientras que los bordes son zonificados con composiciones más cálcicas $\left(\mathrm{An}_{57-65}\right)$. De igual forma, el núcleo de los megacristales de Cpx contiene 7-9\% en peso de $\mathrm{Al}$, mientras que los bordes sólo contienen 1-5\% en peso. En ambos casos la composición de los bordes de los megacristales es similar a la de los fenocristales y microfenocristales primarios en las rocas. Algunos núcleos de la $\mathrm{Pl}$ son agregados policristalinos que dan una idea de las paragénesis $(\mathrm{Pl}+\mathrm{Spl}+\mathrm{Ap}+\mathrm{Po} ; \mathrm{Pl}+\mathrm{Spl}+\mathrm{Cpx} ; \mathrm{Pl}+\mathrm{Cpx}+\mathrm{Ol})$ de los protolitos de los que fueron desagregados. Por sus características mineralógicas y químicas se interpreta a los protolitos como fragmentos derivados de la parte profunda de la corteza subyacente.

Las muestras de Rodeo y Nazas están moderada a pobremente preservadas y tienen contenidos elevados de $\mathrm{TiO}_{2}$ (2.1-2.4\% peso), Nb (40-82 ppm) y Ta (2.1-4.2 ppm). De acuerdo con el diagrama de total de álcalis $v s$. sílice (TAS por sus siglas en inglés) de Le Maitre et al. (2002) son hawaiitas (Figura 2b) y con excepción de aquellas alteradas intensamente, tienen $[\mathrm{Ne}]$ en la norma (Figura 3b). Sus contenidos de $\mathrm{MgO}$ (5.5-7.1\% peso), \#Mg (52.2-59.7), $\mathrm{Ni}(48-83 \mathrm{ppm})$ y $\mathrm{Cr}(73-186 \mathrm{ppm})$ indican que fueron diferenciadas y que no son magmas primarios derivados directamente de peridotitas del manto. La abundancia de elementos incompatibles en ellas es similar al de muchas 
rocas de tipo intraplaca cuaternarias de la porción meridional de la provincia Cuencas y Sierras (Figuras $4 \mathrm{~b}$ y $5 b)$. Excepciones notables son cuatro ejemplares en que el Cs muestra un enriquecimiento muy marcado y el $\mathrm{Rb}$ está empobrecido (Figura 9). Se cree que esas características geoquímicas son consistentes con la interacción de estos magmas con corteza continental y con la incorporación preferente de $\mathrm{Cs}$ respecto a $\mathrm{Rb}$, lo que hizo que disminuyera la relación $\mathrm{Rb} / \mathrm{Cs}$ en ellas. Las hawaiitas de Rodeo y Nazas tienen composiciones isotópicas distintivas formando grupos separados, aunque las variaciones observadas son pequeñas (Figuras $6 \mathrm{~b}$ y $7 \mathrm{~b}$ ). Respecto a las rocas de Nazas, las hawaiitas de Rodeo tienen más bajo ${ }^{87} \mathrm{Sr} /{ }^{86} \mathrm{Sr}_{\mathrm{i}}(0.7037-0.7038$ vs. $0.7040-0.7041)$, más alto $\varepsilon_{\mathrm{Nd}, \mathrm{i}}(+4.2-+4.8$ vs. $+2.8-+3.5)$, más alto ${ }^{206} \mathrm{~Pb} / 204 \mathrm{~Pb}_{\mathrm{i}}$ (18.84-18.91 vs. $18.77-18.84)$ y más alto ${ }^{208} \mathrm{~Pb}^{204} \mathrm{~Pb}_{\mathrm{i}}$ (38.55-38.61 vs. 38.51-38.57). Los valores de ${ }^{207} \mathrm{~Pb}^{204} \mathrm{~Pb}_{\mathrm{i}}$ traslapan (15.57-15.60). Las relaciones isotópicas son interpretadas como evidencia de interacción entre estos magmas y la corteza.
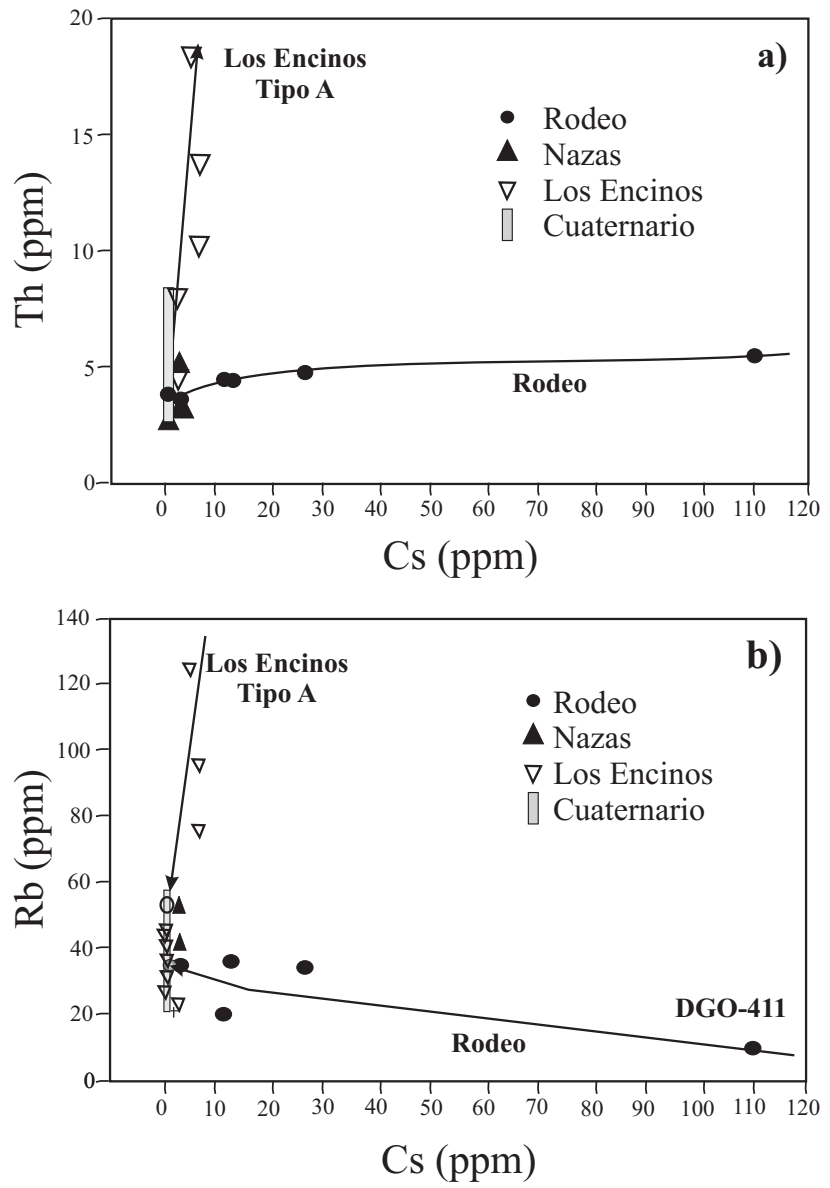

Figura 9. a) y b) Abundancias de Cs $v s$. Th y $\mathrm{Rb}$ (ppm, roca total) en rocas volcánicas del Mioceno de los campos volcánicos de Los Encinos y Rodeo-Nazas. Las áreas pequeñas entre 0-2 ppm de Cs y 0-8 ppm de Th representan la composición de las 50 rocas cuaternarias. Los vectores de contaminación observados en Rodeo y Los Encinos son mostrados con las flechas. Las Figuras fueron tomadas de Luhr et al. (2001)

\subsubsection{Campo volcánico Los Encinos (S. L. P.)}

Los Encinos ocupa un área extensa $\left(\geq 5000 \mathrm{~km}^{2}\right)$ en la Mesa Central, en el noroeste de San Luis Potosí y noreste de Zacatecas (Figura 10). La petrogénesis de las rocas volcánicas de tipo intraplaca de Los Encinos y el significado de los conjuntos de inclusiones en ellas son analizados en detalle por Luhr et al. (1995b). Algunas implicaciones tectónicas de la distribución de los volcanes son discutidas por Henry y Aranda-Gómez (2000). En términos generales, la región de Los Encinos puede ser descrita como un altiplano con una elevación promedio sobre el nivel del mar de más de 2000 $\mathrm{m}$ en donde sobresalen algunas sierras aisladas con alturas hasta de $2600 \mathrm{msnm}$. El límite oriental de la distribución de los volcanes de Los Encinos es la Sierra de Catorce $(\leq 3800$ $\mathrm{msnm}$ ), una estructura N-S limitada al oeste por una falla normal importante (Figura 10a). Los afloramientos de rocas volcánicas en Los Encinos ocurren en una región extensa de $\sim 50 \times 100 \mathrm{~km}$, pero sólo cubren una parte pequeña del área y en la zona también hay vestigios erosionales de rocas calcialcalinas del Eoceno-Oligoceno. Las rocas máficas de tipo intraplaca del Mioceno medio (K-Ar: 10.6-13.6 Ma, Luhr et al., 1995b) forman cuellos volcánicos con juntas columnares conspicuas y mesas pequeñas cubiertas por derrames de lava. Algunos de los cuellos ubicados inmediatamente al oeste y norte de la sierra de Catorce están en el proceso de ser sepultados por abanicos aluviales activos provenientes de la misma. Esto sugiere creación de relieve, posiblemente asociada a fallamiento postvolcánico y que la sierra de Catorce se ubica en un bloque relativamente elevado respecto al área en donde se encuentran la mayoría de los cuellos volcánicos. Así mismo, en esa misma área, los volcanes de Los Encinos definen dos alineamientos burdos (Figura 10a) que son aproximadamente paralelos a la trama tectónica definida por fallas normales cenozoicas en la porción meridional de la Mesa Central (Figura 10c). Esto es interpretado como evidencia de un control estructural del volcanismo y de actividad vulcano-tectónica durante el Mioceno medio (Henry y Aranda-Gómez, 2000).

La paragénesis estable en las hawaiitas (Figura 3b) de Los Encinos es $\mathrm{Pl}\left(\mathrm{An}_{53-64}\right)+\mathrm{Ol}\left(\mathrm{Fo}_{61-88}\right)+\mathrm{Cpx}+\mathrm{TMt}+\mathrm{Bt}($ trazas $)$. Invariablemente estas rocas contienen conjuntos de megacristales $(1-3 \mathrm{~cm})$ de feldespato ( $\mathrm{Sa}$, Anor, y/o Pl), Krs, Cpx y Mt que pueden ser accidentales o cogenéticos con el magma que los transportó a la superficie. También es común que las rocas volcánicas máficas contengan xenocristales más pequeños $(<1 \mathrm{~cm}) \mathrm{Ap} \mathrm{y} \mathrm{de} \mathrm{Ol}\left(\mathrm{Fo}_{45-79}\right)$ y $\mathrm{Cpx}$, ricos en Fe en comparación con las fases primarias cristalizadas a partir del magma. Xenocristales de Qtz rodeados por anillos de reacción son casi ubicuos en todas las muestras. Tanto megacristales como xenocristales presentan evidencias de haber sido parcialmente reabsorbidos, o bien incluyen anillos de reacción notables en contacto con la matriz. Algunas de estas rocas contienen agregados policristalinos con paragénesis consistentes con: (1) granulitas feldespáticas (paragneisses con Qtz y Sil) provenientes de la parte profunda de la corteza, o (2) con rocas gabróicas 


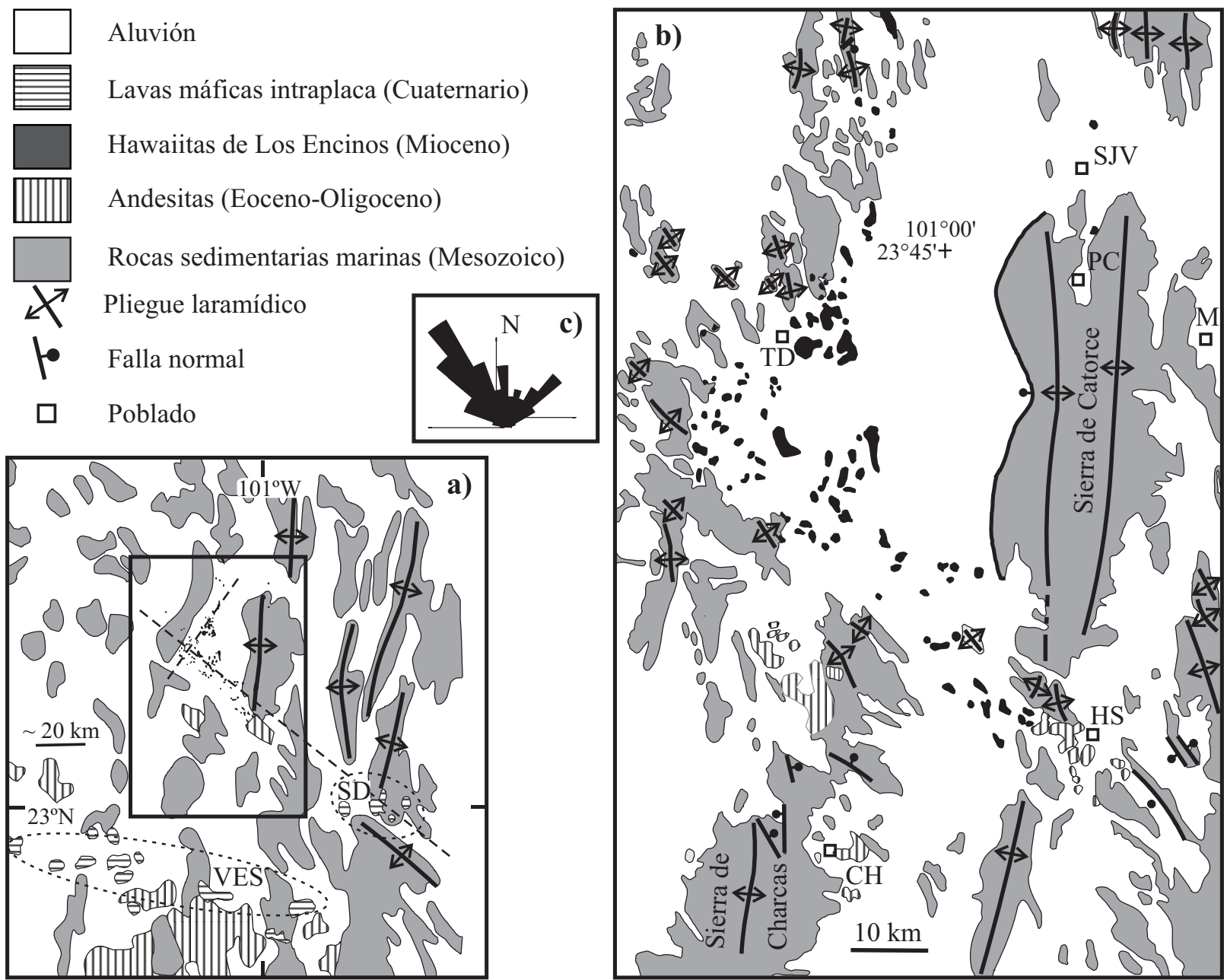

Figura 10. a) Entorno geológico del campo volcánico de los Encinos. Se muestra diagramáticamente su relación con las rocas de tipo intraplaca del Cuaternario ( $\mathrm{SD}=$ Santo Domingo y VES=Ventura-Espíritu Santo). Nótese que SD se ubica a lo largo de la misma estructura inferida en el basamento que Los Encinos. Las líneas formadas por rayas cortas muestran la tendencia general de los alineamientos de volcanes descritos en el texto. Localidades mostradas: SJV=San Juan de Vanegas, PC=Potrero de Catorce, M=Matehuala, TD=Tanque de Dolores, HS=Hacienda Solís, CH=Charcas. La Figura 10b corresponde al rectángulo. b) Mapa geológico generalizado del campo volcánico de Los Encinos (Henry y Aranda-Gómez, 2000). Se muestra la distribución de los afloramientos de rocas volcánicas del Terciario y su posible relación con una discontinuidad en el basamento. Ésta influyó en la orientación de los pliegues laramídicos y en la localización de los volcanes del Terciario medio y del Mioceno. c) Roseta que muestra la orientación de las fallas normales del Terciario medio y tardío en la porción meridional de la Mesa Central, en la región ubicada entre las ciudades de San Luis Potosí y Guanajuato; las tendencias principales coinciden con el alineamiento de volcanes en Los Encinos.

cristalizadas a alta presión y que tienen una composición global similar al magma huésped, sólo que más evolucionada. La composición de los minerales en estos gabros es comparable con la de los megacristales por lo que se cree son muestras de los protolitos de donde se derivan los megacristales. Hasta ahora no se han reportado xenolitos de peridotitas del manto o xenocristales derivados de ellos en los volcanes de Los Encinos.

Las rocas de tipo intraplaca de Los Encinos son hawaiitas y hawaiitas de $[\mathrm{Ne}]$ (Figura 3b), similares a las de Transpecos (Texas), Rodeo-Nazas y Metates (Durango). La mayor parte de estas rocas muestran diferencias notables con las rocas cuaternarias de los campos volcánicos de Santo Domingo y Ventura-Espíritu Santo, ubicados más al sur en la Mesa Central (Figura 10b). Los campos volcánicos cuaternarios también incluyen hawaiitas pero éstas se asocian a basanitas y nefelinitas considerablemente más primitivas. El rango de composición de las rocas de Los Encinos es distinto al de las rocas cuaternarias (e. g., $\mathrm{SiO}_{2}: 46.9-57.0$ y $\mathrm{MgO}: 11.9-3.9$ vs. $\mathrm{SiO}_{2}: 41.8-51.2$, MgO: $15.8-5.7 \%$ peso, respectivamente). El contenido de elementos traza en unas cuantas rocas de Los Encinos es similar al de las rocas cuaternarias (Figuras $5 \mathrm{~b}$ y $5 \mathrm{c}$ ), pero otros productos volcánicos están muy enriquecidos en Cs, $\mathrm{Rb}$, Th y U (Figuras 5 b y 9). Estos enriquecimientos son interpretados como evidencia de contaminación con materiales de la corteza inferior. Esto es porque los valores anómalamente altos de estos elementos son independientes de las concentraciones de muchos otros elementos incompatibles en las mismas rocas y que se cree fueron 
controlados por su abundancia en las rocas madre de los magmas en el manto y/o por el grado de fusión parcial y/o por el grado de diferenciación de las mismas.

Las muestras estudiadas por Luhr et al. (1995b) fueron divididas en tres grupos en función de sus características geoquímicas. El tipo U (sin contaminar) es similar a las rocas cuaternarias (compárese el diagrama de multielementos de SLP-145 en Figura 5b con los patrones característicos del grupo Ventura en Figura 5c), sólo que más evolucionado. La composición isotópica del tipo U (e. g., SLP-145, Figura 6b) es $\varepsilon_{\mathrm{Nd}}=+7.6,{ }^{87} \mathrm{Sr} /{ }^{86} \mathrm{Sr}=0.70286$ y ${ }^{206} \mathrm{~Pb} / 204 \mathrm{~Pb}=18.74$, más extrema que en las rocas de los campos cuaternarios vecinos (Santo Domingo y Ventura-Espíritu Santo, Figura 6c). Los otros dos tipos, A y B, están contaminados, tienen valores altos de $\mathrm{Yb}$ y relaciones isotópicas más altas de ${ }^{87} \mathrm{Sr} /{ }^{86} \mathrm{Sr}$ (hasta 0.7040 ) y ${ }^{206} \mathrm{~Pb} / 204 \mathrm{~Pb}$ (hasta 18.98 ) y $\varepsilon_{\mathrm{Nd}}$ más bajo (hasta +3.1 ), que reflejan asimilación, ya sea de roca total (bulk) o asimilación acompañada con cristalización fraccionada ( $A F C$ por sus siglas en inglés) de granulitas feldespáticas, especialmente paragneises con Grt. Las rocas de tipo A tienen valores anómalamente altos en $\mathrm{Cs}, \mathrm{Rb}, \mathrm{Th}$, $\mathrm{Sb}, \mathrm{U}, \mathrm{Pb}, \mathrm{K}$ y Si (e. g., Figura 9 y SLP-156 en Figura 5b). Aquellas muestras que no satisfacen claramente los criterios para los tipos U o A, fueron clasificadas como tipo B.

\subsubsection{Metates (Durango)}

El basalto (sensu lato) Metates (Córdoba, 1963) aflora en y cerca del graben Río Chico-Otinapa, a $\sim 20 \mathrm{~km}$ al oeste de la ciudad de Durango (Figura 8). La edad (K-Ar, hornblenda) de esta unidad es $12.7 \mathrm{Ma}$ (McDowell y Keizer, 1977) y ésta se ha utilizado como el argumento principal para fechar un pulso de fallamiento normal al este de la Sierra Madre Occidental, contemporáneo con la formación del Protogolfo de California (Henry y Aranda-Gómez, 2000). Las relaciones estratigráficas y estructurales indican que el graben fue formado un poco antes que la expulsión del basalto Metates. Cerca del sitio en donde la carretera Durango-Mazatlán cruza al graben se puede observar que el derrame más antiguo de basalto dentro del graben sobreyace a un depósito delgado de gravas que rellenaron parcialmente la estructura. En ese sitio, el basalto sólo contiene una cantidad pequeña de megacristales (feldespato y Krs). En la margen oeste del graben se observa otro derrame de lava del basalto Metates, sin inclusiones, desplazado unos $60 \mathrm{~m}$ por una falla normal. Así mismo, se observa un dique máfico sin inclusiones que aparentemente se emplazó a través de una falla y que puede ser el alimentador de los basaltos suprayacentes. Una localidad del basalto Metates con megacristales abundantes y con algunos xenolitos de granulita feldespática se puede observar en el kilómetro 44 de la misma carretera. En ese sitio, el basalto sobreyace a un domo riolítico y depósitos piroclásticos asociados con una edad isotópica (K-Ar, Sa) de 29.3 Ma. La edad del basalto (K-Ar, Hbl) es de $12.0 \mathrm{Ma}$ (McDowell y Keizer, 1977).

Hasta ahora no existe un estudio petrológico detallado del basalto Metates. Sólo se han reportado análisis químicos de tres muestras (Aranda-Gómez et al., 1997) y se ha hecho énfasis en la semejanza que existe entre la composición química de estas hawaiitas (Figura 3b) y su contenido de megacristales con las rocas de Los Encinos y Rodeo-Nazas (Luhr et al., 1995b, 2001).

3.2. Magmatismo tardío (Plioceno temprano-Cuaternario): Región occidental/Baja California

\subsubsection{Campo volcánico de San Quintín}

Este es un sitio excepcional, ya que es la única localidad hasta ahora reportada con volcanismo de tipo intraplaca con xenolitos del manto y granulitas de la corteza en la península de Baja California (Figura 1). San Quintín está formado por diez complejos volcánicos del Cuaternario $\left({ }^{40} \mathrm{Ar}-{ }^{39} \mathrm{Ar}\right.$, matriz: 126 y $90 \mathrm{ka}$, Luhr et al., 1995b y ${ }^{3} \mathrm{He}-{ }^{4} \mathrm{He}$ : 165-22 ka, Williams, 1999), formados por escudos de lava pequeños y conos cineríticos. A diferencia de otras muchas localidades en México, las rocas volcánicas y los xenolitos del manto de San Quintín han sido objeto de varias investigaciones (e. g., Basu, 1977a, 1977b, 1978, 1979; Basu y Murthy, 1977; Bacon y Carmichael, 1978; Rogers et al., 1985; Cabanes y Mercier, 1988; Storey et al., 1989; Righter y Carmichael, 1993), siendo ésta una de las localidades más intensamente estudiadas en México.

San Quintín se encuentra afuera de la región evidentemente afectada por la extensión relacionada a la provincia de Cuencas y Sierras y/o a la transtensión asociada al Golfo de California (Figura 1). El carácter de tipo intraplaca de las rocas en San Quintín ha sido atribuido a: (1) la creación de un no-slab window que pudo permitir el acceso al manto astenosférico debajo de esta región (Rogers et al., 1985; Saunders et al., 1987), (2) a que San Quintín se encuentra tan cerca de la paleotrinchera que el manto debajo de esta localidad no pudo ser afectado por la subducción (Sawlan, 1991).

El estudio más sistemático de la geología, geoquímica y petrología de las rocas volcánicas de San Quintín es aquel desarrollado por Luhr et al. (1995a). A continuación se resumen algunos de sus resultados: (1) la paragénesis estable en las rocas de San Quintín es: $\mathrm{Ol}+\mathrm{Pl}+\mathrm{Cpx}+\mathrm{TMt}+\mathrm{Ilm}$. El olivino usualmente contiene inclusiones de Spl. Estas fases mineralógicas usualmente van acompañadas de xenocristales y megacristales. Los xenocristales más comunes son aquellos derivados de las peridotitas del manto y su abundancia se correlaciona con la abundancia de xenolitos observada en el campo. Aproximadamente la mitad de las muestras contienen algunos xenocristales de Qtz. Algunos ejemplares contienen xenolitos parcialmente fundidos de granulitas gabróicas. En los volcanes en donde los xenolitos son más abundantes se observan megacristales de Pl y Cpx hasta de $2 \mathrm{~cm}$; (2) casi todas las muestras estudiadas $(\mathrm{n}=63)$ contienen $[\mathrm{Ne}]$ y fueron clasificadas como hawaiitas, hawaiitas nefelínicas, basaltos alcalinos 
y basanitas (Figuras 2d y 3d). Estas variedades ocurren en aproximadamente la misma proporción en el conjunto. Además de esto, se encontraron tres muestras con $[H y]$ y se clasificaron como basaltos o hawaiitas (Figura 3c); (3) el \#Mg en las rocas varía de 51 a 67 . Los volcanes más antiguos expulsaron lavas y piroclastos primitivos (\#Mg $>64)$ que rara vez contienen xenolitos pequeños. Con el tiempo los volcanes expulsaron productos más diferenciados con xenolitos grandes abundantes. Los volcanes más jóvenes extravasaron lavas y tefras primitivas, prácticamente sin xenolitos, pero muy ricas en fenocristales de Ol; (4) se observa un decremento en la abundancia de elementos incompatibles con el tiempo, lo que implica un aumento en el grado de fusión parcial o el agotamiento progresivo de estos elementos en la fuente de donde provienen los magmas; (5) la mayor parte de las rocas diferenciadas pueden ser modeladas a partir de los magmas más primitivos en la serie por cristalización fraccionada de $\mathrm{Ol}$, $\mathrm{Pl}, \mathrm{Cpx}$ y Spl en un sistema cerrado; (6) las variaciones isotópicas en las muestras estudiadas $(n=20)$ son pequeñas: ${ }^{87} \mathrm{Sr} /{ }^{86} \mathrm{Sr}=0.703140-0.703459, \varepsilon_{\mathrm{Nd}}=+5.38-+6.28 \mathrm{y}$ ${ }^{206} \mathrm{~Pb} /{ }^{204} \mathrm{~Pb}=19.008-19.357$ (Figuras $6 \mathrm{~d}$ y $7 \mathrm{c}$ ). Los valores poco variables de composiciones isotópicas de $\mathrm{Sr}, \mathrm{Nd}$ y $\mathrm{Pb}$ que se observan en las rocas diferenciadas y su traslape con aquellos en rocas primitivas apoyan la interpretación de cristalización fraccionada. Sólo en dos de los complejos volcánicos se encontró evidencia elemental e isotópica de contaminación con material cortical; (7) un rasgo poco usual de las rocas primitivas de San Quintín, en comparación con otras localidades de tipo intraplaca en el mundo, es que tienen valores relativamente altos de $\mathrm{Al}_{2} \mathrm{O}_{3}$ e $\mathrm{Yb}$ (Figura 5d), así como bajos en las relaciones $\mathrm{La} / \mathrm{Yb}$ y en $\mathrm{CaO} / \mathrm{Al}_{2} \mathrm{O}_{3}$ (Figura 11c). Estas características, junto con las tendencias a aumentar del $\mathrm{Al}_{2} \mathrm{O}_{3}$ y a decrecer del $\mathrm{CaO}$ con el incremento de elementos incompatibles (Figuras 11a y 11b) son consistentes con la generación de los magmas de San Quintín por fusión parcial progresiva de lherzolitas de Spl a presiones relativamente bajas dentro del manto.

\subsection{Magmatismo tardío (Plioceno temprano-}

Cuaternario): Región Cuencas y Sierras meridional

\subsubsection{Campo volcánico El Pinacate}

Es un campo volcánico extenso ubicado al noreste del extremo septentrional del Golfo de California (Figura 1). Se encuentra dentro de un área de aproximadamente de 55 x $60 \mathrm{~km}$ y sus productos cubren un área de $\sim 1500 \mathrm{~km}^{2}$. La actividad temprana del Cuaternario (K-Ar: 1.7-1.1 Ma: Lynch et al., 1993) formó un escudo (volcán Santa Clara) que alcanza una altura de 1200 m y está formado por una serie de diferenciación alcalina que, en orden estratigráfico, varía de basanita a traquita (Figuras 2c y 2d). Sobre el volcán Santa Clara y las arenas del desierto circundante hicieron erupción un gran número de volcanes monogenéticos (maares, conos de toba y conos cineríticos)
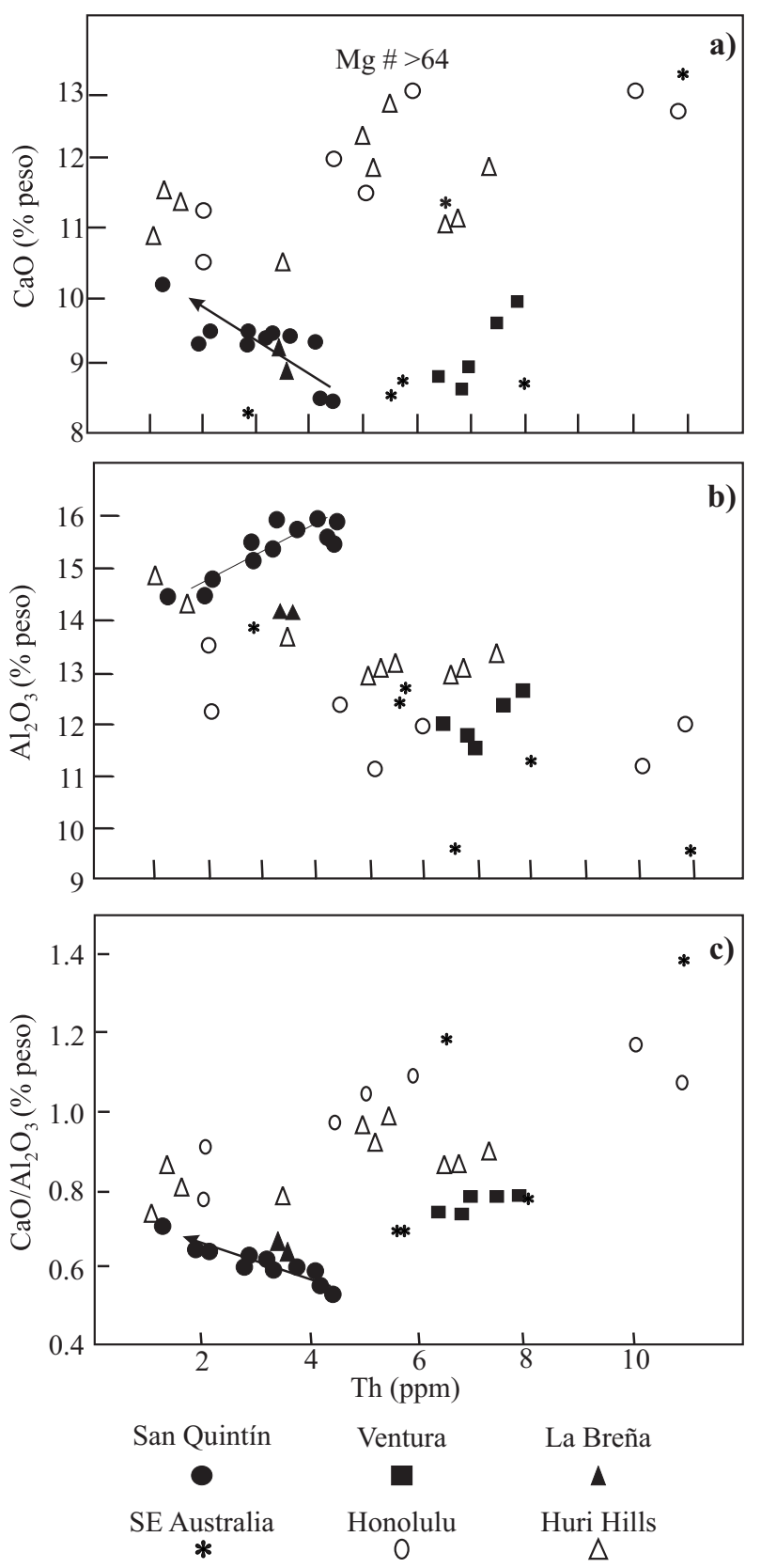

Figura 11. Diagramas de variación de $\mathrm{Th}$ vs. $\mathrm{CaO}, \mathrm{Al}_{2} \mathrm{O}_{3}$ y $\mathrm{CaO} / \mathrm{Al}_{2} \mathrm{O}_{3}$ para las muestras más primitivas de San Quintín. Las flechas indican las tendencias lineales que generaría la fusión parcial progresiva después de que el Cpx se ha agotado en la fuente. Tomado de Luhr et al. (1995a). Para comparación se incluyen muestras selectas de Ventura, La Breña, SE de Australia, Honolulu y Huri Hills (véanse fuentes de datos en Luhr et al., 1995a).

de composición basáltica (K-Ar $\leq 0.19$ Ma: Lynch et al., 1993). En la parte meridional del campo se distingue el derrame de lava Ives que fue extravasado a través de fisuras $\mathrm{N}-\mathrm{S}$, cubre $\sim 75 \mathrm{~km}^{2}$, que representa $\sim 5 \%$ del área total de El Pinacate, y tiene un volumen estimado entre 0.25 y 0.50 $\mathrm{km}^{3}$ (Lynch et al., 1993). A diferencia de otras lavas en el área, la morfología de la superficie de Ives es pahoehoe. El Pinacate tiene un entorno tectónico particular ya que 
yace sobre corteza continental a sólo $\sim 50 \mathrm{~km}$ de un límite de placas activo formado por una cresta oceánica y fallas transformantes asociadas (Figura 1).

A pesar de que se han publicado trabajos de vulcanología física (e. g., Arvidson y Mutch, 1974; Gutmann y Sheridan, 1978; Gutmann, 1979, 2002; Lutz y Gutmann, 1995) y de algunos aspectos mineralógicos de las rocas volcánicas de El Pinacate (e. g., Gutmann, 1974, 1986; Gutmann y Martín, 1976) y de sus xenolitos (Gutmann, 1986), no existe ningún estudio exhaustivo y sistemático de la geoquímica y petrología de sus lavas y tefras. Los datos que resumimos provienen de Lynch (1981) y de Lynch et al. (1993) acerca de un muestreo de reconocimiento $(n=7)$ para determinar la composición isotópica ( $\mathrm{Sr}$ y $\mathrm{Nd}$ ) de las series cuaternarias temprana, tardía, del derrame Ives y de un xenolito de lherzolita. Todas las rocas excepto una, tienen valores de ${ }^{87} \mathrm{Sr} /{ }^{86} \mathrm{Sr}$ entre 0.70312 y 0.70342 y de $\varepsilon_{\mathrm{Nd}}$ entre $+5.0 \mathrm{y}+5.7$ (Figura $6 \mathrm{c}$ ). La traquita del volcán Santa Clara tiene valores de ${ }^{87} \mathrm{Sr} /{ }^{86} \mathrm{Sr}$ más altos $(\sim 0.70611)$ y el valor más bajo de $\varepsilon_{\mathrm{Nd}}(+5)$, posiblemente debido a contaminación cortical (no se muestra en la Figura 6c). A pesar de que el derrame de lava Ives es distinto en varios aspectos al resto de las rocas de El Pinacate (e.g., contiene $[H y])$, su composición isotópica de $\mathrm{Sr}$ y $\mathrm{Nd}$ es idéntica. Esto demuestra que Ives vino de la misma fuente (o de la misma mezcla de fuentes) que el resto de los magmas y que su composición particular se debe a un grado de fusión parcial mayor. La composición isotópica de los ejemplares estudiados, así como la de una Di separada de un xenolito de lherzolita es similar a OIB (basalto de isla oceánica) o MORB (basalto de dorsal oceánica) enriquecido, que sugiere una fuente dominada por manto astenosférico en vez de un manto litosférico enriquecido para los magmas de El Pinacate. Lynch et al. (1993) no encontraron evidencias isotópicas convincentes de una influencia de la tectónica del Golfo de California en la geoquímica de las rocas de El Pinacate, pero sí una semejanza considerable con otras localidades de tipo intraplaca de la porción norteamericana de Cuencas y Sierras (e. g., Geronimo y Kilbourne Hole; Menzies, 1989).

\subsubsection{Campo volcánico de Moctezuma}

Esta localidad fue estudiada por Paz-Moreno et al. (2003). Los datos que aquí se asientan se tomaron de dicho trabajo. Moctezuma está ubicado en Sonora, en las estribaciones al noroeste de la Sierra Madre Occidental (Figura 1) y se caracteriza por una asociación íntima entre rocas con $[\mathrm{Hy}] \mathrm{y} / \mathrm{o}[\mathrm{Qtz}]$ y rocas con $[\mathrm{Ne}]$ (Figuras $3 \mathrm{c}$ y $3 d)$. El campo volcánico se encuentra en un semigraben con rumbo NNW. La extensión en esta región inició en el Mioceno temprano como lo atestiguan basaltos $\left({ }^{40} \mathrm{Ar}-{ }^{39} \mathrm{Ar}\right.$, Pl: 22.3 Ma) intercalados con un fanglomerado que rellenó parcialmente a la estructura. Estas rocas máficas asociadas a las fases tempranas de extensión tienen características geoquímicas similares a los SCORBA documentados por Cameron et al. (1989) en Chihuahua. El volcanismo má- fico en Moctezuma reinició en el Cuaternario $\left({ }^{40} \mathrm{Ar}-{ }^{39} \mathrm{Ar}\right.$, roca total: $1.7 \mathrm{Ma}$ ) después de una pausa prolongada en la actividad magmática. Las fases iniciales del volcanismo dieron origen a mesas extensas cubiertas por derrames de lava con $[H y]$ y/o $[Q t z]$ que provienen de conductos fisurales ubicados cerca de la falla maestra en el lado oriental del semigraben. La actividad más reciente produjo rocas máficas alcalinas $(\mathrm{K}-\mathrm{Ar}=0.53 \mathrm{Ma})$ que fueron expulsadas por conductos centrales localizados más hacia el centro del semigraben. Esta actividad formó conos de escoria y derrames de lava asociados. El área cubierta por las rocas volcánicas cuaternarias es de $\sim 400 \mathrm{~km}^{2}$ y su volumen estimado es $<2 \mathrm{~km}^{3}$. A diferencia de otras localidades continentales de tipo intraplaca, en Moctezuma no se han encontrado xenolitos del manto o corticales, ni cristales derivados de su desagregación. La mineralogía primaria en ambos tipos de rocas máficas es: $\mathrm{Ol}+\mathrm{Pl}+\mathrm{Cpx}+\mathrm{Ilm}$. Las rocas saturadas con $\mathrm{SiO}_{2}$ tienden a ser pobres en fenocristales, mientras que algunas rocas alcalinas pueden llegar a tener hasta un 30\% (volumen) de los mismos. El Ol es la única fase que forma fenocristales en las rocas saturadas con $\mathrm{SiO}_{2}$, mientras que en las hawaiitas son comunes los agregados glomeroporfídicos de $\mathrm{Ol}+\mathrm{Cpx}+\mathrm{Pl}$. Una diferencia notable en la mineralogía de las dos suites de rocas es que el Cpx en las rocas con $[H y]$ y/o [Qtz] es Aug pobre en Ca o Pgt, mientras que en las hawaiitas son Aug rica en $\mathrm{Ca}$ o Di. Conforme a los criterios de clasificación de Le Maitre et al. (2002) y de Irvine y Baragar (1971) las rocas saturadas con $\mathrm{SiO}_{2}$ son basaltos y andesitas basálticas subalcalinas y las rocas alcalinas son hawaiitas (Figuras 2c y 2d). En Moctezuma hay rocas transicionales que grafican en el campo alcalino pero que carecen de $[\mathrm{Ne}]$. Los valores de \#Mg en las rocas de Moctezuma varían de 57 a 66, pero la mayoría están entre 60 y 62 . Estos valores de \#Mg, así como los contenidos relativamente bajos de $\mathrm{Ni}$ (rocas saturadas con $\mathrm{SiO}_{2}$ : 154-220; hawaiitas: 101-203) y $\mathrm{Cr}$ (rocas saturadas con $\mathrm{SiO}_{2}$ : 190-322; hawaiitas: 171-272) llevan a la conclusión que estas rocas no representan magmas primarios derivados por fusión parcial de peridotitas normales del manto. El diagrama de REE normalizadas con condritas muestra patrones marcadamente distintos para las dos series (Figura 4c), con un arreglo lineal y una pendiente marcada para las hawaiitas con $[\mathrm{Ne}](78-82$ en Figura 4c), debido al enriquecimiento pronunciado de LREE, mientras que los arreglos para el otro grupo (8-82 en Figura $4 \mathrm{c}$ ) tienen pendiente más pequeña debido a un enriquecimiento menor en las LREE. La concentración de Tierras Raras pesadas HREE es similar en ambas suites, lo que es interpretado como evidencia de Grt en la roca madre de ambas. Los diagramas multielementos normalizados respecto al manto primitivo (Figura 5c) muestran los patrones característicos de OIB para las hawaiitas con $[\mathrm{Ne}]$ y las rocas con $[\mathrm{Hy}] \mathrm{y} / \mathrm{o}[\mathrm{Qtz}]$ se asemejan a aquellos de MORB enriquecido o de tholeiitas OIB. Las lavas y tefras cuaternarias de Moctezuma tienen valores elevados de $\varepsilon_{\mathrm{Nd}}$ 
entre $+8 \mathrm{y}+11$ y bajos de ${ }^{87} \mathrm{Sr} /{ }^{86} \mathrm{Sr}=0.7028-0.7036$ (Figura $6 \mathrm{c})$. Estos valores, y la forma de la gráfica de multielementos normalizados respecto al MORB, son interpretados por Paz-Moreno et al. (2003) como que la fuente de donde se derivan los magmas de Moctezuma estaba dominada por el manto astenosférico.

\subsubsection{Mesa Cacaxta}

En la región ubicada a unos $50 \mathrm{~km}$ al norte de Mazatlán, Sinaloa, existen varios afloramientos aislados de rocas máficas alcalinas. Aquí nos referimos a este campo como Mesa Cacaxta (Figura 1) por ser este afloramiento el más extenso $\left(\sim 500 \mathrm{~km}^{2}\right)$ en la zona. La Mesa Cacaxta es un campo de lava de $3.2 \mathrm{Ma}\left({ }^{40} \mathrm{Ar}-{ }^{39} \mathrm{Ar}\right.$, roca total y Pl: Aranda-Gómez et al., 1997) en donde hay algunos megacristales de Pl. En Punta Piaxtla, ubicada al oeste de Mesa Cacaxta, en la costa del Golfo de California (véase localización en Figura 24 de Aranda-Gómez et al., 1997), hay hawaiitas nefelínicas de $2.1 \mathrm{Ma}\left({ }^{40} \mathrm{Ar}-{ }^{39} \mathrm{Ar}\right.$, roca total y Pl: Aranda-Gómez et al., 1997) con xenolitos de lherzolita de Spl (Luhr y ArandaGómez, 1997), piroxenita, granulitas feldespáticas y megacristales de piroxeno y Pl (Henry y Fredrikson, 1987 y Righter y Carmichael, 1993). Otros sitios, ubicados al sur de Punta Piaxtla, en donde están expuestas rocas similares son Punta Prieta, Cerro Carey, Punta Los Labrados y Punta Gruesa. Análisis químicos de dos muestras realizados por Smith (1989) indican que estas rocas son hawaiitas nefelínicas (Figura 3d). La composición de estas rocas es comparada con muestras del campo volcánico de Durango y con el basalto Metates en un diagrama de variación de Sr vs. \#Mg (Figura 12).

Es notable que estas hawaiitas son contemporáneas con expansión del piso oceánico y expulsión de MORB en el vecino Golfo de California y que la Mesa Cacaxta carezca de fallamiento o inclinación que indiquen deformación. Esto contrasta con la deformación transtensional del Plioceno documentada por Umhoefer et al. (2002) en el otro lado del Golfo, en una región en donde hasta ahora no se han encontrado rocas similares con xenolitos.

\subsubsection{Isla Isabel}

Es una isla pequeña (1.5 km de largo) ubicada a 30 $\mathrm{km}$ de la costa de Nayarit (Figura 1). Está formada por una serie de volcanes coalescentes que fueron formados sobre la plataforma continental (Aranda-Gómez et al., 1999). Isabel está en el lado este de la boca del Golfo de California. Al sureste de la isla, dentro del continente, existe el rift de Tepic-Zacoalco (Allan, 1986), un rasgo estructural mayor en la parte occidental de la FVTM. La mayor parte de las rocas expuestas en Isabel son depósitos de tefra acumulados de nubes rasantes asociadas a la formación de conos de toba. También hay derrames de lava expuestos en los acantilados marinos y en la parte noroeste de la isla, así como algunos depósitos de escoria productos de actividad estromboliana. La composición química de las rocas analizadas por Cabral-Cano (1988)
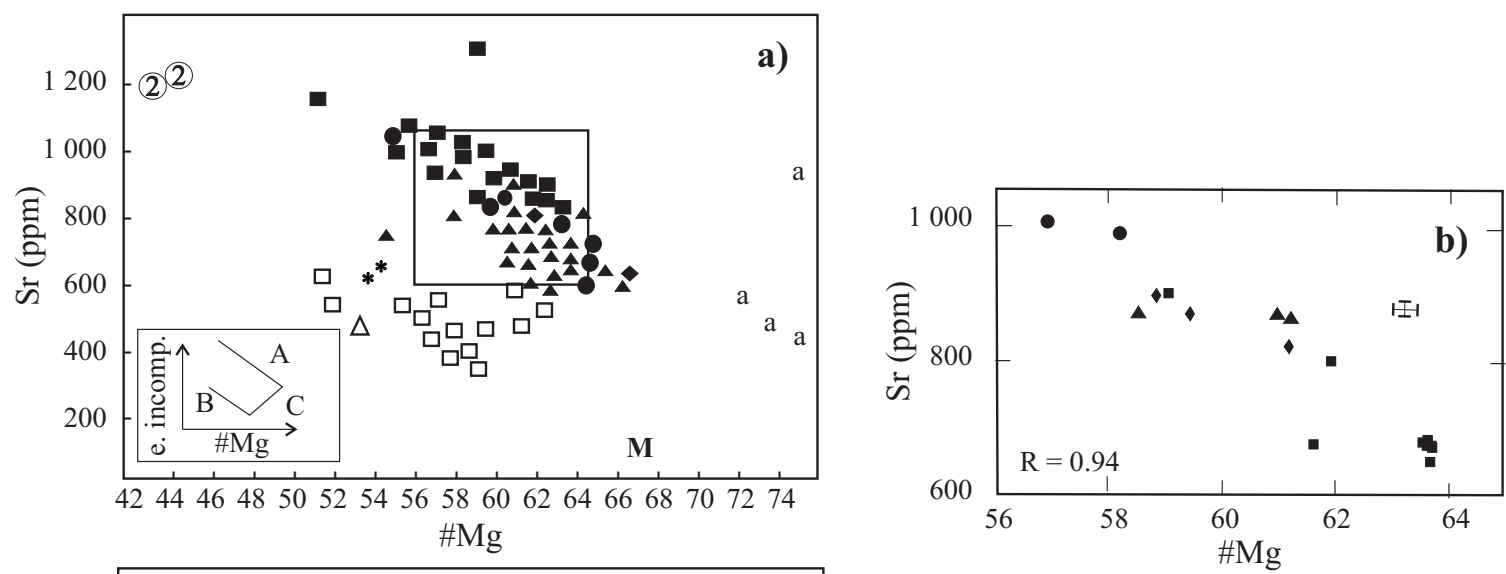

\begin{tabular}{|ll|}
\hline Campo Volcánico de Durango & Otras localidades \\
\cline { 2 - 2 } - Hawaiita $[\mathrm{Ne}]>5 \%$ & $\Delta$ Basalto (SCORBA) \\
• Hawaiita $[\mathrm{Ne}]<5 \%$ & $*$ Mesa Cacaxta \\
$\square$ Hawaiita con $[\mathrm{Hy}]$ & (2) Metates \\
- Basanita $[\mathrm{Ne}]>5 \%$ & a Basalto FVTM \\
- Basalto alcalino $[\mathrm{Ne}]<5 \%$ & $\mathrm{M}$ MORB \\
\hline
\end{tabular}

\begin{tabular}{|cccc|}
\hline $\begin{array}{l}\text { Lavas } \\
\text { pre-maar }\end{array}$ & $\begin{array}{c}\text { Escoria sin- } \\
\text { maares }\end{array}$ & $\begin{array}{c}\text { Escoria post- Lavas post- } \\
\text { maares }\end{array}$ & maares \\
& $\bullet$ & $\bullet$ & \\
\hline
\end{tabular}

Figura 12. a) Diagramas de variación de Sr vs. \#Mg en el conjunto de muestras estudiadas por Smith (1989) en el campo volcánico de Durango, Mesa Cacaxta y Metates. En el recuadro en el ángulo inferior izquierdo de a) se muestra un diagrama esquemático con las tendencias lineales A, B y C identificadas por Smith. Otros símbolos: a=basaltos de arco provenientes de la FVTM (tomados de Luhr et al., 1989a, muestras MAS-21, JOR-44, 417A y 426B). M=MORB (Wood, 1979). b) El subconjunto de rocas provenientes del complejo volcánico La Breña-El Jagüey sigue la tendencia A y tiene un coeficiente de correlación alto. Nótese que el \#Mg aumentó conforme sucedió la erupción. Tomado de Pier et al. (1992). El recuadro en la parte central de a) corresponde al rango de composiciones representado en b). 
corresponde a basaltos (sensu lato) alcalinos con 5-14\% peso de $[\mathrm{Ne}]$ similares en composición a las rocas en muchas localidades de tipo intraplaca de la porción mexicana de Cuencas y Sierras. En la isla se encuentran xenolitos de peridotitas del manto (lherzolitas de $\mathrm{Spl}$ y/o de $\mathrm{Pl}$ ), algunos megacristales de feldespato y xenolitos feldespáticos raros (Ortega-Gutiérrez y González-González, 1980). No se tiene noticia de edades isotópicas de las rocas de Isabel, pero el aspecto juvenil de los derrames de lava hace suponer que la isla es cuaternaria.

\subsubsection{Campo volcánico de Palomas}

Está ubicado en la frontera con Estados Unidos, a unos $70 \mathrm{~km}$ al oeste de Ciudad Juárez (Figura 1). Cubre un área de aproximadamente $150 \mathrm{~km}^{2}$. En él se han identificado más de 30 conos cineríticos, comúnmente con forma de herradura, debido a la presencia de derrames de lava que destruyeron parcialmente al edificio. En el campo también se observan diques lineales de basalto de orientación N-S y otros de forma curva. Algunos de los volcanes se encuentran en la intersección de diques. Palomas está ubicado en el flanco occidental del rift del Rio Grande y muestra algunas diferencias con los campos volcánicos en su interior (Frantes y Hoffer, 1982): (1) Palomas parece ser más antiguo, (2) en Palomas hay afloramientos de andesitas y traquitas que se consideran como diferenciados asociados a los basaltos de $[\mathrm{Ol}]$ y (3) están presentes lavas almohadilladas y diques. Las relaciones de campo indican que las andesitas y traquitas son más antiguas que los basaltos. En algunas localidades se han reportado xenolitos del manto. No existen edades isotópicas reportadas. Con base en comparaciones con otros campos volcánicos de Nuevo México, Frantes y Hoffer (1982) concluyen que la edad del campo volcánico es "al menos del Plioceno".

\subsubsection{Campo volcánico de Potrillo}

El maar de Potrillo se encuentra ubicado justo en la frontera México-E. U. A., a $\sim 40 \mathrm{~km}$ al oeste de Ciudad Juárez (Figura 1). Este volcán yace en el extremo meridional del campo volcánico de Potrillo, que cubre $\sim 4600 \mathrm{~km}^{2}$ en el condado de Doña Ana (Nuevo México), en la parte meridional del rift del Río Grande. Durante el Cuaternario medio y tardío ( 1Ma-8 ka: Williams, 2002), basalto alcalino con $[\mathrm{Ol}]$ fue extravasado a través de numerosos conos cineríticos, maares y al menos un volcán escudo en una región en donde existen al menos tres fallas normales mayores: Fitzgerald, Robledo y Aden. Hay evidencias de fallamiento activo (Pleistoceno tardío-Holoceno) en las dos primeras (Hoffer, 1976). Los depósitos piroclásticos asociados a la formación del maar de Potrillo fueron cortados por la falla Robledo (Williams, 2002). En el campo volcánico de Potrillo hay al menos dos localidades importantes con xenolitos: Kilbourne Hole y el maar de Potrillo, en donde se han encontrado peridotitas del manto, granulitas feldepáticas de la corteza y megacristales de Krs (Aranda-Gómez y Ortega-Gutiérrez, 1987). Las relaciones de isótopos de Pb,
Sr y Nd en los cristales de Anf son semejantes a aquéllas en los OIB, lo que sugiere que son derivados de la astenósfera $\mathrm{y}$ las fuentes tienen afinidad con MORB enriquecido u OIB (Ben-Othman et al., 1990). Muestras colectadas en la porción norte del anillo de tefra del maar de Potrillo y en una lava asociada a un cono dan edades K-Ar de $1.23 \pm 0.06$ y $1.18 \pm 0.03 \mathrm{Ma}$ (Hawley, 1981).

\subsubsection{Campo volcánico de Camargo}

Está ubicado en la porción sureste de Chihuahua, cerca de límite con Coahuila (Figuras 1 y 13). Es el campo volcánico formado por rocas de tipo intraplaca más extenso $\left(\sim 3000 \mathrm{~km}^{2}\right)$ y voluminoso $\left(\sim 120 \mathrm{~km}^{3}\right)$ hasta ahora reportado en el centro y norte de México. En él se han identificado más de 300 volcanes, principalmente conos cineríticos y lavas asociadas y algunos maares. La edad isotópica $\left({ }^{40} \mathrm{Ar}-{ }^{39} \mathrm{Ar}\right)$ de sus rocas $(\mathrm{n}=23)$ varía entre 4.7 y $0.09 \mathrm{Ma}$ y se ha documentado un desplazamiento sistemático de la actividad volcánica de SW a NE a una tasa estimada de $15 \mathrm{~mm} / \mathrm{a}$. A diferencia de muchas otras localidades de volcanismo de tipo intraplaca en México, en Camargo la relación entre volcanismo y extensión es evidente, ya que es cortado por un graben complejo (Figura 13). Información parcial acerca de las edades de las fallas indica que es posible que también haya existido migración de la deformación, contemporánea con la actividad volcánica (Aranda-Gómez et al., 2002b). Camargo se encuentra sobre la traza sepultada de la falla de San Marcos (Figura 13), que es un rasgo tectónico mayor formado en el Jurásico (McKee et al., 1984; McKee et al., 1990) y que ha sido reactivado en cada uno de los pulsos de deformación posteriores, incluyendo la extensión del Cenozoico medio y tardío (Aranda-Gómez et al., 2005).

Hasta ahora no se ha publicado ningún estudio sistemático acerca de la petrología de las rocas máficas del campo. Sólo se conocen algunos datos geoquímicos (Nimz, 1989) acerca de los volcanes cercanos a La Olivina, una localidad importante con xenolitos del manto y granulitas de la corteza (Nimz et al., 1986; Rudnick y Cameron, 1991; Cameron et al., 1992; Nimz et al., 1993; Nimz et al., 1995). Con base en seis muestras de roca volcánica colectadas en las cercanías de La Olivina, Nimz (1989) indica que: (1) las rocas son basanitas con un contenido de $[\mathrm{Ne}]$ entre 9.4 y 15.6 y \#Mg entre 56 y 66; (2) los cambios en los valores de \#Mg y otros parámetros químicos se atribuyen a fraccionamiento de $\mathrm{Cpx}$ y Ol; (3) con base en los patrones en diagramas de REE normalizados respecto a las condritas y en diagramas de multielementos, se asienta que las concentraciones de elementos traza son muy similares a aquéllas encontradas en otras localidades con xenolitos del manto en la provincia de Cuencas y Sierras de los Estados Unidos, sin embargo los magmas de Camargo requieren de una proporción mayor de Grt/piroxeno en su fuente en comparación con otras localidades; (4) las concentraciones y proporciones de elementos traza en las rocas de $\mathrm{La}$ Olivina son similares a las de rocas alcalinas del Cenozoico 


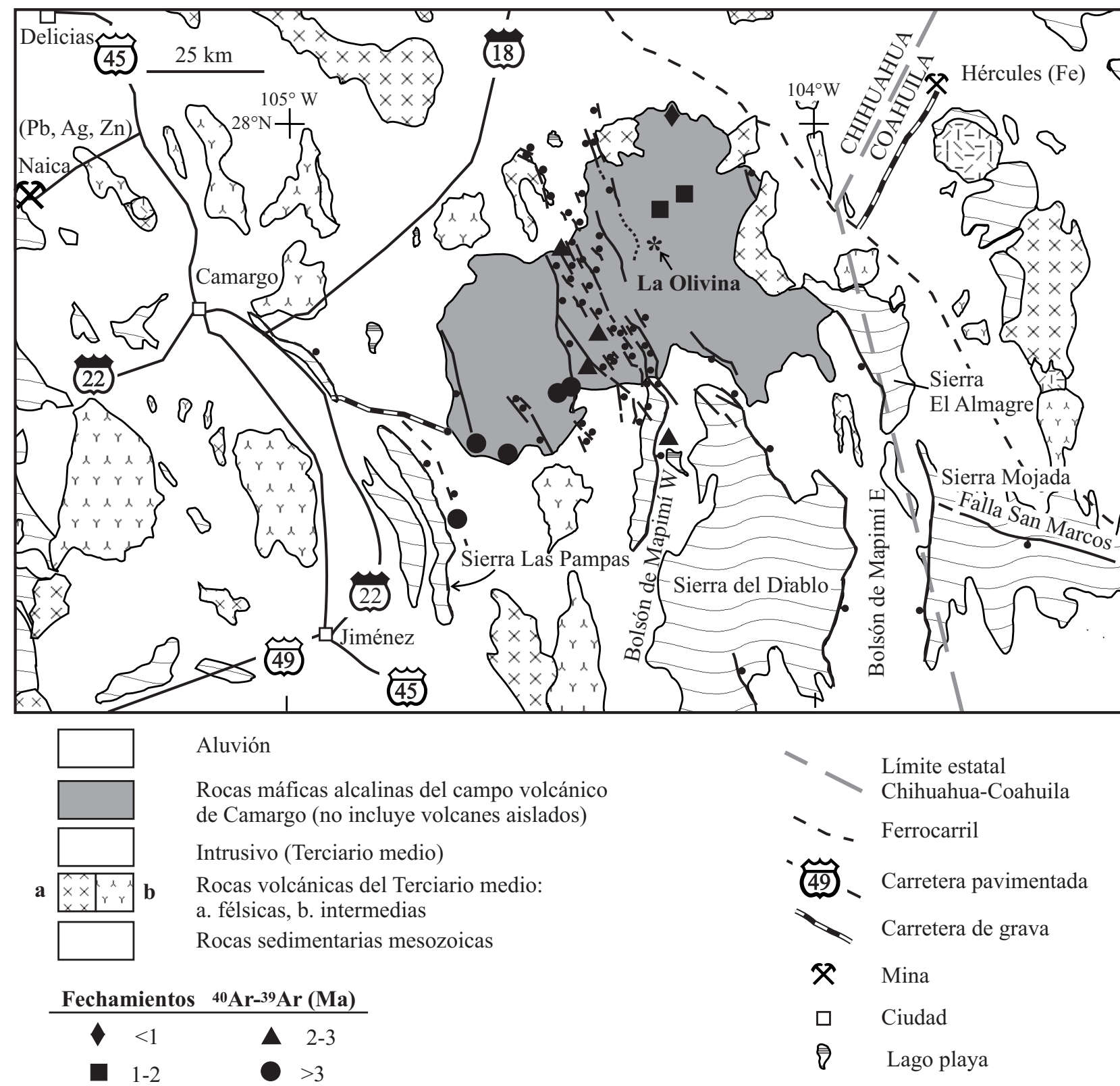

Figura 13. Mapa geológico simplificado de la región del campo volcánico de Camargo (modificado de Aranda-Gómez et al., 2002b). Nótese la presencia de la falla de San Marcos (véase Figura 15) en la esquina SE del mapa, el cambio sistemático en la edad del volcanismo de tipo intraplaca y la presencia del graben central a través del campo volcánico. Se cree que la falla de San Marcos continúa hacia el NW, pasando abajo del campo volcánico de Camargo, sólo que la traza está sepultada debajo de rocas volcánicas cenozoicas (Aranda-Gómez et al., 2005).

temprano y medio del oeste de Texas, lo que se interpreta tentativamente como que puede haber una fuente común, que ha sido estable químicamente durante el Cenozoico, y que produjo los magmas en estos eventos volcánicos; (5) las composiciones isotópicas de las basanitas de $\mathrm{La}$ Olivina (Figuras $6 \mathrm{~d}$ y $7 \mathrm{c}$ ) son $\varepsilon_{\mathrm{Nd}} \sim+3.4 \mathrm{a}+5.2,{ }^{87} \mathrm{Sr} /{ }^{86} \mathrm{Sr}$ $\sim 0.7030$ a $0.7033,{ }^{206} \mathrm{~Pb} / 2{ }^{204} \mathrm{~Pb} \sim 19.3$ a $19.6,{ }^{207} \mathrm{~Pb} /{ }^{204} \mathrm{~Pb}$ $\sim 15.58$ a 15.63 , siendo los valores de $\mathrm{Pb}$ distintos a los de otras localidades con xenolitos en la porción septentrional de Cuencas y Sierras, tanto en el suroeste de los Estados Unidos como en México (Figura 7c). De acuerdo con Nimz (1989) esta diferencia puede deberse a contaminación con material cortical o a la presencia de un límite tectónico importante al norte de Camargo o a que el manto es considerablemente heterogéneo bajo Norteamérica. Nimz opina que la contaminación cortical es poco probable con base en la presencia de xenolitos del manto. Por otro lado, las semejanzas entre los conjuntos de xenolitos corticales de La Olivina y aquellos en Kilbourne Hole (e. g., Padovani y Carter, 1977) y en el contenido y proporción de elementos traza en otras localidades del suroeste de los Estados Unidos, llevan a Nimz (1989) a concluir que no existe un límite cortical importante al norte de La Olivina. Por tanto, 
las variaciones isotópicas posiblemente son debidas a heterogeneidad isotópica en el manto que subyace a América del Norte. Las basanitas de La Olivina requieren $\mathrm{de}$ una fuente con valores isotópicos de $\mathrm{Pb}$ semejantes al HIMU (manto con una alta relación U/Pb) de Zindler y Hart (1986).

\subsubsection{Campo volcánico de Durango}

Está ubicado en el extremo noroccidental de la Mesa Central, al este la Sierra Madre Occidental (Figura 1). Es una meseta de lava extensa que cubre un área de aproximadamente $2100 \mathrm{~km}^{2}$ (Figura 8) y tiene un volumen estimado de magma de $20 \mathrm{~km}^{3}$. En el área hay aproximadamente 100 conos cineríticos y conos de lava. La edad isotópica (K-Ar, roca total) de dos muestras colectadas en campo volcánico de Durango es $<0.8 \mathrm{Ma}$ (Smith, 1989). Una muestra del complejo de La Breña- El Jagüey (Figura 8) fechada por nosotros por ${ }^{40} \mathrm{Ar}-{ }^{39} \mathrm{Ar}$ dio una edad cero, lo que se cree que refleja que este es un volcán muy joven. Sin embargo, con base en el estudio de la degradación de conos cineríticos, es evidente que en el campo volcánico de Durango existen volcanes considerablemente más viejos, posiblemente del Cuaternario temprano o aun del Plioceno. La región ha experimentado varios períodos de fallamiento normal durante el Cenozoico medio y tardío. El episodio más reciente afectó al campo volcánico, como lo indican fallas normales con rumbo NW que afectan a las lavas. Alineamientos de conos cineríticos sugieren que los magmas alcanzaron la superficie a través de grietas tensionales de rumbo NW, similar al de las fallas normales cuaternarias y a fallas regionales más antiguas (Figura 13).

Smith (1989) realizó un muestreo extenso $(n=93)$ de los productos volcánicos en el campo y obtuvo que la mayoría (82\%) de las muestras contienen $[\mathrm{Ne}]$ (hawaiitas de $[\mathrm{Ne}]$, basaltos alcalinos, y basanitas) y el resto (18\%) tienen $[H y]$ (hawaiitas de $[H y]$ y basaltos). En el campo no existe un patrón geográfico o estratigráfico definido de distribución de las dos series y las rocas con $[\mathrm{Hy}]$ a veces contienen xenolitos. En un tercio de los sitios de muestreo se encontraron xenolitos del manto y/o de la base de la corteza. El \#Mg de las rocas varía de 51 a 67. En los diagramas de variación de \#Mg vs. elementos incompatibles se observa una dispersión considerable (Figura 12), pero se perciben al menos tres tendencias lineales distintas (A, $\mathrm{B}, \mathrm{C}$ ). Las tendencias A y B son subparalelas y tienen una correlación inversa con el \#Mg. A corresponde a rocas con $[\mathrm{Ne}]$ : hawaiitas de $[\mathrm{Ne}]$, hawaiitas, basanitas y basaltos alcalinos. B tiene un contenido menor de elementos incompatibles y son rocas con $[H y]$ (hawaiitas y basaltos). $\mathrm{C}$ es una tendencia débil, incluye sólo a hawaiitas de $[\mathrm{Hy}]$ y tiene una pendiente positiva (Figura 12a) que es difícil de explicar con modelos de cristalización fraccionada o fusión parcial. Las variaciones en composición en las rocas con $[\mathrm{Ne}]$ pueden modelarse por cristalización fraccionada de dos paragénesis distintas, una de presión alta $(\mathrm{Grt}+\mathrm{Aug}$ rica en $\mathrm{Al}+\mathrm{Krs}+\mathrm{Ol})$ otra de presión baja $(\mathrm{Pl}+\mathrm{TMt}+\mathrm{Cpx}+\mathrm{Ol})$. Smith (1989) prefiere el modelo de presión alta con base en la presencia de los xenolitos de peridotita que indica que el magma ascendió rápidamente a la superficie. Las rocas con $[\mathrm{Hy}]$ poseen muchas características geoquímicas asociadas a basaltos de subducción. Smith (1989) propone la existencia de un componente, producto de subducción, que es fundido ocasionalmente para generar estas rocas. La variabilidad química de las rocas con $[H y]$ no puede ser explicada por cristalización fraccionada.

En contraste con los resultados obtenidos a nivel regional por Smith (1989), un estudio detallado de 16 muestras colectadas en el complejo de maares de La Breña-El Jagüey (Aranda-Gómez et al., 1992; Pier et al., 1992) muestra variaciones coherentes de la composición química que sugieren que las rocas en este complejo de maares son cogenéticas. La tendencia lineal observada en la Figura $12 \mathrm{~b}$ es consistente con la tendencia A (Figura 12a) identificada por Smith (1989). El complejo está formado por dos maares, dos conos cineríticos y derrames de lava sepultados por la secuencia hidrovolcánica y al menos tres conos de salpicadura mayores que se formaron en el interior del cráter de La Breña (Aranda-Gómez et al., 1992). Las rocas son hawaiitas o basanitas con un contenido de $\mathrm{SiO}_{2}$ que varía entre 45.8 y $48.1 \%$ peso y de $[\mathrm{Ne}]$ entre 4.9 y 9.7 (Figura $3 \mathrm{~d})$. La paragénesis primaria es $\mathrm{Ol}+\mathrm{Pl}+\mathrm{Cpx}+\mathrm{TMt}+\mathrm{Ilm}$. Xenocristales derivados de las peridotitas del manto y de las granulitas feldespáticas son comunes. Un rasgo notable de algunas de las muestras postmaar es la presencia de minerales tardíos, de grano relativamente grueso, que se formaron a partir de líquidos residuales ricos en Fe y Ti y que rellenaron vesículas hasta de $1 \mathrm{~cm}$ de diámetro. Las fases identificadas en estas vesículas son cristales de TAug y cristales aciculares de Ilm.

El \#Mg de los productos volcánicos de la Breña y El Jagüey aumentó de manera sistemática durante la evolución del complejo de maares (Figura 12b). Las muestras pre-maar tienen \#Mg de 57.0 a 58.2, las escorias asociadas a las erupciones freatomagmáticas entre 58.6 y 61.2 y las escorias y lavas postmaar de 59.9 a 63.6. La mayoría de los elementos analizados exhiben cambios sistemáticos respecto al \#Mg. Elementos relativamente incompatibles muestran variaciones lineales con correlaciones negativas respecto al \#Mg, lo que es interpretado como evidencia de cristalización fraccionada a partir de un magma primario que sería similar a los productos volcánicos postmaar, pero con valores de $\# \mathrm{Mg} \geq 65$. Sin embargo, para un rango restringido de valores de $\# \mathrm{Mg}$ (e.g., \#Mg entre 61 y 62 en la Figura 12b), la mayoría de los elementos incompatibles tienen variaciones mayores que la incertidumbre analítica, por lo que se cree que hubo algo de variabilidad en la composición de los magmas primarios, que refleja grados de fusión parcial ligeramente distintos. Los diagramas de Tierras Raras normalizados respecto a las condritas, tienen tendencias subparalelas con un aumento del contenido total de REE con la disminución del \#Mg. La información isotó- 
pica también es consistente con cristalización fraccionada. Los rangos de variación son pequeños: ${ }^{87} \mathrm{Sr} /{ }^{86} \mathrm{Sr}=0.70327$ $0.70347, \varepsilon_{\mathrm{Nd}}=+4.2-+5.0$ (Figura $6 \mathrm{~d}$ ), ${ }^{206} \mathrm{~Pb} /{ }^{204} \mathrm{~Pb}=18.60$ 18.61 (Figura $7 \mathrm{c}$ ), ${ }^{207} \mathrm{~Pb} /{ }^{204} \mathrm{~Pb}=15.58-15.65$ (Figura 7c) y ${ }^{208} \mathrm{~Pb} /{ }^{204} \mathrm{~Pb}=38.19-38.58$. Aunque la evidencia petrográfica de contaminación con materiales del manto y de la corteza es notable, aparentemente ésta no causa variaciones elementales o isotópicas considerables.

\subsubsection{San Luis Potosí}

Las porciones central y occidental de San Luis Potosí forman parte de un altiplano semiárido conocido como la Mesa Central. La mayoría de las sierras en la parte oriental del altiplano están formadas por rocas sedimentarias marinas del Cretácico, las cuales fueron plegadas durante la orogenia Laramide. Hacia su extremo meridional, la Mesa Central está cubierta por rocas volcánicas félsicas del Terciario medio, asociadas al magmatismo de la Sierra Madre Occidental (Figura 14). La fisiografía de la Mesa
Central es controlada por un conjunto complejo de fallas normales del Cenozoico medio a tardío (Figura 10c) que afectan tanto a rocas sedimentarias mesozoicas como a la cubierta volcánica (e. g., Labarthe-H. et al., 1982; ArandaGómez et al., 1989; Nieto-Samaniego et al., 1997). En muchos sitios aislados de San Luis Potosí hay volcanes monogenéticos del Terciario tardío-Cuaternario. En función de la presencia o ausencia de xenolitos del manto, estos volcanes pueden dividirse en dos grupos. En términos generales, los volcanes del Plioceno-Cuaternario ubicados al occidente del meridiano $100^{\circ} \mathrm{W}$ contienen xenolitos del manto y/o de la base de la corteza (Figura 14). Aquellos situados al oriente generalmente carecen de inclusiones y nos referimos a ellos como los volcanes del Este de San Luis Potosí. Con base en la composición química de sus lavas y piroclastos, los conjuntos de inclusiones accidentales y la ubicación geográfica, los volcanes con xenolitos se agrupan en los campos volcánicos de Ventura-Espíritu Santo y Santo Domingo (Figuras 10a y 14).

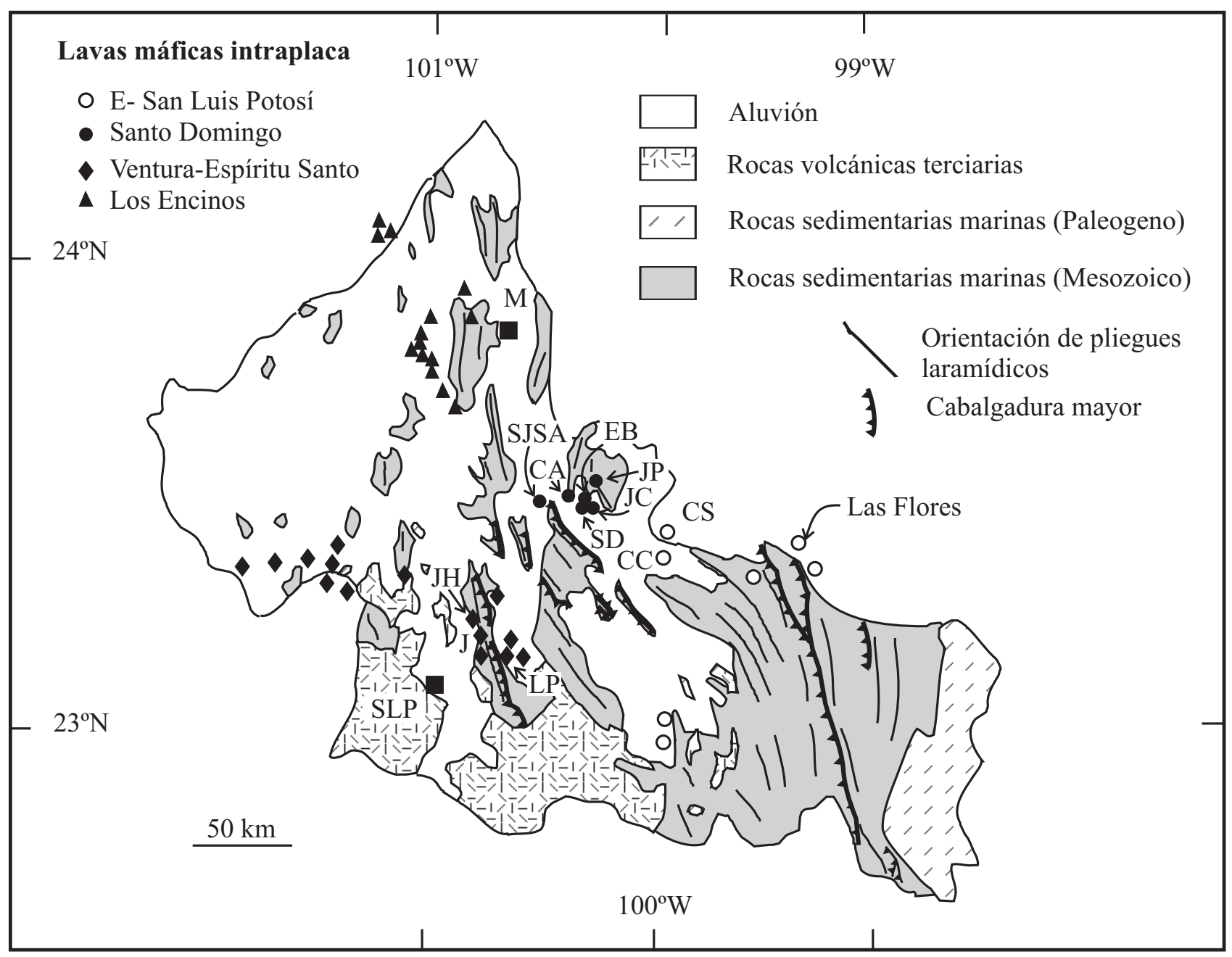

Figura 14. Mapa geológico generalizado del estado de San Luis Potosí. En él se muestran la localización de campos volcánicos de tipo intraplaca. Las localidades al este del meridiano $100^{\circ} \mathrm{W}$ (círculos en blanco) generalmente carecen de inclusiones (xenolitos y/o megacristales). Clave de localidades: $\mathrm{M}=$ Matehuala, SJSA=San Juan $\sin$ Agua, $\mathrm{CA}=$ Cerro El Apaste, $\mathrm{SD}=$ Santo Domingo, JC=Joya Los Contreras, EB=El Banco, JP=Joya Prieta, CS=Cerro Sarnoso, $\mathrm{CC}=$ Cerro Colorado, JH=Joya Honda, J=Joyuela, LP=Laguna de los Palau y SLP=San Luis Potosí. 
Ventura-Espíritu Santo. Este campo volcánico está formado principalmente por conos cineríticos aislados y derrames de lava asociados, los cuales descansan sobre caliza del Mesozoico, sobre rocas volcánicas félsicas del Terciario medio, o sobre depósitos clásticos del Terciario tardío o Cuaternario. Las localidades mejor estudiadas de este campo son tres maares (Joya Honda, Joyuela y Laguna de los Palau) ubicados en la porción oriental del mismo (e. g., Labarthe-Hernández, 1978; Aranda-Gómez, 1982; Luhr et al., 1989b; Pier et al., 1989; Heinrich y Besch, 1992; Schaaf et al., 1994; Aranda-Gómez y Luhr, 1996), los cuales son importantes por la abundancia y variedad de sus xenolitos. Las edades radiométricas de los maares de Joya Honda y Joyuela, determinadas en concentrados de la matriz por el método de K-Ar son, respectivamente, 1.1 y 1.4 Ma (Aranda-Gómez y Luhr, 1996).

En comparación con otras rocas continentales de tipo intraplaca en San Luis Potosí, las de Ventura-Espíritu Santo (Figura 3c) tienen un contenido más elevado de [Ne] (hasta $28 \%$ ) y algunas de ellas contienen [ $L c t]$. Con la excepción del Bernal de Horcasitas, las rocas de tipo intraplaca de este campo son las más subsaturadas en sílice que han sido encontradas hasta ahora en la porción meridional de Cuencas y Sierras.

Santo Domingo. Estos volcanes se encuentran al noreste de Ventura-Espíritu Santo y están separados por una zona de aproximadamente $50 \mathrm{~km}$ de ancho en donde aparentemente no hay centros eruptivos cuaternarios (Figuras 10a y 14). Los volcanes son considerablemente más escasos en Santo Domingo y las localidades mejor documentadas son cuatro maares: Santo Domingo, El Banco, Joya de los Contreras y Joya Prieta (Labarthe-Hernández, 1978; Aranda-Gómez et al., 1993). Además existen en el área varios derrames de lava aislados, un cono cinerítico bien preservado (Cerro El Apaste) y tres campos de lava (¿escudos de lava?) más o menos extensos (San Juan sin Agua, Cerro Colorado y Cerro Sarnoso; Figura 14). En la región en donde se ubican los volcanes de Santo Domingo hay un cambio muy marcado en el rumbo de los ejes de las estructuras laramídicas. Al sur de Santo Domingo los ejes de los pliegues tienen un rumbo NW. Unos kilómetros al norte de Santo Domingo las estructuras tienen un rumbo N o NE (Figura 10a). Por tanto, se cree que en esa zona hay una discontinuidad estructural (¿una falla de basamento?) importante que fue capaz de influenciar en el estilo de la deformación laramídica durante el Terciario temprano. Esa misma discontinuidad se proyecta al sur de la sierra de Catorce hacia la parte central de Los Encinos (Figuras 10a y 10b) y en ella se encuentran centros volcánicos de edades diversas (Eoceno, Oligoceno, Mioceno y Cuaternario) lo que sugiere que también influyó repetidamente en la localización del volcanismo (ArandaGómez y Luhr, 1993). La mayor parte de los xenolitos del manto en los volcanes de Santo Domingo tienen fábricas miloníticas (Luhr y Aranda-Gómez, 1997), lo que argumenta a favor de deformación dúctil en el manto superior potencialmente contemporánea al volcanismo Cuaternario en Santo Domingo. Las edades radiométricas (K-Ar, matriz) de ejemplares colectados en el Cerro El Apaste y la Joya de los Contreras son 0.35 y 0.45 Ma respectivamente (Aranda-Gómez y Luhr, 1996). La diferencia más obvia en el campo entre los volcanes de Ventura-Espíritu Santo y Santo Domingo es que en los segundos son muy comunes los megacristales de Krs y los xenolitos de hornblendita y de piroxenitas con $\mathrm{Hbl}$, mientras que en los primeros estos tipos de inclusiones no están presentes.

Petrología de las rocas de Ventura-Espíritu Santo y $\underline{\text { Santo Domingo. Estas rocas forman una serie petrológica }}$ bien definida, que va desde las basanitas y nefelinitas de $[O l]$ muy subsaturadas en $\mathrm{SiO}_{2}$ de Ventura-Espíritu Santo hasta basaltos alcalinos y hawaiitas que dominan en Santo Domingo (Figuras 3c y 3d). La mineralogía primaria de todas las rocas es $\mathrm{Ol}+\mathrm{TAug}+\mathrm{OFT} \pm \mathrm{Pl}$. La Pl es ubicua en las paragénesis primarias de Santo Domingo, mientras que en Ventura-Espíritu Santo sólo se presenta en algunas rocas (Aranda-Gómez et al., 1993). En general, la abundancia de Pl modal disminuye conforme aumenta el contenido de $[\mathrm{Ne}]+[L c t]$. Además de los minerales primarios, en las rocas hay una cantidad variable de xenocristales derivados de la desagregación de los xenolitos de peridotitas de Spl $(\mathrm{Ol}+\mathrm{Opx}+\mathrm{Cpx}+\mathrm{Spl})$ y en menor grado de granulitas feldespáticas $(\mathrm{Q}+\mathrm{Pl})$. En Ventura-Espíritu Santo a veces se encuentran megacristales de piroxeno (Aranda-Gómez, 1982).

El contenido de $\mathrm{SiO}_{2}$ decrece en la secuencia hawaiita (51.2\% peso), basalto alcalino, basanita, nefelinita de $[\mathrm{Ol}]$ ( $41.8 \%$ peso). En el mismo orden aumentan los contenidos de $[N e]$ y $[D i]$, conforme disminuye la $[A b]$ y $[A n]$. Muchos elementos tienen un comportamiento incompatible y aumentan progresivamente en la serie junto con la $[\mathrm{Ne}]$ : Ti, $\mathrm{K}, \mathrm{Na}, \mathrm{P}, \mathrm{Rb}, \mathrm{Sr}, \mathrm{Zr}, \mathrm{Nb}, \mathrm{Ba}, \mathrm{La}, \mathrm{Ce}, \mathrm{Nd}, \mathrm{Sm}, \mathrm{Eu}, \mathrm{Hf}, \mathrm{Ta}$, Th y U. Todos los datos isotópicos de $\mathrm{Sr}$ y Nd grafican en o cerca del "arreglo del manto" y su distribución es bimodal (Figuras 6c y 6d), aunque ésta no se correlaciona con la proveniencia de las muestras, ya sea de Ventura-Espíritu Santo o Santo Domingo (Figura 6d). La distribución bimodal en los isótopos de $\mathrm{Sr}$ y Nd se da en el contenido de ambos isótopos y contrasta con las variaciones continuas observadas en los diagramas de variación de elementos. Una vez que se estudia por separado cada uno de los agrupamientos de datos isotópicos de $\mathrm{Sr}$ y $\mathrm{Nd}$, para un valor dado de $\mathrm{Nd}$, los datos de $\mathrm{Sr}$ de Santo Domingo son más radiogénicos que los de Ventura-Espíritu Santo. En contraste, los valores de isótopos de $\mathrm{Pb}$ no muestran una distribución bimodal (Figura 7c).

Muchas de las variaciones químicas elementales observadas pueden explicarse por fusión parcial progresiva de un manto formado por peridotita con Grt. En este esquema, las rocas de Santo Domingo representarían un porcentaje mayor de fusión parcial que las de Ventura-Espíritu Santo. De manera alternativa, las variaciones también pueden explicarse por la mezcla de magmas provenientes de dos fuentes en el manto (Luhr et al., 1989b). La variabilidad en las 
relaciones isotópicas de $\mathrm{Sr}$ y $\mathrm{Nd}$ no puede explicarse con un modelo simple a partir de un sólo componente en el manto ni únicamente por contaminación con rocas corticales. Pier et al. (1989) concluyeron que los datos isotópicos requieren de al menos tres fuentes en el manto: 1) una componente empobrecida, similar a la fuente de los MORB, 2) una tipo St. Helena y 3) una componente hidratada, derivada de una placa subducida. Aquí se considera que los datos de $\mathrm{Sr}-\mathrm{Nd}$ de Pier et al. (1989) también pueden ser consistentes con la existencia de dos suites de magmas (véase Figura 1a en Pier et al., 1989), siendo la composición del Grupo 1 consistente con un origen en la astenósfera y la del Grupo 2 en la litósfera. Existen además evidencias suficientes para considerar que la contaminación con material cortical jugó un papel en la génesis de los magmas de Ventura-Espíritu Santo y Santo Domingo y es posible describir al Grupo 2 como derivado de magmas semejantes a los del Grupo 1 a través de este mecanismo. Sin embargo, la separación tan marcada entre los grupos sugiere que no puede desecharse la posibilidad de que las muestras reflejen la existencia de al menos dos fuentes en el manto y que algunos de los magmas derivados de cada una ellas hayan experimentado contaminación cortical.

Este de San Luis Potosí. Diseminados en la parte oriental del estado de San Luis Potosí y meridional de Tamaulipas (Figura 14) existen afloramientos aislados de hawaiita y basalto alcalino (Figura 2d) picrítico, la mayoría de ellos sin xenolitos o megacristales. Una excepción notable es una localidad cerca de Cárdenas (S. L. P.) en donde hay algunas peridotitas del manto. Sin duda, el volcán más importante en este campo extenso $\left(\sim 15000 \mathrm{~km}^{2}\right)$ es el de Las Flores (Siebert et al., 2002), ubicado en la región en donde se unen San Luis Potosí, Tamaulipas y Nuevo León (Figura 14) y que cerca de la fuente forma un área de malpaís de $\sim 200 \mathrm{~km}^{2}$. Los productos de este volcán tienen apariencia juvenil (superficies cordadas bien preservadas, tubos de lava, colapsos y costillas de presión) a pesar del clima húmedo subtropical de la región, lo que hace suponer que es muy joven. Del volcán Las Flores parte un derrame de lava excepcionalmente largo, que puede seguirse de manera continua hacia el sur por cerca de $80 \mathrm{~km}$ a lo largo de un valle sinclinal de la Sierra Madre Oriental. El frente del derrame se encuentra cerca de Ciudad Valles (S. L. P.). No existe un estudio geoquímico-petrológico publicado acerca de estas hawaiitas, sólo se han incluido algunos análisis en gráficas en donde se comparan algunos rasgos químicos de rocas de tipo intraplaca en México (e. g., Figura 23 en Aranda-Gómez et al., 1997) de donde se desprende que son similares a éstas. También se ignora si tienen alguna relación con el "vulcanismo del Altiplano" descrito por Robin (1976) más al sur, en el estado de Hidalgo, en donde se han reportado basaltos alcalinos y basanitas. Nuestro grupo ha analizado la composición isotópica de algunas muestras provenientes de del E de San Luis Potosí encontrando, respecto a las rocas Santo Domingo y Ventura-Espíritu Santo, valores más elevados de ${ }^{87} \mathrm{Sr} /{ }^{86} \mathrm{Sr}$ (Figuras 6c y 6d) sin que haya una disminución de ${ }^{143} \mathrm{Nd} /{ }^{144} \mathrm{Nd}$, por lo que suponemos que existe una contaminación con carbonatos de la Sierra Madre Oriental, los cuales tienen valores más altos de ${ }^{87} \mathrm{Sr} /{ }^{86} \mathrm{Sr}$.

\subsubsection{Coahuila}

En Coahuila existen al menos tres campos volcánicos con rocas de tipo intraplaca (Figuras 1 y 15): Las Esperanzas (CVLE) cerca de Sabinas, Ocampo (CVO) en el centro del estado, y Las Coloradas (CVLC) situado en la parte noreste del bloque de Coahuila, cerca de la falla San Marcos. Los primeros dos fueron estudiados por ValdezMoreno (2001) mientras que del tercero sólo se conoce la geoquímica isotópica de dos muestras colectadas recientemente por nosotros.

Campo volcánico Las Esperanzas. El CVLE $\left({ }^{40} \mathrm{Ar}-{ }^{39} \mathrm{Ar}\right.$, matriz: 2.8 Ma; Valdez-Moreno, 2001) se puede dividir en dos zonas: occidental y oriental. La parte occidental se caracteriza por derrames de lava extensos, extravasados a través de fisuras localizadas en los bordes del anticlinal de la sierra de Santa Rosa (Figura 15). Estas lavas fluyeron hasta $60 \mathrm{~km}$ de distancia y rellenaron la paleotopografía existente. En la parte oriental del campo son comunes los derrames de lava que forman escudos con espesores hasta de 35 m (COREMI, 1994). Las rocas del CVLE tienen la paragénesis $\mathrm{Ol}+\mathrm{Cpx}+\mathrm{Pl}+\mathrm{OFT} \pm \mathrm{Ap}$. Algunas muestras incluyen xenocristales de $\mathrm{Ol}$ provenientes de la desagregación de lherzolita. Otros ejemplares contienen xenocristales de $\mathrm{Q}$ rodeados por coronas de piroxeno. Según la clasificación TAS de Le Maitre et al. (2002), la composición de las rocas del CVLE varía de basalto a hawaiita (Figura 2d). Todas las muestras analizadas, excepto dos, contienen [Ne] (Figura 3d). Los valores de \#Mg en el CVLE oscilan entre 60.5 y 66.5 (Figura 16). La mitad de las muestras tienen valores en el rango 63-73, propuesto por Green (1971) para reconocer magmas primitivos. En cambio los contenidos de Ni (118-263 ppm) y Cr (186-377 ppm) son relativamente bajos para magmas primarios, por lo que se cree que las rocas experimentaron segregación de $\mathrm{Ol}$ y Cpx antes de alcanzar la superficie. El estudio de diagramas de variación de \#Mg vs. elementos mayores y traza indica que las rocas de occidente y oriente son dos suites que evolucionaron independientemente (Figura 16). Las características geoquímicas observadas sugieren que parte de las variaciones observadas en las suites son debidas a que los magmas representan distintos grados de fusión parcial y/o heterogeneidad de la fuente en el manto.

Campo volcánico de Ocampo. El CVO $\left({ }^{40} \mathrm{Ar}-{ }^{39} \mathrm{Ar}\right.$, matriz, 3.4-1.8 Ma; Valdez-Moreno, 2001) es una región $\sim 600 \mathrm{~km}^{2}$ con áreas pequeñas aisladas cubiertas por lavas y piroclásticos máficos. El afloramiento más importante se encuentra cerca del poblado de Ocampo (Figura 15) y está formado por derrames de lava intracañón apilados, que en algunos lugares tiene hasta $80 \mathrm{~m}$ de espesor y provienen de al menos dos conos de escoria. En el CVO también hay un alineamiento $\sim \mathrm{N}-\mathrm{S}$ de cuatro conos y derrames de lava 


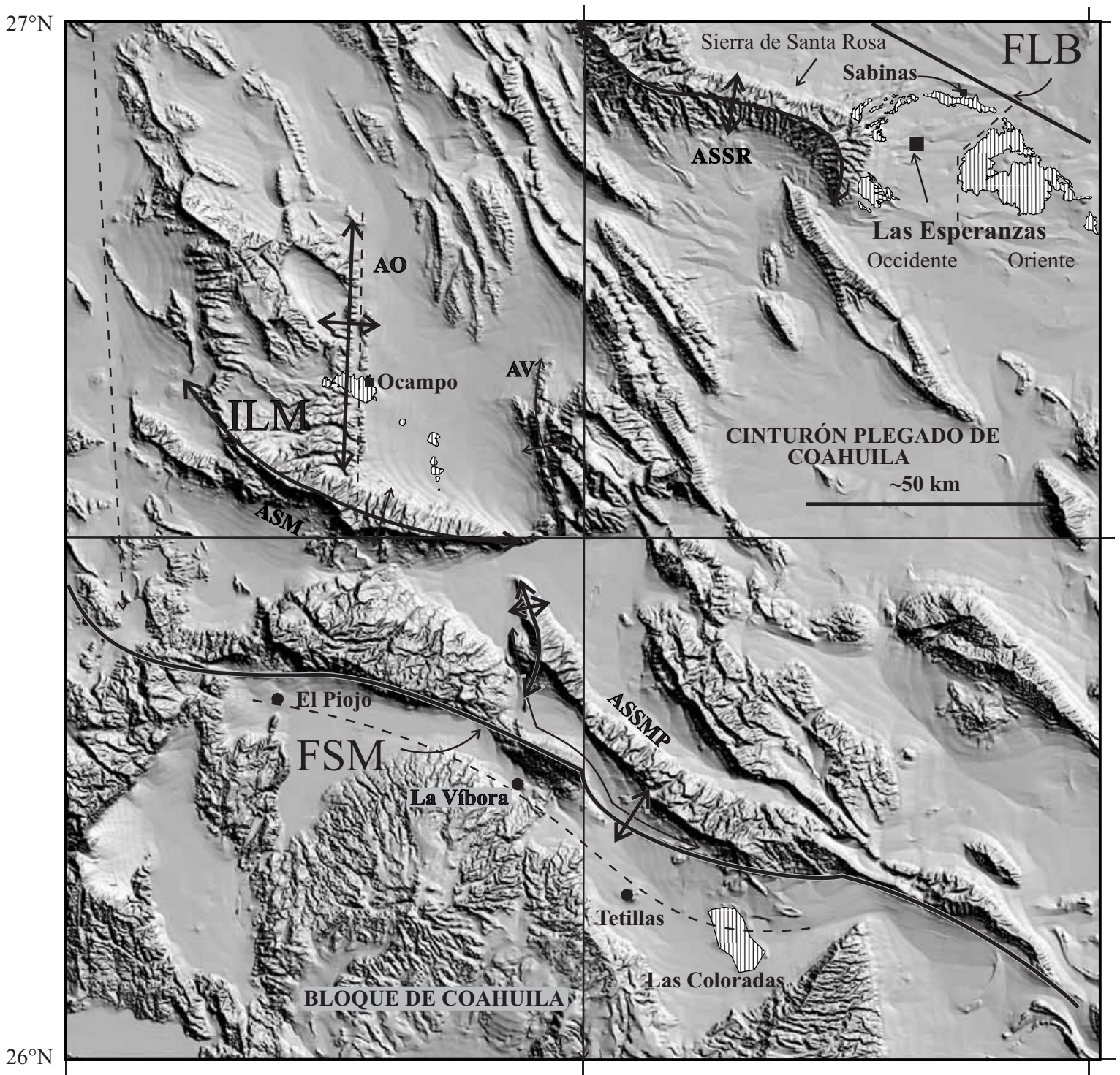

Figura 15. Modelo de elevación digital de la porción meridional del estado de Coahuila. En él se muestra la localización de los campos volcánicos de Las Esperanzas, Ocampo y Las Coloradas, así como los volcanes El Piojo, La Víbora y el intrusivo Tetillas. También se incluyen las fallas San Marcos (FSM) y La Babia (FLB) y otros rasgos estructurales mencionados en el texto. Nótese que en el Cinturón Plegado de Coahuila, ubicado entre la FSM y la FLB, la morfología es controlada por pliegues formados durante la orogenia Laramide (Terciario temprano) y contrasta con aquélla en el bloque de Coahuila al sur y en la Plataforma Burro-Peyotes (no se muestra en el modelo). En el Cinturón Plegado de Coahuila es común que los ejes de los pliegues formen arreglos ortogonales entre sí o cambien bruscamente de rumbo. Se cree que esto fue causado por fallas en el basamento pre-Cretácico, las cuales fueron reactivadas durante la deformación del Terciario temprano e influyeron en el plegamiento. ILM=Isla de la Mula, un rasgo paleogeográfico del Mesozoico, posiblemente limitado por fallas de basamento como se infiere de cambios del patrón de plegamiento laramídico. AO=Anticlinal de Ocampo, AV=Anticlinal La Virgen, ASM=Anticlinal Sierra La Madera, ASSR=Anticlinal Sierra de Santa Rosa, ASSMP $=$ Anticlinal de las sierras de San Marcos y Pinos.

asociados (Figura 15). Las muestras del CVO contienen $\mathrm{Pl}+\mathrm{Ol}+\mathrm{Cpx}+\mathrm{OFT}+\mathrm{Ap}$. Algunos ejemplares contienen xenocristales de Qtz y/o de Kspar. Según la clasificación TAS, las rocas son basanitas, hawaiitas y basaltos (Figura 2d). Todas las muestras, excepto una, tienen [Ne] (Figura 3d). $\mathrm{El}$ \#Mg en el conjunto varía desde 54 hasta 66 (Figura 16). Sin embargo, la mayoría de las muestras presentan valores $>60$. Las rocas con los valores de \#Mg más bajos (54-57) proceden del alineamiento de conos en la porción occi- dental del CVO. Los diagramas de variación de elementos mayores vs. \#Mg muestran arreglos lineares burdos. $\mathrm{Nb}$ y $\mathrm{Sr}$ tienen correlaciones negativas con el \#Mg. Elementos incompatibles como el $\mathrm{Zr}, \mathrm{Sr}$ y $\mathrm{Nb}$ muestran variaciones muy amplias dentro de un rango limitado de \#Mg (Figura 16). Otros elementos incompatibles como Ba y Rb muestran tendencias semejantes, aunque su dispersión es menor. Ni, Cr y Co definen arreglos lineares con correlaciones positivas y dispersión baja contra el \#Mg. 
Petrología de las rocas del CVLE y del CVO. Una característica común de las muestras del CVLE y CVO es que están enriquecidas en los elementos traza incompatibles (LILE) y no presentan anomalías negativas de $\mathrm{Nb}$ y $\mathrm{Ti}$ (Figura 5d). Las Tierras Raras ligeras están enriquecidas con respecto a las pesadas, lo que sugiere la presencia de Grt residual en la fuente donde se originaron los magmas. La relación inicial de ${ }^{87} \mathrm{Sr} /{ }^{86} \mathrm{Sr}$ (Figura 6d) varía de 0.70334 a 0.70359 para las rocas del CVLE, mientras que para las rocas del CVO la misma relación varía de 0.70337 a 0.70346 . Finalmente para las rocas del CVLC varía de 0.70333 a 0.70338 . En el CVLE, el $\varepsilon_{\mathrm{Nd}}$ varía de $+5.0 \mathrm{a}+5.5$. En el CVO los valores del $\varepsilon_{\mathrm{Nd}}$ van de $+6.0 \mathrm{a}+6.1$ (Figura 6d). Las relaciones isotópicas de ${ }^{206} \mathrm{~Pb} / 204 \mathrm{~Pb}$ (Figura 7c) son más altas para el CVLE (18.51-18.77) que para el CVO (18.45-18.48). ${ }^{207} \mathrm{~Pb} /{ }^{204} \mathrm{~Pb}$ es similar en ambos campos volcánicos (CVLE: 15.55-15.58; CVO: 15.55-15.56) y la
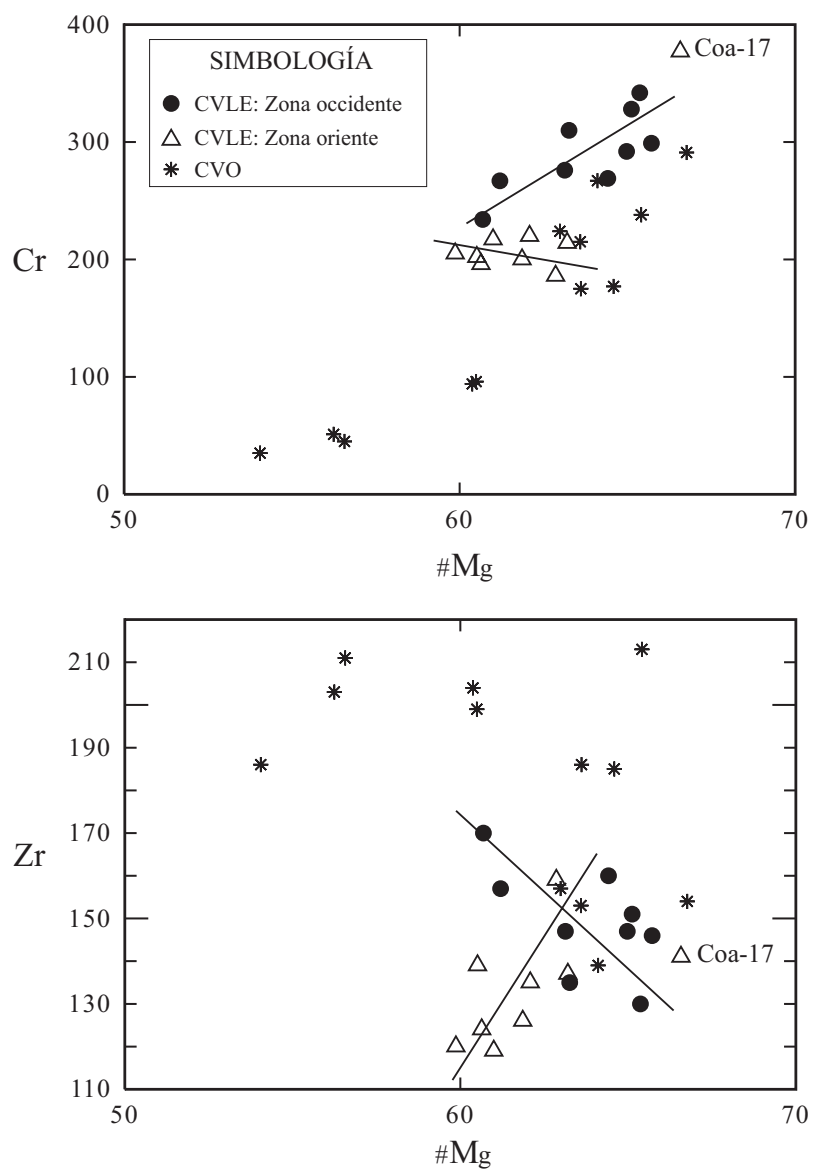

Figura 16. Diagramas de variación de las muestras colectadas en dos campos volcánicos de Coahuila (CVLE=Campo volcánico Las Esperanzas; CVO=Campo volcánico de Ocampo). La muestra Coa1-7 fue colectada en la porción oriental de Las Esperanzas y contiene xenocristales de $\mathrm{Ol}$ provenientes de una peridotita del manto. En muchos diagramas de variación Coa-17 grafica afuera de las tendencias lineales definidas por otras muestras de la porción oriental. Nótese que las pendientes de las tendencias lineales para muestras de occidente y oriente son radicalemente distintas por lo que se consideran como dos suites independientes. Asimismo, véase que la dispersión en los datos es considerable. Tomado de Valdez-Moreno (2001). relación ${ }^{208} \mathrm{~Pb} /{ }^{204} \mathrm{~Pb}$ es más baja para el CVO (38.08-38.18) que para el CVLE (38.29-38.38). Estos resultados fueron interpretados por Valdez-Moreno (2001) como el resultado de la marcada influencia de la fuente del manto e interacción de los magmas con la corteza continental.

Campo volcánico Las Coloradas (CVLC). El campo volcánico Las Coloradas forma un alineamiento paralelo con otras estructuras volcánicas menores ubicadas al noroeste, como los volcanes La Víbora y El Piojo, así como con el intrusivo subalcalino Las Tetillas con firma geoquímica de subducción (Cavazos-Tovar, 2004). Una línea que une a estos cuerpos ígneos es burdamente paralela a la traza de la falla San Marcos (Figura 15) en la parte central de Coahuila (McKee et al., 1984, 1990) y se localiza aproximadamente a $15 \mathrm{~km}$ al sur de ésta. Al menos en el volcán La Víbora se ha observado que existe una relación entre una falla normal, con bloque caído al sur, y la actividad volcánica. El carácter de tipo intraplaca de las rocas del CVLC se supone de: 1) su edad inferida (Plioceno-Cuaternario), 2) de su ubicación geográfica; 3) las relaciones isotópicas (Figura 6d) en dos muestras colectadas recientemente por nosotros.

Es importante destacar que el fallamiento normal del rift del Río Grande cesa abruptamente al llegar a Coahuila (Gries, 1979; Seager y Morgan, 1979). Por otro lado, en la región el magmatismo de tipo intraplaca presenta una estricta relación espacial con fallas antiguas de basamento que delimitan a bloques tectónicos. Por ejemplo, el CVLE está desarrollado justo en la base de la sierra de Santa Rosa, que aparentemente es un pliegue por doblez de falla y separa a estilos de deformación contrastantes entre el Cinturón Plegado de Coahuila (Figura 15) y la Plataforma Burro-Peyotes al noreste. Se sabe que sobre esta zona pasa la traza principal de la falla La Babia (Charleston, 1974, 1981) que es una estructura maestra de basamento de importancia regional que se encuentra sepultada debajo de los sedimentos del Cretácico y Terciario. Por otro lado, el CVO se encuentra en la parte oriental de un bloque de basamento menor dentro del Cinturón Plegado de Coahuila. Dicho bloque formó en el Mesozoico el rasgo paleogeográfico conocido como la Isla de la Mula (Jones et al., 1984). Una parte de los volcanes del CVO definen un alineamiento orientado N-S, igual al de las estructuras anticlinales menores desarrolladas durante la deformación Laramide; de esta manera, el CVO se desarrolló en una falla de basamento que delimita al borde oriental de la Isla de La Mula. Por lo anterior, concluimos que al menos en Coahuila existe una estrecha relación entre la distribución del magmatismo de tipo intraplaca y fallas de basamento generadas durante el Jurásico.

3.4. Magmatismo tardío (Plioceno temprano-Cuaternario): Región Oriental/Alcalina

Geomorfológicamente coincide con la planicie costera del Golfo de México y sus complejos magmáticos han sido 
englobados en la provincia Alcalina Oriental de México (Demant y Robin, 1975), que es una franja de actividad magmática con una historia larga y compleja. En la región ha habido actividad magmática intermitente desde el Terciario temprano hasta el Reciente. Geográficamente la región Oriental/Alcalina se extiende como un cinturón de orientación NNW a NS (Figura 1) a lo largo de la planicie costera del Golfo de México y en lugares parece traslapar sobre la Sierra Madre Oriental (Demant y Robin, 1975). Durante el Oligoceno, la actividad magmática en la región fue aproximadamente paralela a la paleotrinchera del Pacífico (Ramírez-Fernández et al., 2000). En su extremo septentrional la región Oriental/Alcalina se une a la provincia de Transpecos en Texas. Al sur parece estar parcialmente cubierta por la FVTM y/o interactuar de manera compleja con ella. Conforme a la interpretación de Robin (1982) la provincia Alcalina Oriental continúa al sur de la FVTM y llega hasta la región de los Tuxtlas en la parte sur del estado de Veracruz. En el extremo septentrional de la región Oriental/Alcalina el magmatismo contemporáneo a la subducción de la placa Farallón ha sido interpretado como asociado a extensión transarco (Demant y Robin, 1975) o como asociado a subducción, por el aumento de la profundidad de fusión asociada a la zona de Benioff al migrar el arco hacia el oriente (e. g., Clark et al., 1982). En Transpecos se ha documentado un cambio en la composición geoquímica de las rocas ígneas, de arco magmático continental a volcanismo de tipo intraplaca, que se asocia a una variación en el régimen tectónico (inicio de la extensión Cuencas y Sierras en esa región) y que sucedió en el lapso 32-28 Ma (James y Henry, 1991). En el cinturón Candela-Monclova, la sierra de Tamaulipas y en la sierra de San Carlos (Figura 1) los intrusivos más antiguos (Eoceno tardío-Oligoceno temprano) tienen firmas geoquímicas relacionadas con la subducción de la placa Farallón, mientras que intrusivos más jóvenes $(\sim 30$ $\mathrm{Ma}$ ) y rocas volcánicas expuestas alrededor de ellos tienen composiciones congruentes con un ambiente extensional de tipo intraplaca (Viera-Décida, 1998; Ramírez-Fernández et al., 2000; Chávez-Cabello, 2005). En las partes norte y central de Veracruz (Figura 1) hay cuatro regiones en donde se ha documentado (Orozco-Esquivel et al., 2003; Ferrari et al., 2005) volcanismo del Neogeno (Mioceno tardíoCuaternario): 1) Tlanchinol-Huautla; 2) Alamo-sierra de Tantima; 3) Poza Rica; 4) Chiconquiaco-Palma Sola. La última región coincide con el extremo oriental de la FVTM. Estas localidades en Veracruz y las localidades aisladas al sur de la sierra de Tamaulipas (Bernal de Horcasitas y cerros Auza, Nopal y El Murciélago: Figura 17) fueron descritas por Robin (1976) como el "vulcanismo de las planicies de la Huasteca".

\subsubsection{Sierra de San Carlos-Cruillas}

Este extenso complejo alcalino está formado por afloramientos aislados de rocas ígneas en un área de aproximadamente $5000 \mathrm{~km}^{2}$. Ha sido estudiado por Nick (1988),
Ramírez-Fernández et al. (2002) y Rodríguez-Saavedra (2003), está compuesto por: (1) plutones (gabro-sienitamonzonita) que fueron emplazados durante el Terciario medio (32-28 Ma: Bloomfield y Cepeda-Dávila, 1973; Romer y Heinrich, 1999) en caliza y lutita del Mesozoico; (2) enjambres de sills (pórfidos gabroicos) y diques (basalto $>$ fonolita); (3) cuellos volcánicos y derrames de basalto de $[\mathrm{Ol}]$ y traquibasalto. Se cree que la facies volcánica es producto de una actividad tardía, posiblemente asociada a extensión, y se sabe que es portadora de xenolitos del manto (Treviño-Cázares, 2001). Las relaciones petrológicas entre los distintos componentes del complejo no son claras ni directas y se considera que los magmas básicos provienen del manto mientras que las fases magmáticas más evolucionadas son productos de cristalización fraccionada en cámaras magmáticas estratificadas (Ramírez-Fernández et al., 2002). Se desconoce la edad isotópica de las rocas volcánicas de tipo intraplaca postoligocénicas.

\subsubsection{Complejo magmático de la sierra de Tamaulipas}

La sierra de Tamaulipas se encuentra entre la Sierra Madre Oriental y la costa del Golfo de México (Figura 17). Es un anticlinorio con orientación N-S desarrollado en caliza cretácica. En una región de aproximadamente 3 $600 \mathrm{~km}^{2}$ (Ortega-Gutiérrez et al., 1992) están expuestos cuerpos intrusivos alcalinos con composiciones que van de gabro a granito (sensu lato). En la porción central de la sierra se ubica el complejo El Picacho (Figura 17) en donde hay gabro de $[O l]$, diorita de Krs, sienita nefelínica, rocas hiperalcalinas con nefelina, diques de carbonatita (Ramírez-Fernández et al., 2000) y vetas hidrotermales ricas en Ap, Bri y Calc (Elías-Herrera, 1984; Elías-Herrera et al., 1990, 1991). Se desconoce la edad isotópica de $\mathrm{El}$ Picacho, pero con base en relaciones de campo se estima que puede ser entre el Oligoceno y Mioceno. Otras edades reportadas para rocas intrusivas de la sierra de Tamaulipas oscilan entre 31.5 y $17.5 \mathrm{Ma}$ (Cantagrel y Robin, 1978; Seibertz, 1990; Camacho-Angulo, 1993). Las rocas de El Picacho son interpretadas por Ramírez-Fernández et al. (2000) como una asociación característica de carbonatitaijolita-roca félsica alcalina desarrollada en un ambiente de tipo intraplaca a partir de magmas provenientes del manto. Con base en la presencia de cristales intersticiales de calcita en las sienitas nefelínicas y de la composición isotópica (C y O) de los mismos se cree que las carbonatitas se originaron por inmiscibilidad de un líquido carbonatítico a partir de un magma silíceo rico en $\mathrm{CO}_{2}$. Las vetas de Ap, Bri y Calc son interpretadas por Ramírez-Fernández et al. (2000) como un segundo líquido inmiscible formado a partir del magma carbonatítico aunque para Elías-Herrera (1984) son rasgos hidrotermales.

En la periferia de la sierra de Tamaulipas hay varios campos volcánicos del Cenozoico tardío (Figura 17). Para su descripción se dividen en los campos volcánicos de Llera de Canales, ubicado al oeste de la sierra y de Aldama-sierra de Maratínez, localizado al este. Al sur de 
la sierra hay afloramientos aislados de rocas alcalinas. Al menos en dos localidades cercanas a Ébano (S. L. P.) se han encontrado xenolitos de peridotita (Cerro Nopal y Auza: Treviño-Cázares, 2001).

Llera de Canales. Al occidente de la sierra de Tamaulipas, justo al pie de la Sierra Madre Oriental (Figura 17), existe una serie de mesetas cubiertas por capas delgadas de lava $(\leq 10 \mathrm{~m})$, las cuales yacen hasta $200 \mathrm{~m}$ arriba del nivel actual de los ríos principales de la región. En la misma zona ocurren cuellos volcánicos que son conocidos en la región como "bernales". Las rocas máficas de la región incluyen basanitas, basaltos alcalinos y hawaiitas (Figura 3d). Estas rocas máficas muestran características geoquímicas de magmas relativamente primitivos $(\# \mathrm{Mg} \leq 62, \mathrm{Ni}=210$ ppm, $\mathrm{Cr} \leq 345 \mathrm{ppm}$ ) y su contenido de REE sugiere que fueron generados por fusión parcial de lherzolita con Grt y Anf (Ramírez-Fernández, 1997). La hawaiita del Cerro La Clementina tiene una edad isotópica (K-Ar) de $2.4 \mathrm{Ma}$ (Camacho-Angulo, 1993). Edades ${ }^{40} \mathrm{Ar}-{ }^{39} \mathrm{Ar}$ reportadas en un resumen por Aranda-Gómez et al. (2002a) para muestras colectadas en el área son del Plioceno temprano ( $\sim 5 \mathrm{Ma})$. En este campo existen varias localidades importantes con xenolitos del manto, algunas de las cuales fueron reportadas por Pettus (1979) y estudiadas en más detalle por TreviñoCázares (2001).

Aldama y Sierra de Maratínez. El campo volcánico de Aldama está ubicado en la planicie costera del Golfo de México, inmediatamente al este de la Sierra de Tamaulipas (Figura 17). El campo tiene una superficie estimada de $\sim 800 \mathrm{~km}^{2}$ y en él hay aproximadamente 20 volcanes, principalmente conos cineríticos y derrames de lava asociados. Los conos están moderadamente bien preservados, lo que en un clima húmedo subtropical hace suponer que son relativamente jóvenes. Treviño-Cázares (2001) informa acerca de edades de K-Ar (2.6 y $1.4 \mathrm{Ma})$ obtenidas por Camacho-Angulo (1993) en muestras provenientes de la región de Aldama. Con base en la morfología de los volcanes suponemos que puede haber rocas más jóvenes que aquéllas fechadas. La composición de sus productos varía de traquita a basalto alcalino (Figura 2c), siendo ésta junto con Palomas y el volcán (El Pinacate), las únicas localidades continentales del Plioceno-Cuaternario de rocas de tipo intraplaca en el centro y norte de México en donde se han reportado rocas tan evolucionadas. Nuestros datos isotópicos $(\mathrm{Sr}$ y $\mathrm{Nd})$ inéditos acerca de esta serie de rocas muestran que las traquitas y basaltos son isotópicamente similares (Figura 6d) y, por tanto, probablemente son cogenéticos. Al parecer las primeras erupciones fueron de traquita y fonolita y fueron seguidas por la emisión de basalto a partir de conos cineríticos (Siebert et al., 2002). Aunque Vasconcelos et al. (2002) consideran a la serie de rocas de Aldama como bimodal, en el diagrama TAS de la Figura 2c se aprecia que forman una tendencia más o menos continua dentro del rango de basalto a traquita. El grupo de rocas máficas está compuesto por basalto alcalino, basalto subalcalino y hawaiita (Figura 3d). Las rocas más evolucionadas son benmoreitas y traquitas con paragénesis: $\mathrm{Sa}+$ Anor $+\mathrm{Ne}+\mathrm{Ol}$ fayalítico + Aug egirínica. Las traquitas forman dos grupos, el primero contiene $[\mathrm{Ne}]$ y $[\mathrm{Ol}]$ y el segundo $[H y]$ y $[Q t z]$. Los patrones de REE obtenidos por Ramírez-Fernández (1997) muestran un enriquecimiento en LREE respecto a los HREE (Figura 5c), con anomalías positivas de Eu en algunas de las muestras con $[\mathrm{Hy}]$ y $[\mathrm{Qtz}]$ y anomalías negativas en el mismo elemento en las rocas del grupo $[\mathrm{Ne}]$ y $[\mathrm{Ol}]$.

Al norte de Aldama está ubicada la sierra de Maratínez (Figura 17) en donde existen una serie de afloramientos aislados de rocas volcánicas máficas del Cenozoico medio o tardío. En comparación con Aldama, estos derrames de lava están profundamente intemperizados. Las cuatro muestras analizadas por Ramírez-Fernández (1996) son basaltos alcalinos (Figura 2d). Los afloramientos definen un alineamiento notable de unos $60 \mathrm{~km}$ de longitud con rumbo NNW (Ortega-Gutiérrez et al., 1992). En estos dos campos volcánicos no se han reportado xenolitos del manto. Nosotros hemos encontrado algunos xenolitos feldespáticos, aparentemente derivados de rocas intrusivas similares a las que afloran en la sierra de Tamaulipas.

Bernal de Horcasitas y cerros Auza, Nopal y El Murciélago. Son afloramientos aislados ubicados al sur de la sierra de Tamaulipas (Figura 17). Se desconoce si existe una relación entre estas localidades y los intrusivos expuestos en la sierra. El Bernal de Horcasitas es un cuello volcánico que se eleva $750 \mathrm{~m}$ de sus alrededores, tiene una edad isotópica K-Ar de $28 \mathrm{Ma}$ (Cantagrel y Robin, 1978) y está compuesto por foidita de $[\mathrm{Ol}]$ (Figura 2c) con contenidos elevados de $\mathrm{K}_{2} \mathrm{O}, \mathrm{TiO}_{2}$ y $\mathrm{P}_{2} \mathrm{O}_{5}$ (Ramírez-Fernández, 1996). En la planicie al oriente de Tampico se encuentran los cerros: (1) El Murciélago, compuesto por dique-estratos de tinguaita emplazados en lutita mesozoica, (2) El Nopal formado por fonolita peralcalina y (3) Auza formado por basanita. En las dos últimas localidades se han reportado xenolitos de peridotita (Treviño-Cázares, 2001). Los cerros Nopal y Murciélago son lacolitos con diquestratos pequeños asociados; su edad inferida es Mioceno (Robin, 1976). El cerro Auza es un domo subvolcánico (Robin, 1976).

\subsubsection{Norte y centro de Veracruz}

Orozco-Esquivel et al. (2003) reportan las edades isotópicas (K-Ar) y las características geoquímicas de las rocas ígneas del Neogeno en esta extensa región $(\sim 100 \mathrm{x}$ $200 \mathrm{~km}$ ). De norte a sur, los campos volcánicos que ellos estudiaron son: 1) Tlanchinol-Huautla en donde afloran basanitas y hawaiitas con edades de 7.4 a 5.7 Ma; 2) AlamoTantima con basaltos alcalinos de 7.5 a $6.6 \mathrm{Ma}$; 3) Poza Rica con basaltos alcalinos y hawaiitas del Cuaternario (1.6-1.3 Ma); 4) basaltos alcalinos y hawaiitas (7.0-2.0 Ma) en Chicoanquiaco-Palma Sola. Las rocas en los campos 1) y 2) tienen afinidad con los OIB ( $\mathrm{Nb}=33-90 \mathrm{ppm}, \mathrm{Ba} /$ $\mathrm{Nb}=6.7-8.1, \mathrm{Zr} / \mathrm{Nb}=3.7-6.5, \mathrm{La} / \mathrm{Yb}=14.6-28.5)$ y pueden ser modeladas por grados bajos de fusión parcial a partir de una lherzolita enriquecida, con Grt y Hbl como fases 

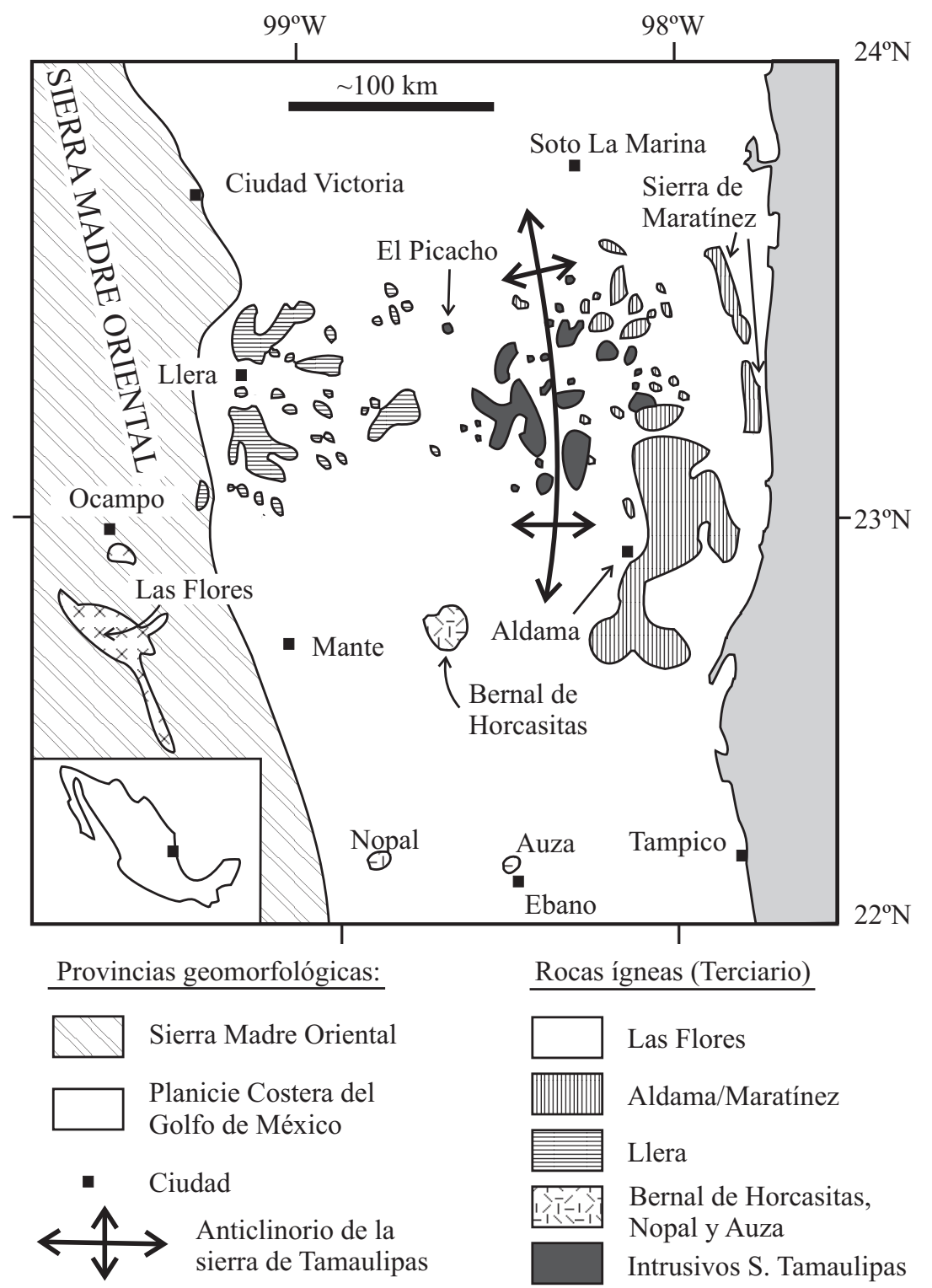

Rocas igneas (Terciario)

Figura 17. Bosquejo de la distribución de rocas ígneas alrededor de la sierra de Tamaulipas (simplificado de Ramírez-Fernández, 1996 y Treviño-Cázares, 2001). El volcán de Las Flores es considerado en este trabajo como parte del campo volcánico del E de San Luis Potosí (véase Figura 14).

residuales. En el área 3) coexisten productos de volcanismo asociado a subducción y tipo OIB. En Chiconquiaco-Palma Sola presentan una firma clara de actividad relacionada con subducción $(\mathrm{Nb}=16-22 \mathrm{ppm}, \mathrm{Ba} / \mathrm{Nb}=10.7-23.3$, $\mathrm{Zr} / \mathrm{Nb}=10.5-16.1, \mathrm{La} / \mathrm{Yb}=6.5)$. Gómez-Tuena et al. (2003) atribuyen los cambios en el tiempo de las características geoquímicas de la región de Palma Sola a la inyección de distintos componentes asociados a la subducción (corteza oceánica, sedimentos, fluidos) dentro de una cuña del manto compuesta por un manto enriquecido tipo OIB. De acuerdo con su modelo, las variaciones temporales en el ángulo de la zona de Benioff controlaron el material que fue fundido.

Las edades reportadas por Orozco-Esquivel et al. (2003) no se ajustan al modelo de Robin (1982), quien propuso que el volcanismo cenozoico en la región Oriental/Alcalina es de tipo intraplaca, está asociado a fallamiento normal paralelo a la costa del Golfo de México y migró de norte a sur a partir del Eoceno hasta el presente (región de los Tuxtlas). Claramente, no existe una sucesión ordenada de la edad del volcanismo en esta área.

\section{Sumario y Conclusiones}

\subsection{Localidades oceánicas}

Las islas se encuentran ubicadas sobre o cerca de dorsales volcánicas abandonadas y sus productos representan a los magmas formados después de que cesó la generación 
de piso oceánico. Como un todo, la composición química de las rocas estudiadas varía de basalto alcalino a riolita (Figura 2a). En Guadalupe las muestras forman una serie basalto-traquita, completa y coherente, incluyendo a todos los miembros intermedios (hawaiita, mugearita y benmoreita). Las variaciones en la serie pueden modelarse con éxito por cristalización fraccionada a partir de un basalto alcalino de conjuntos de minerales similares a las paragénesis observadas en las muestras, a presiones entre 2 y $10 \mathrm{~kb}$. Los valores relativamente homogéneos de ${ }^{87} \mathrm{Sr} /{ }^{86} \mathrm{Sr}$ (0.70321-0.70330) son consistentes con esta hipótesis.

Las muestras estudiadas de Socorro son claramente bimodales (Figura 2a), con basaltos y hawaiitas en un extremo y traquitas y riolitas en el otro. Socorro es un caso excepcional entre las islas oceánicas, ya que la parte subaérea del volcán, que se cree que es basáltico, es dominada $(\sim 80 \%)$ por rocas félsicas. El volumen estimado de este volcán alcalino es veinte veces más grande que el del campo volcánico de Camargo, que es el ejemplo más extenso de actividad intraplaca en la porción continental del centro y norte de México.

$\mathrm{Al}$ parecer, no hay un modelo simple que explique la geoquímica de las muestras de Socorro. Algunas de las variaciones elementales en las rocas máficas de Socorro pueden modelarse por cristalización fraccionada de $\mathrm{Pl}+\mathrm{Cpx}+\mathrm{Ol}+\mathrm{OFT}$ a presión baja, a partir de un magma basáltico alcalino. Sin embargo, las anomalías en $\mathrm{Ce}$, $\mathrm{P}_{2} \mathrm{O}_{5}$, Ba y REE intermedias (Figuras 4a y 5a) no pueden ser explicadas por ese proceso. Estos valores anómalos, así como variaciones en el $\mathrm{Sr}$ radiogénico (Figura 6a), son atribuidos a contaminación con componentes provenientes de corteza oceánica somera, sedimentos metalíferos o Ap formado en etapas previas en el sistema magmático o por contaminación con agua de mar o fluidos hidrotermales.

El conjunto de rocas félsicas de Socorro no puede derivarse de un basalto alcalino por cristalización fraccionada. Las traquitas pueden haberse generado por 5-10\% de fusión parcial de un basalto alcalino. Por otro lado, la cristalización fraccionada de $\mathrm{Cpx}+\mathrm{Ol}($ rico en $\mathrm{Fe})+\mathrm{Ilm}+\mathrm{Ap}$ a partir de una traquita es un proceso factible para la generación de las riolitas. Al igual que con las rocas máficas, algunas anomalías de Ce y algunas REE (Figuras 4a y 5a) se atribuyen a asimilación de sedimentos hidrotermales y los cambios en los isótopos de $\mathrm{Sr}$ a interacción con un sistema hidrotermal dominado por agua marina.

\subsection{Localidades continentales}

En la literatura no existen estudios petrogenéticos sistemáticos y detallados acerca de muchas de las localidades incluidas en la Figura 1, como Isla Isabel, Mesa Cacaxta y E de San Luis Potosí. De estos campos sólo se han incluido análisis de muestras aisladas en gráficas en donde se comparan algunos rasgos químicos de rocas de tipo intraplaca en México (e. g., Figura 23 en Aranda-Gómez et al., 1997) de donde se desprende que son similares a éstas. En otros sitios, como los volcanes cerca de Fresnillo, Sombrerete y Nieves (Zac.) sólo hemos inferido la existencia de actividad de tipo intraplaca por la presencia de xenolitos del manto en las rocas máficas y por la ubicación geográfica y entorno geológico de estas regiones. Algunas de las localidades con xenolitos del manto reportadas en la Figura 1 del trabajo de Aranda-Gómez y Ortega-Gutiérrez (1987) no son incluidas en esta nueva compilación. Por ejemplo, las localidades Jiménez, Lago Jaco y La Olivina en Chihuahua, ahora sabemos que corresponden al campo volcánico de Camargo. En El Cardel, Puente Negro y Los Tuxtlas en la región del Golfo de México no se ha podido constatar la existencia de inclusiones del manto. En cambio, Gómez-Tuena et al. (2003) y Blatter y Carmichael (1998) han documentado xenolitos en o cerca de la FVTM. Estas localidades junto con campos volcánicos con rocas OIB en el FVTM son excluidas de esta discusión por su asociación o proximidad geográfica y temporal con magmas de arco que hacen su interpretación petrológica y tectónica más complicada que la de las localidades descritas en este artículo.

\subsubsection{Distribución geográfica y asociación con provin- cias y/o rasgos tectónicos regionales}

Asumiendo que todos los campos volcánicos continentales mostrados en la Figura 1 son debidos a actividad de tipo intraplaca del Cenozoico medio-tardío, se observa que ésta se presenta en toda la región ubicada al norte de la FVTM (Figura 1), independientemente de la placa tectónica (Pacífico o América del Norte), de las provincias volcánicas más antiguas, de los límites entre provincias tectónicas actuales y de las fronteras entre los terrenos tectonoestratigráficos propuestos por distintos autores (e. g., Campa y Coney, 1983; Sedlock et al., 1993).

Ciertamente, la mayoría de los campos con xenolitos del manto en la zona continental se hayan en la porción meridional de Cuencas y Sierras (Figura 1), pero hay localidades que yacen en donde las fallas normales no son obvias o cuantitativamente importantes en la geología expuesta en la superficie. Ejemplos notables son: 1) San Quintín que está en la porción estable de la península de Baja California, al occidente del Escarpe Principal del Golfo (Gastil et al., 1975); este campo yace en un sitio en donde la plataforma continental es muy estrecha y en donde con base en estudios geofísicos se ha argumentado que existe un semigraben que está enmascarado por un depósito grueso de sedimentos sin litificar (Espinosa-Cardeña et al., 1991; Almeida-Vega et al., 2000); 2) Los campos volcánicos de Las Esperanzas y Ocampo, Coahuila, se hayan en una región en donde el fallamiento relacionado a la extensión del Cenozoico pudo ser suprimido o enmascarado por la presencia de paquetes gruesos de evaporitas (e. g., Gries, 1979) de la secuencia mesozoica acumulada en la Cuenca de Sabinas; 3) En las localidades ubicadas alrededor de la sierra de Tamaulipas, ubicadas en la planicie costera del Golfo de México, una provincia que actualmente está en un régimen extensional 
(Suter, 1991) y en donde se ha argumentado que debe de existir extensión causada por deslizamiento gravitacional hacia un depocentro ubicado en el Golfo de México (Bryant et al., 1968); 4) El modelo propuesto por Robin (1982) para el origen del volcanismo en la provincia Oriental/Alcalina ha sido cuestionado con base en datos nuevos (Ferrari et al., 2005). El análisis del entorno estructural de los campos volcánicos en el norte y centro de Veracruz ha mostrado que en la región no existe fallamiento normal contemporáneo con el volcanismo y paralelo a la costa del Golfo de México. Por tanto, el magmatismo no puede estar asociado a rifting. Los alineamientos de volcanes y las elongaciones de los cuellos volcánicos son paralelos a fallas de basamento con rumbos NE a ENE y NW a NNW que fueron formadas en el Jurásico durante la apertura del Golfo de México. Se cree que estas estructuras corticales facilitaron y controlaron el ascenso de los magmas, que son atribuidos a una anomalía térmica transitoria causada por la ruptura y hundimiento de la placa subducida (Cocos).

Algunos de los campos volcánicos de tipo intraplaca más voluminosos y extensos del norte de México $(e . g$., Camargo y Durango: Smith, 1989, 1993; Aranda-Gómez et al., 2002b) muestran evidencias de que el volcanismo y la extensión cortical fueron al menos en parte simultáneos, ya que los campos de lavas fueron cortados por fallas normales que a su vez fueron sepultadas por material volcánico más reciente (Aranda-Gómez et al., 2002b). Algunas de estas estructuras exceden el tamaño del área donde se ubican los volcanes y continúan en regiones adyacentes (Figuras 8 y 13). En Durango y Camargo se ha argumentado que esos sistemas de fallas normales fueron formados en el Terciario y reactivados en el Cuaternario (ArandaGómez et al., 1997, 2002b). En otros sitios, como en los campos de Moctezuma (Son.), Rodeo-Nazas y Río Chico (Dgo.) los conductos volcánicos se encuentran asociados y/o alineados a lo largo de fallas normales regionales y los productos volcánicos están intercalados con depósitos de grava que rellenaron parcialmente a fosas tectónicas activas al tiempo de su acumulación, lo que también es evidencia de que la extensión y el volcanismo de tipo intraplaca fueron contemporáneos (e. g., Aranda-Gómez et al., 1997; Luhr et al., 2001). Sin embargo, la mayoría de las veces el nexo entre extensión y magmatismo de tipo intraplaca es tenue, como en Ventura-Espíritu Santo (S. L. P.) y en el campo volcánico de Los Encinos (S. L. P.) en donde en el ámbito regional parecen existir discontinuidades estructurales importantes (Figura 10), pero que son difusas $y / o$ no han sido formalmente documentadas en la literatura.

La ubicación geográfica de algunos campos sugiere que el ascenso de magmas de tipo intraplaca en algunas regiones fue influenciado por fallas regionales antiguas como las fallas de San Marcos (McKee y Jones, 1979; McKee et al., 1984, 1990), San Tiburcio (Mitre-Salazar, 1989) y el sistema de fallas del río Santa María (S. L. P.-Zac.) que delimitan dominios tectónicos regionales en el basamento y que fueron reactivados en eventos tectónicos posteriores (e. g., Aranda-Gómez et al., 2002b, 2004).

\subsubsection{Consideraciones petrológicas}

Variaciones en la petrogénesis en relación con un ambiente tectónico cambiante. Hay evidencias claras de que la geoquímica y procesos petrológicos involucrados en la evolución de las rocas de tipo intraplaca del Oligoceno tardío y el Plioceno-Cuaternario difieren significativamente. Los procesos de asimilación y cristalización fraccionada (AFC) jugaron un papel muy importante en la petrogénesis en las primeras. Esto se ve reflejado en contaminación selectiva con elementos provenientes de rocas corticales (Figuras 5 b y 9) y evidencias claras de cristalización fraccionada a presiones relativamente altas. Datos clave empleados para apoyar estas conclusiones son: 1) en comparación con rocas de tipo intraplaca más jóvenes, las rocas de tipo intraplaca tempranas tienden a ser relativamente más evolucionadas (hawaiitas) y usualmente contienen conjuntos complejos de megacristales y xenocristales; 2) los megacristales pueden o no ser cogenéticos con las roca huésped, pero provienen de magmas con un origen inferido similar, pero que llegaron a ser más evolucionados que la roca huésped; 3) las lavas y tefras en ocasiones incluyen xenolitos parcialmente digeridos de granulitas feldespáticas y/o de gabros cristalizados a presión relativamente alta; 4) la paragénesis en los xenolitos es igual o semejante a la mineralogía del conjunto de megacristales/xenocristales, lo que indica que estos últimos provienen de la desagregación/asimilación de esas rocas; 5) la ausencia de xenolitos de peridotita en las rocas máficas del Oligoceno-Mioceno implica un ascenso significativamente más lento que el de las rocas del Plioceno-Cuaternario que sí los contienen; 6) la presencia en Los Encinos de algunas rocas primitivas sin contaminar, cuya geoquímica es muy similar a la de rocas del PliocenoCuaternario y que se encuentran en uno de los extremos de "vectores de mezcla" observados en ciertos diagramas de variación (e. g., Figura 9).

El modelo propuesto por Luhr et al. (2001) para explicar las diferencias geoquímicas y petrológicas entre los magmas de tipo intraplaca tempranos y los tardíos en la porción meridional de Cuencas y Sierras alude a un cambio progresivo en las condiciones tectónicas y en el estado térmico de la litósfera. En el Oligoceno medio ( $c a$. $32 \mathrm{Ma}$ ) hubo en la parte oriental de la porción meridional de Cuencas y Sierras una transición de compresión ENE a extensión ENE (e. g., Henry y Aranda-Gómez, 1992). La generación y ascenso de magmas de tipo intraplaca, caracterizados por enriquecimientos de $\mathrm{Ti}, \mathrm{Nb}$ y Ta, pudo haber comenzado simultáneamente o un poco después de este cambio. El inicio de la extensión también coincidió con la fase paroxísmica (flare-up) del volcanismo ignimbrítico de la Sierra Madre Occidental (e.g., McDowell y Keizer, 1977; Aranda-Gómez et al., 2000), lo que causó un calentamiento en la litósfera y trajo como consecuencia el ascenso de la transición dúctil-frágil en la corteza. 
Bajo estas circunstancias, la posibilidad de que estructuras frágiles penetraran profundamente fue cancelada, por lo que el ascenso de magmas de tipo intraplaca a la superficie posiblemente no sucedió. Consecuentemente, los primeros magmas de tipo intraplaca cristalizaron en la corteza profunda formando plutones gabroicos e intrusivos cogenéticos más diferenciados. Conforme la litósfera se fue enfriando la transición frágil-dúctil descendió, lo que permitió formación de conductos para que algunas hawaiitas ascendieran más eficientemente y llegaran a la superficie. Al atravesar lentamente la corteza, estos magmas de 24-11 Ma incorporaron megacristales y algunos xenolitos producto de la cristalización/diferenciación de los primeros magmas de tipo intraplaca que nunca arribaron a la superficie; también tuvieron tiempo de interactuar con la corteza contaminándose selectivamente con los elementos más incompatibles, como Cs, Th, U y Rb (Figuras 5b, 5c y 9), en los minerales más usuales de la corteza (e.g., Qtz) y para diferenciarse por cristalización fraccionada, lo que resultó en rocas más evolucionadas que las del Plioceno-Cuaternario. En contraste, las rocas de tipo intraplaca plio-cuaternarias tienden a ser más primitivas y comúnmente arribaron a la superficie con xenolitos grandes de la corteza profunda y del manto superior. Su composición geoquímica señala que experimentaron comparativamente poca diferenciación y contaminación con material cortical. Estas características son congruentes con ascenso a través de estructuras frágiles formadas en una etapa más avanzada de la extensión ENE a NE, que penetraron más profundamente y que posiblemente fueron favorecidas por una corteza más fría. Este modelo es congruente con los datos derivados de las rocas del Oligoceno tardío de Rodeo-Nazas, en el estado de Durango, y aquellas de Mioceno medio en Los Encinos en San Luis Potosí y Zacatecas, y Metates, en Durango. Debido a que no se han documentado otras localidades con este tipo de volcanismo temprano, no es posible establecer si es de aplicación general para toda la porción meridional de la provincia de Cuencas y Sierras.

La localidad con rocas alcalinas más antiguas es Bernal de Horcasitas (28 Ma). Su composición química es más extrema que la de la mayoría de las muestras de la PENM y sólo comparable con otras localidades ubicadas en la provincia Oriental/Alcalina (Figura 2c). Su contenido de Tierras Raras ligeras e intermedias es considerablemente más elevado que el de todas las rocas continentales tempranas o del Plioceno-Cuaternario (Figuras 4b y 4c). Hasta donde sabemos, en esta localidad no se han reportado megacristales ni xenolitos del manto, y en el diagrama de multielementos (Figuras 5b y 5c) no se observan los enriquecimientos característicos en algunos elementos incompatibles documentados en las localidades tempranas de la provincia Cuencas y Sierras. Por estos motivos creemos que el modelo arriba esbozado puede no ser aplicable para esta localidad.

Cambios seculares en las fuentes de los magmas de tipo intraplaca. Con base en las variaciones en composición (elemental e isotópica) de las rocas de tipo intraplaca, en la porción norteamericana de Cuencas y Sierras se ha inferido que en los últimos 5-10 Ma las fuentes de los magmas máficos han cambiado de una parte somera del manto litosférico a una fuente más profunda en la astenósfera ( $e$. g., Perry et al., 1987; Fitton et al., 1991). En contraste, las rocas de tipo intraplaca oligoceno-miocénicas (24-10 Ma) de México (i. e., Rodeo-Nazas, Los Encinos y Metates) tienen contenidos de elementos traza que generalmente se asocian con magmas astenosféricos y composiciones isotópicas que sugieren una fuente litosférica más somera. Las evidencias de contaminación cortical significativa documentadas por Luhr et al. (1995b, 2001) hacen pensar que estos magmas no reflejan fielmente la geoquímica de sus fuentes ya que los procesos experimentados durante su ascenso oscurecen muchas de las características geoquímicas heredadas directamente de las rocas madre. Estos autores concluyen que en la porción meridional de Cuencas y Sierras no hay evidencias incontrovertibles de una variación en las fuentes durante la evolución de esta parte de la provincia. Cabe señalar que Paz-Moreno et al. (2003) argumentan a favor de un cambio en la fuente de magmas máficos en Moctezuma (Son.) de manto litosférico en las primeras etapas (Mioceno temprano) de la extensión a manto astenosférico en el Cuaternario, siendo esto similar a lo que se ha observado en el suroeste de los Estados Unidos. Por otro lado, la distribución bimodal de los datos isotópicos de Ventura-Espíritu Santo y Santo Domingo (Figura 6d) deja la posibilidad de interpretar la existencia de dos fuentes, una en la astenósfera y otra en la litósfera, en dos campos cuaternarios de la porción meridional de Cuencas y Sierras.

Composiciones extremas observadas. Con la excepción del Bernal de Horcasitas, las rocas volcánicas más subsaturadas en sílice son aquellas que forman al campo Ventura-Espíritu Santo, en San Luis Potosí. Asumiendo fuentes similares, compuestas por lherzolita de Grt, la diferencia entre la composición de las rocas de VenturaEspíritu Santo y Santo Domingo, en San Luis Potosí, podría ser explicada por un grado de fusión mayor para las rocas de Santo Domingo. En un estudio sistemático de xenolitos de peridotita en México, las presiones y temperaturas de equilibración más elevadas calculadas corresponden a las muestras provenientes de VenturaEspíritu Santo (Luhr y Aranda-Gómez, 1997). Existen evidencias de que este campo se encuentra en una región que ha experimentado varios pulsos de extensión (ArandaGómez et al., 2000) desde el Oligoceno medio ( 30 $\mathrm{Ma})$, lo cual no difiere radicalmente de otras regiones en donde ocurren rocas de tipo intraplaca de edades similares (e. g., Santo Domingo, S. L. P., y Durango), pero con composiciones más evolucionadas (e. g., Aranda-Gómez et al., 1997). El estudio detallado de xenolitos del manto provenientes de esta región y la posición geográfica de Ventura-Espíritu Santo ha hecho pensar a Heinrich y Besch (1992) que en esta zona existe una perturbación térmica en 
el manto superior causada por extensión trasarco asociada a la actividad cuaternaria de la FVTM. Hasta ahora no se han explorado las implicaciones de este pulso térmico en la generación de los magmas que transportaron a los xenolitos a la superficie.

Con la excepción de las traquitas en el volcán Santa Clara del Pinacate y algunas rocas en Palomas, las series magmáticas de los campos volcánicos de San CarlosCruillas y de Aldama, en Tamaulipas, incluye a las únicas traquitas de tipo intraplaca (Figura 2c) documentadas al norte de la FVTM. De acuerdo con nuestros datos inéditos, la composición isotópica de las traquitas de Aldama es similar a las rocas máficas alcalinas asociadas (Figuras 6d y 7c). Hasta ahora se desconoce cuales factores en esta región favorecieron una diferenciación extrema dentro de un sistema cerrado. Cabe señalarse que en la región Oriental/Alcalina existen otros ejemplos (San Carlos y sierra de Tamaulipas) de variaciones extremas en composición en las series que han sido interpretadas como producto de cristalización fraccionada, que esto ha sucedido en complejos magmáticos de edades variables (Oligoceno-Cuaternario) y que en la planicie costera del Golfo de México no hay evidencias en la geología expuesta en la superficie de extensión cortical significativa. La actividad magmática alcalina en la región Oriental/Alcalina es larga y complicada. La fase temprana del volcanismo alcalino sucedió contemporáneamente con el magmatismo asociado a la subducción que originó a la Sierra Madre Occidental y se ha interpretado como actividad trasarco (Demant y Robin, 1975) asociada a dicho fenómeno o como un aumento en la alcalinidad en magmas de arco causada por el aumento en la profundidad de la zona de fusión cercana a la zona de Benioff(Clark et al., 1982). Conforme el frente activo del arco continental del Terciario medio fue desplazándose al oeste (Clark et al., 1982), hacia la paleotrinchera, esta actividad cambió a magmatismo de tipo intraplaca, sobreponiendo sus productos a las rocas alcalinas formadas en el evento anterior.

Las panteleritas y comenditas de Sonora son ejemplos aún más extremos de diferenciación en una serie alcalina. Sin embargo, se sabe poco de ellos porque hasta ahora sólo se ha reportado en resúmenes breves su asociación con basaltos transicionales posiblemente asociados a extensión temprana y se ha especulado que están relacionadas con la extensión que formó al Protogolfo de California en el Mioceno medio (Vidal-Solano et al., 2000).

Asociación geográfica y temporal de las rocas máficas alcalinas con rocas con [Hy] en ambientes continentales de tipo intraplaca. En varios campos volcánicos (e. g., Santo Domingo, Durango, San Quintín) se ha encontrado que hay muestras que contienen $[H y]$ (Figura 3c) y/o que poseen algunas características geoquímicas que las hacen semejantes a magmas calcialcalinos, aun y cuando no se les puede asociar de manera razonable al fenómeno de subducción. Las relaciones de campo sugieren que éstas fueron extravasadas durante el mismo ciclo de volcanismo que las rocas máficas con [Ne]. En general este fenómeno no es discutido en la literatura ni se proponen hipótesis para explicarlo. El caso más claro de esta asociación, por los volúmenes relativos de rocas con $[\mathrm{Hy}] \mathrm{y}$ basalto alcalino involucrados, es el de Moctezuma, en donde PazMoreno et al. (2003) señalan que las rocas saturadas con $\mathrm{SiO}_{2}$ antecedieron a la expulsión de aquéllas con $[\mathrm{Ne}] \mathrm{y}$ que hay un cambio en el estilo eruptivo asociado a los dos tipos de magma. Smith (1989) para el campo volcánico de Durango señala que: 1) algunas de las rocas con contenido bajo a moderado de [Hy] son portadoras de xenolitos del manto y corticales, 2) no hay una coherencia geográfica en la distribución de las rocas con $[H y]$ ni una variación cronológica en el aumento en la saturación con sílice en las muestras. Las tendencias lineales B y C identificadas por Smith (1989) en muchos diagramas de variación (e.g., Figura 12a) corresponden a las rocas con [Hy]. Con base en el análisis de diagramas multielementos de las rocas del campo volcánico de Durango y comparación con una muestra de basalto de la FVTM, Smith (1989) concluyó que en las rocas con $[\mathrm{Hy}]$ hay componentes heredados de la subducción terciaria que pudieron persistir en el manto y contribuir periódicamente a la formación de los magmas del campo volcánico de Durango.

Aún más sorprendente es el caso de una muestra proveniente de un dique-estrato andesítico del campo volcánico de Camargo. Su edad ${ }^{40} \mathrm{Ar}-{ }^{39} \mathrm{Ar}$ es de $\sim 14$ Ma y su composición indican que fue formado por un magma relacionado con la actividad del arco Terciario (Aranda-Gómez et al., 2002 b, p. 300). Esto sucedió 16 Ma después del inicio de la extensión y $\sim 10$ Ma después de las primeras manifestaciones de actividad magmática de tipo intraplaca en el norte de México y sur de los Estados Unidos. Un ejemplo similar es el volcán Tres Vírgenes (Figura 1) en donde la actividad cuaternaria ha formado un complejo eruptivo con afinidad calcialcalina, en una región actualmente dominada por trantensión asociada a la Provincia Extensional del Golfo de California. La composición anómala calcialcalina, generada al menos 10 Ma después de que cesó la subducción es atribuida a un proceso de contaminación cortical (Sawlan, 1986). Otras explicaciones posiblemente factibles, como fusión a presión baja o un grado alto de fusión, no han sido exploradas para explicar esta asociación cercana entre rocas con $[\mathrm{Ne}]$ y rocas saturadas con sílica en los ambientes de tipo intraplaca del centro y norte de México.

Diversidad de procesos involucrados en la petrogénesis de las rocas de tipo intraplaca. En general, el \#Mg en las muestras indican que los magmas de tipo intraplaca no están en equilibrio con el contenido de Fo en el Ol de los xenolitos del manto que transportaron a la superficie (i. e., las peridotitas son accidentales). Comúnmente los magmas tienen composiciones (e. g., \#Mg y contenido de $\mathrm{Ni}, \mathrm{Cr}$ ) que son congruentes con algo de cristalización fraccionada y diferenciación de minerales máficos antes de la incorporación de los xenolitos o bien, el contenido de $\mathrm{Fe}$ en la fuente era más alto que el observado en los xenolitos (e. g., Luhr et al., 1989, 1995a). En Durango, 
el modelado señala que los cambios químicos son igualmente congruentes con conjuntos de minerales de presión baja o alta (Smith, 1989). Cuando esto sucede, los autores prefieren el conjunto de presión alta porque los xenolitos de peridotita demandan un ascenso rápido y la ausencia de una cámara magmática somera de larga duración. Este rasgo es una diferencia notable entre la mayoría de las localidades en corteza continental y las islas, en donde existen cámaras magmáticas que permiten cristalización fraccionada a presiones relativamente bajas.

En términos generales no se puede decir que haya un proceso petrogenético dominante que explique las variaciones químicas en todos los campos volcánicos continentales del Plioceno-Cuaternario mostrados en la Figura 1. Algunas series parecen estar influenciadas al menos en parte por distintos grados de fusión parcial de rocas madre con composiciones similares y/o por heterogeneidades de las fuentes en el manto. En otras, el proceso dominante parece ser cristalización fraccionada (e. g., La Breña; Pier et al., 1992). En otros más, como San Quintín, los cambios temporales en composición química implican un aumento en el grado de fusión parcial o empobrecimiento progresivo de elementos incompatibles en la fuente.

\subsubsection{Relación genética entre volcanismo alcalino y extensión}

Una exploración acerca del estado de esfuerzo que existe en la corteza continental al norte de la FVTM muestra que la información es escasa (e. g., Suter, 1991; Zoback y Zoback, 1991), pero ésta ha llevado a Suter (1991) a concluir que la magnitud de los esfuerzos actuales en Chihuahua, Coahuila, Durango, Nuevo León, Tamaulipas, San Luis Potosí, y Querétaro es $\mathrm{S}_{\mathrm{V}}>\mathrm{S}_{\mathrm{N}}>\mathrm{S}_{\mathrm{E}}$ (V=vertical; $\mathrm{N}=$ norte; $\mathrm{E}=$ este), y que esta región se caracteriza por tensión horizontal desviatórica (horizontal deviatoric tension). Por otro lado, no se sabe hasta cuando en el pasado podemos extrapolar esta conclusión y si esto puede hacerse de manera indiscriminada para toda la región continental considerada en esta revisión.

De los datos presentados en este trabajo se desprende que el volcanismo alcalino intraplaca existe en todo el norte de México, independientemente de la magnitud de la deformación causada por la extensión, siendo ésta máxima en la Provincia Extensional del Golfo de California y en la porción meridional de Cuencas y Sierras, y mínima o ausente en la planicie costera del Golfo de México. Por tanto, concluimos que la presencia de volcanismo intraplaca debe ser más función de los procesos en el manto superior abajo de la región, que del estado de esfuerzos en la corteza superior. Los datos de Grand (1994) y de van der Lee y Nolet (1997) muestran que la mayor parte o toda la región, en el rango de profundidades entre 100 y 200 km, está subyacida por un manto caracterizado por velocidades de las ondas S anómalamente bajas. Esto es interpretado por van der Lee y Nolet (1997) como consecuencia de ascenso de manto astenosférico o presencia de volátiles y fusión parcial en la "no-slab window" causada por la subducción de la placa Farallón.

Ciertamente, en algunos sitios parece ser que el estado de esfuerzos, las propiedades mecánicas y/o la existencia de discontinuidades importantes influyen en si un magma intraplaca llega a la superficie o no y, si lo hace, en la ubicación de los volcanes o aún en la naturaleza de algunos procesos petrológicos que modifican su composición ( $e$. g., procesos AFC), pero la causa última de la generación de estos magmas es independiente de la deformación en la superficie.

\section{Agradecimientos}

Este artículo de revisión fue elaborado cuando el primer autor se encontraba en un año sabático en el Instituto Potosino de Investigación Científica y Tecnológica, A. C. Nuestro trabajo ha recibido apoyo económico del Consejo Nacional de Ciencia y Tecnología (3657PT y 37429-T) y PAPIIT (INI 114198 a J. Aranda), National Science Foundation y Smithsonian Institution Scholarly Studies Program (a J. Luhr) y al Posgrado en Ciencias de la Tierra de la UNAM (a G. Chávez y G. Valdez). A todas estas instituciones expresamos nuestro más sincero agradecimiento. Teresa Soledad Medina Malagón, bibliotecaria del CGEO-UNAM, auxilió en la compilación de los materiales bibliográficos consultados y revisó las referencias en la lista de trabajos citados. Alejandro Morales y Cristina Morán auxiliaron en la preparación de algunas de las Figuras. Rufino Lozano Santa-Cruz efectuó los análisis de elementos mayores en las rocas de Coahuila. Juan Tomás Vazquez y Crescencio Garduño prepararon láminas delgadas de roca. José Luis Macías otorgó un complemento de beca que permitió a G. Valdez finalizar su investigación en Coahuila.

\section{Referencias bibliográficas}

Aguirre-Díaz, G. J., McDowell, F. W., 1993, Nature and timing of faulting and synextensional magmatism in the southern Basin and Range, central-eastern Durango, Mexico: Geological Society of America Bulletin, 105, 1435-1444.

Allan, J. F., 1986, Geology of the northern Colima and Zacoalco grabens, southwest Mexico: late Cenozoic rifting in the Mexican Volcanic Belt: Geological Society of America Bulletin, 97, 473-485.

Almeida-Vega, M., Espinosa-Cardeña, J. M., Ledesma-Vázquez, J., 2000, Structure of the San Quintín coastal valley, B.C. from aeromagnetic data análisis (resumen), en V Reunión Internacional sobre la Geología de la Península de Baja California, Memorias: Loreto, Baja California Sur, Universidad Autónoma de Baja California; Universidad Nacional Autónoma de México, Sociedad Geológica Peninsular, 64.

Aranda-Gómez, J. J., 1982, Ultramafic and high grade metamorphic xenoliths from central Mexico: Eugene, Oregon, University of 
Oregon, Tesis doctoral, $228 \mathrm{p}$.

Aranda-Gómez, J. J., Luhr, J. F., 1993, Geology of the Joya Honda and Santo Domingo maars, San Luis Potosí, Mexico -A visit to the mantle and crustal xenolith localities in the Sierra Madre Terrane, en Ortega-Gutiérrrrez, F., Centeno-García, E., Morán-Zenteno, D. J., Gómez-Caballero, A. (eds.), First circum-Pacific and circum-Atlantic Terrane Conference. Pre-Mesozoic basement of NE Mexico, crust and mantle xenoliths of central Mexico, and northern Guerrero terrane. Guidebook of field trip A: Guanajuato, Gto., Universidad Nacional Autónoma de México, Instituto de Geología, 10-35.

Aranda-Gómez, J. J., Luhr, J. F., 1996, Origin of the Joya Honda maar, San Luis Potosí, México: Journal of Volcanology and Geothermal Research, 74, 1-18.

Aranda-Gómez, J. J., Ortega-Gutiérrez, F., 1987, Mantle xenoliths in Mexico, en Nixon, P. H. (ed.), Mantle xenoliths: New York, Wiley, 75-84.

Aranda-Gómez, J. J., Aranda-Gómez, J. M., Nieto-Samaniego, A. F., 1989, Consideraciones acerca de la evolución tectónica durante el Cenozoico de la Sierra de Guanajuato y la parte meridional de la Meseta Central: Universidad Nacional Autónoma de México, Revista del Instituto de Geología, 8(1), 33-46.

Aranda-Gómez, J. J., Henry, C. D., Luhr, J. F., 2000, Evolución tectonomagmática post-paleocénica de la Sierra Madre Occidental y de la porción meridional de la provincia tectónica de Cuencas y Sierras, México: Boletín de la Sociedad Geológica Mexicana, $53(1), 59-71$

Aranda-Gómez, J. J., Luhr, J. F., Housh, T. B., 1999, Reconnaissance geology of Isla Isabel, Nayarit, México: Geos, 19(4), 320.

Aranda-Gómez, J. J., Luhr, J. F., Pier, J. G., 1992, The La Breña-El Jagüey maar complex, Durango, México: I Geological evolution: Bulletin of Volcanology, 54, 393-404.

Aranda-Gómez, J. J., Luhr, J. F., Pier, J. G., 1993, Geología de los volcanes cuaternarios portadores de xenolitos del manto y de la base de la corteza en el Estado de San Luis Potosí, México: Boletín del Instituto de Geología, Universidad Nacional Autónoma de México, 106 , pt. 1, 1-22.

Aranda-Gómez, J. J., Henry, C. D., Luhr, J. F., McDowell, F. W., 1997, Cenozoic volcanism and tectonics in NW Mexico a transect across the Sierra Madre Occidental volcanic field and observations on extension related magmatism in the southern Basin and Range and Gulf of California tectonic provinces, en Aguirre-Díaz, G. J., Aranda-Gómez, J. J., Carrasco-Nuñez, G., Ferrari, L. (eds.), Magmatism and tectonics in the central and northwestern Mexico a selection of the 1997 IAVCEI General Assembly excursions: México, D.F., Universidad Nacional Autónoma de México, Instituto de Geología, 41-84.

Aranda-Gómez, J. J., Carranza-Castañeda, O., Luhr, J. F., Housh, T. B., 2002a, Origen de los sedimentos continentales en el valle de Jaumave, Tamaulipas: Geos, 22(2), 327.

Aranda-Gómez, J. J., Luhr, J. F., Housh, T. B., Connor, C. B., Becker, T., Henry, C. D., 2002b, Synextensional, Plio-Pleistocene eruptive activity in the Camargo volcanic field, Chihuahua, México: Geological Society of America Bulletin, 115(3), 298-313.

Aranda-Gómez, J.J., Luhr, J. F., Housh, T. B. Valdez-Moreno, G., ChávezCabello, G., 2004, El vulcanismo intraplaca del Cenozoico tardío en el centro y norte de Méxco: una revisión, en Frías-Camacho, V.M., Silva-Corona, J. J., Orozco-Esquivel, M.T. (eds.), IV Reunión Nacional de Ciencias de la Tierra, Libro de resúmenes: Geos, 24(2), 147

Aranda-Gómez, J. J., Housh, T. B., Luhr, J. F., Henry, C. D., Becker, T., Chávez-Cabello, G., 2005, Reactivation of the San Marcos fault during mid- to late Tertiary extension, Chihuahua, México, en Nourse, J.A., Anderson, T.H., McKee, J.W., Steiner, M.B. (eds.), The Mojave-Sonora megashear hypothesis: Development, assessment, and alternatives: Geological Society of America, Special Paper, 393, 509-522.

Arvidson, R. E., Mutch, T.A., 1974, Sedimentary patterns in and around craters from the Pinacate Volcanic Field, Sonora, Mexico: some comparisons with Maars: Geological Society of America Bulletin, $85,99-104$
Bacon, C. R., Carmichael, I. S. E., 1978, Stages in the P-T path of ascending basalt magma: and example from San Quintín, Baja California: Contributions to Mineralogy and Petrology, 41, 1-22.

Basu, A. R., 1977a, Olivine-spinel equilibria in lherzolite xenoliths from San Quintín, Baja California: Earth and Planetary Science Letters, $33,443-450$.

Basu, A. R., 1977b, Textures, microstructures and deformation of ultramafic xenoliths from San Quintín, Baja California: Tectonophysics, 43, 213-246.

Basu, A. R., 1978, Trace elements and $\mathrm{Sr}$ isotopes in some mantlederived hydrous minerals and their significance: Geochimica et Cosmochimica Acta, 42, 659-668.

Basu, A. R., 1979, Geochemistry of ultramafic xenoliths from San Quintin, Baja California, en Boyd, F.R., Meyer, H.O.A. (eds.), The mantle sample: inclusions in kimberlites and other volcanics. Proceedings of the Second International Kimberlite Conference: Washington, D.C., American Geophysical Union, 2, 391-399.

Basu, A. R., Murthy, V. R., 1977, Ancient lithospheric lherzolite xenoliths in alkalic basalt from Baja California: Earth and Planetary Science Letters, 35, 239-246.

Batiza, R., 1977. Petrology and chemistry of Guadalupe Island: an alkalic seamount on a fossil ridge crest: Geology, 5, 760-764

Batiza, R., 1982, Abundances, distributions, and sizes of volcanoes in the Pacific Ocean and the implications for the origin of non-hotspot volcanoes: Earth and Planetary Science Letters, 60, 195-206

Ben Othman, D., Tilton, G. R., Menzies, M. A., 1990, Pb, Nd and $\mathrm{Sr}$ isotopic investigations of kaersutite and clinopyroxene from ultrmafic nodules, and their host basalts: the nature of the subcontinental mantle: Geochimica et Cosmochimica Acta, 54(12), 3449-3460.

Blatter, D. L., Carmichael, I. S. E., 1998, Hornblende peridotite xenoliths from central Mexico reveal the highly oxidized nature of subarc upper mantle: Geology, 26(11), 1035-1038.

Bloomfield, K., Cepeda-Dávila, L., 1973, Oligocene alkaline igneous activity in NE Mexico: Geological Magazine, 110, 551-555.

Bohrson, W. A., Reid, M. R., 1995, Petrogenesis of alkaline basalts from Socorro Island, Mexico; trace element evidence for contamination of ocean island basalt in the shallow ocean crust: Journal of Geophysical Research, 100(B12). 24,555-24,576.

Bohrson, W. A., Reid, M. R., 1997, Genesis of silicic peralkaline volcanic rocks in an ocean island setting by crustal melting and open-system processes; Socorro Island, México: Journal of Petrology, 38, 11371166.

Bohrson, W. A., Reid, M. R., Grunder, A. L., Heizler, M. T., Harrison, T. M., Lee, J., 1996, Prolonged history of silicic peralkaline volcanism in the eastern Pacific Ocean: Journal of Geophysical Research, 101(B5), 11,457-11,474.

Bryan, W. B., 1959, High-silica lavas of Clarion and Socorro island, Mexico -their genesis and regional significance: Madison, Wisconsin, University of Wisconsin, Tesis doctoral, $164 \mathrm{p}$.

Bryan, W. B., 1966, History and mechanism of eruption of soda-rhyolite and alkali basalt Socorro Island, México: Bulletin of Volcanology, $29,453-479$

Bryan, W. B., 1976, A basalt-pantellerite association from Isla Socorro, Islas Revillagigedo, Mexico, en Aoki, H., Iizuka, S. (eds.), Volcanoes and tectonosphere: Tokyo, Japan, Tokai University Press, 75-91.

Bryant, W. R., Antoine, J., Ewing, M., Jones, B., 1968, Structure of mexican continental shelf and slope, Gulf of Mexico: American Association of Petroleum Geologists Bulletin, 52, 1204-1228.

Cabanes, N., Mercier, J. C. C., 1988, Insight into the upper mantle beneath an active extensional zone: the spinel-peridotite xenoliths from San Quintín (Baja California, Mexico): Contributions to Mineralogy and Petrology, 100, 374-382.

Cabral-Cano, E., 1988, Paleomagnetismo y petrografía de la Isla Isabel, Nayarit: México, Universidad Nacional Autónoma de México, Facultad de Ingeniería, Tesis profesional, $143 \mathrm{p}$.

Camacho-Angulo, F., 1993, Compilación geológica de la vertiente del Golfo de México: Veracruz, Ver., Comisión Federal de Electricidad, Subdirección Técnica, Gerencia de Estudios de Ingeniería Civil, Subgerencia de Estudios Geológicos, Departamento de Geología, Zona Golfo, 169 p. 
Cameron, K. L., Nimz, G. J., Kuentz, D., 1989, Southern cordillera basaltic andesite suite, southern Chihuahua, Mexico: a link between Tertiary continental arc and flood basalt magmatism in North America: Journal of Geophysical Research, 94(B6), 7817-7840.

Cameron, K. L., Robinson, J. V., Niemeyer, S., Nimz, G. J., Kuentz, D. C., Harmon, R. S., Bohlen, S. R., Collerson, K. D., 1992, Contrasting styles of pre-Cenozoic and mid-Tertiary crustal evolution in northern Mexico: evidence from deep crustal xenoliths from La Olivina: Journal of Geophysical Research, 97(B12), 17,353-17,376.

Campa, M. F., Coney, P. J., 1983, Tectono-stratigraphic terranes and mineral resource distribution in Mexico: Canadian Journal of Earth Sciences, 20, 1040-1051.

Cantagrel, J.-M., Robin, C., 1978, K-Ar dating on eastern mexican volcanic rocks- relations between the andesitic and the alkaline provinces: Journal of Volcanology and Geothermal Research, 5, 99-114.

Cavazos-Tovar, J. G., 2004, Petrografía y geoquímica del intrusivo Las Tetillas, Bloque Coahuila, México: Linares, Nuevo León, Universidad Autónoma de Nuevo León, Facultad de Ciencias de la Tierra, Tesis profesional, $127 \mathrm{p}$.

Charleston, S., 1974, Stratigraphy, tectonics and hydrocarbon potential of the lower Cretaceous, Coahuila Series, Coahuila, Mexico: Ann Arbor, Michigan, University of Michigan, Tesis doctoral, $268 \mathrm{p}$.

Charleston, S., 1981, A summary of the structural geology and tectonics of the state of Coahuila, Mexico, en Schmidt, C. I., Katz, S. B., (eds.), Lower Cretaceous stratigraphy and structure, northern México. Field Trip Guidebook: West Texas Geological Society, Publication, (81-74), 28-36.

Chávez-Cabello, G., 2005, Deformación y magmatismo cenozoicos en el sur de la Cuenca de Sabinas, Coahuila, México: Juriquilla, Querétaro, Universidda Nacional Autónoma de México, Centro de Geociencias, Posgrado en Ciencias de la Tierra, Tesis doctoral, 266 p., 1 mapa, 1 disco compacto.

Clark, K. F., Foster, C. T., Damon, P. E., 1982, Cenozoic mineral deposits and subduction-related magmatic arcs in Mexico: Geological Society of America Bulletin, 93, 533-544.

Consejo de Recursos Minerales (COREMI), 1994, Inventario minero y exploración del carbón en el estado de Coahuila: México, Secretaría de Energía, Minas e Industria Paraestatal, Consejo de Recursos Minerales, $122 \mathrm{p}$

Córdoba, D. A., 1963, Geología de la región entre Río Chico y Llano Grande, municipio de Durango, estado de Durango: Boletín del Instituto de Geología, Universidad Nacional Autónoma de México, 71, pt. 1, 1-22, 1 mapa, 1 lámina plegada.

Demant, A., Robin, C., 1975, Las fases del vulcanismo en México; una síntesis en relación con la evolución geodinámica desde el Cretácico: Revista del Instituto de Geología, Universidad Nacional Autónoma de México, 1, 70-83.

Elías-Herrera, M., 1984, Rocas alcalinas y mineralización de lantánidos en el área El Picacho, Sierra de Tamaulipas: Geomimet, 127, 61-75.

Elías-Herrera, M., Rubinovich-Kogan, R., Lozano-Santa Cruz, R., Sánchez-Zavala, J. L., 1990, Petrología y mineralización de Tierras Raras del complejo ígneo El Picacho, Sierra de Tamaulipas: Boletín del Instituto de Geología, Universidad Nacional Autónoma de México, 108, 24-97, 2 láminas.

Elías-Herrera, M., Rubinovich-Kogan, R., Lozano-Santa Cruz, R., Sánchez-Zavala, J. L., 1991, Nepheline-rich foidolites and rareearth mineralization in the El Picacho Tertiary intrusive complex, Sierra de Tamaulipas, northeastern Mexico: Canadian Mineralogist, 29, 319-336.

Espinosa-Cardeña, J. M., Romo-Jones, J. M., Almeida-Vega, M., 1991, Gravimetría y estructura del valle de San Quintín, B. C.: Geos, 21(3), 10-15.

Ferrari, L., Takahiro, T., Mugihiko, E., Orozco-Esquivel, M. T., Petrone, C., Jacobo-Albarrán, J., López-Martínez, M., 2005, Geology, geochronology and tectonic setting of late Cenozoic volcanism along the southwestern Gulf of Mexico: The Eastern Alkalic Province revisited: Journal of Volcanology and Geothermal Research, 146(4), 284-306.

Fitton, J. G., James, D., Leeman, W. P., 1991, Basic magmatism associated with late Cenozoic extension in the western United States: compositional variations in space and time: Journal of Geophysical Research, 96, 13693-13711.

Frantes, T. J., Hoffer, J. M., 1982, Palomas volcanic field, southern New Mexico and northern Chihuahua: New Mexico: Geology, 4(1) 6-8, 16.

Gastil, R. G., Phillips, R. P., Allison, E. C., 1975, Reconnaissance geology of the state of Baja California: Boulder, Colorado, Geological Society of America Memoir, 140, 170 p., 3 mapas.

Gómez-Tuena, A., LaGatta, A. B., Langmuir, C. H., Goldstein, S. L., Ortega-Guitérrez, F., Carrasco-Nuñez, G., 2003, Temporal control of subduction magmatism in the eastern Trans-Mexican Volcanic Belt: mantle sources, slab contributions and crustal contamination: Geochemistry, Geophysics, Geosystems, 4, 1-33.

Grand, S. P., 1994, Mantle shear structure beneath the Americas and surrounding oceans: Journal of Geophysical Research, 99, 1159111621.

Green, D. H., 1971, Composition of basaltic magmas as indicators of conditions of origin; aplications to oceanic volcanism: Philosophical Transactions of Royal Society of London, Series A: Mathematical and Physical Sciences, 268, 707-725.

Gries, J. C., 1979, Problems of delineation of the Rio Grande Rift into the Chihuahua tectonic belt of northeastern Mexico, en Riecker, R. E. (ed.), The Rio Grande Rift-Tectonics and magmatism: Washington, D.C., American Geophysical Union, 107-113.

Gutmann, J. T., 1974, Tubular voids within labradorite phenocrysts from Sonora, Mexico: American Mineralogist, 59(7-8), 666-672.

Gutmann, J. T., 1979, Structure and eruptive cycle of cinder cones in the Pinacate volcanic field and the controls of Strombolian activity: Journal of Geology, 87, 448-454.

Gutmann, J. T., 1986, Origin of four- and five-phase ultramafic xenoliths from Sonora, Mexico: American Mineralogist, 71(9-10), 10761084.

Gutmann, J. T., 2002, Strombolian and effusive activity as precursors to phreatomagmatism: eruptive sequence at maars of the Pinacate volcanic field, Sonora, Mexico: Journal of Volcanology and Geothermal Research, 113, 345-356.

Gutmann, J. T., Martin, R.F., 1976, Crystal chemistry, unit cell dimensions, and structural state of labradorite megacrysts from Sonora, Mexico: Schweizerische Mineralogische und Petrographische Mitteilungen, $56,55-64$

Gutmann, J. T., Sheridan, M. F., 1978, Geology of the Pinacate volcanic field, Sonora, Mexico, en Burt, D.M., Peew, T.L. (eds.), Guidebook to the geology of central Arizona: Arizona Bureau of Geology and Mineral Technology, Special Paper, 2, 47-59.

Hart, S. R., Gerlach, D. C., y White, W. M., 1986, A possible new Sr-Nd-Pb mantle array and consequences for mantle mixing: Geochimimica et Cosmochimica Acta, 50, 1551-1557.

Hawley, J. C., 1981, Pleistocene and Pliocene history of the international boundary area, southern New Mexico, en Hoffer, J-.M., Hoffer, R.L. (eds.), Geology of the border; southern New Mexico-northern Chihuahua: El Paso, Texas, El Paso Geological Society, 26-32.

Heinrich, W., Besch, T., 1992, The upper mantle beneath a young backarc extensional zone: ultramafic xenoliths from San Luis Potosí, central México: Contributions to Mineralogy and Petrology, 111, 126-142.

Henry, C. D., Aranda-Gómez, J. J., 1992, The real southern Basin and Range: mid-to late Cenozoic extension in Mexico: Geology, 20, 701-704.

Henry, C. D., Aranda-Gómez, J. J., 2000, Plate interactions control middlelate Miocene, proto-Gulf and Basin and Range extension in the southern Basin and Range: Tectonophysics, 318(1-4), 1-26.

Henry, C. D., Fredrikson, G., Ames, J. T., 1987, Geology of part of southern Sinaloa, Mexico adjacent to the Gulf of California, scale 1:250,000: Boulder, Colorado, Geological Society of America, Map and Chart Series, MCH063, 1 mapa, 14 .

Hoffer, J. M., 1976, Geology of Potrillo basalt field, south-central New Mexico: New Mexico Bureau of Geology \& Mineral Resources, Circular, 149, 30 p., 1 lámina.

Irvine, T. N., Baragar, W. R. A., 1971, A guide to the chemical classification of the common volcanic rocks: Canadian Journal of Earth Sciences, 
8, 523-548.

James, E. W., Henry, C. D., 1991, Compositional changes in Trans-Pecos Texas magmatism coincident with Cenozoic stress realignment: Journal of Geophysical Research, 96(B8), 13561-13575.

Jones, N. W., McKee, J. W., Márquez-D., B., Tovar, J., Long, L. E., Laudon, T. S., 1984, The Mesozoic La Mula island, Coahuila, Mexico: Geological Society of America Bulletin, 95, 1226-1241.

Kretz, R., 1983, Symbols for rock-forming minerals: American Mineralogist, 68, 277-279.

Labarthe-Hernández, G., 1978, Algunos xalapascos en el estado de San Luis Potosí: Folleto Técnico del Instituto de Geología y Metalurgia, Universidad Autónoma de San Luis Potosí, 58, 17 p.

Labarthe-H., G., Tristán-G., M., Aranda-G., J. J., 1982, Revisión estratigráfica del Cenozoico de la parte central del Estado de San Luis Potosí: Folleto Técnico del Instituto de Geología y Metalurgia, Universidad Autónoma de San Luis Potosí, 85, 208 p., 1 mapa.

Le Maitre, R. W. (ed.), Streckeisen, A., Zanettin, B., Le Bas, M. J., Bonin, B., Bateman, P., Bellieni, G., Dudek, A., Efremova, S. Keller, J., Lameyre, J., Sabine, P.A., Schmid, R., Sorensen, H., Woolley, A.R., 2002, Igneous rocks; a classification and glossary of terms; recommendations of the International Union of Geological Sciences Subcommission on the Systematics of Igneous Rocks. $2^{\text {nd }}$ ed.: Cambridge, Cambridge University Press, 236 p.

Luhr, J. F., Aranda-Gómez, J. J., 1997, Mexican peridotite xenoliths and tectonic terranes: correlations among vent location, texture, temperature, pressure, and oxygen fugacity: Journal of Petrology, 38(8), 1075-1112.

Luhr, J. F., Allan, J. F., Carmichael, I. S. E., Nelson, S. A., Hasenaka, T., 1989a, Primitive calc-alkaline and alkaline rock types from the western Mexican Volcanic Belt: Journal of Geophysical Research, 94(B4), 4515-4530.

Luhr, J. F., Aranda-Gómez, J. J., Pier, J. G., 1989b, Spinel-lherzolitebearing, Quaternary volcanic centers in San Luis Potosí, México. I. Geology, Mineralogy, and Petrology: Journal of Geophysical Research, 94(B6), 7916-7940.

Luhr, J. F., Aranda-Gómez, J. J., Housh, T. B., 1995a, San Quintín Volcanic Field, Baja California Norte, México: Geology, Petrology and Geochemistry: Journal of Geophysical Research, 100(B7), 10353-10380.

Luhr, J. F., Pier, J. G., Aranda-Gómez, J. J., Podosek, F., 1995b, Crustal contamination in early Basin-and-Range hawaiites of the Los Encinos volcanic field, central México: Contributions to Mineralogy and Petrology, 118, 321-339.

Luhr, J. F., Henry, C. D., Housh, T. B., Aranda-Gómez, J. J., McIntosh, W. C., 2001, Early extension and associated mafic alkalic volcanism from the southern Basin and Range Province: Geology and petrology of the Rodeo and Nazas volcanic fields, Durango (Mexico): Geological Society of America Bulletin, 113(6), 760-773.

Lutz, T. M., Gutmann, J. T., 1995, An improved method of determining alignments of point-like features and its implications for the Pinacate volcanic field, Mexico: Journal of Geophysical Research, 100, 17659-17670.

Lynch, D. J., 1981, Genesis and geochronology of alkaline volcanism in the Pinacate volcanic field northwestern Sonora, Mexico: Tucson, Arizona, University of Arizona, Tesis doctoral, $265 \mathrm{p}$.

Lynch, D. J., Musselman, T. E., Gutmann, J. T., Patchett, P. J., 1993, Isotopic evidence for the origin of Cenozoic volcanic rocks in the Pinacate volcanic field, northwestern Mexico: Lithos, 29, 295-302.

Mammerickx, J., Naar, D. F., Tyce, R. L., 1988, The matematician paleoplate: Journal of Geophysical Research, 93(B4), 3025-3040.

McClelland, L. E., Venzke, E., Goldberg, J., 1993, Socorro (Mexico) vesicular lava eruption from underwater vent $3 \mathrm{~km} \mathrm{~W}$ of the island: Smithsonian Institution, Bulletin of the Global Volcanism Network, 18(1), 9-11.

McDowell, F. W., Keizer, R. P., 1977, Timing of mid-Tertiary volcanism in the Sierra Madre Occidental between Durango City and Mazatlan, Mexico: Geological Society of America Bulletin, 88, 1479-1486.

McKee, J. W., Jones, N. W., 1979, A large Mesozoic fault in Coahuila, Mexico: Geological Society of America, Abstracts with Programs, 11,476 .
McKee, J. W., Jones, N. W., Long, L. E., 1984, History of recurrent activity along a major fault in northeastern Mexico: Geology, 12, 103-107.

McKee, J. W., Jones, N. W., Long, L. E., 1990, Stratigraphy and provenance of strata along the San Marcos fault, central Coahuila, Mexico: Geological Society of America Bulletin, 102, 593-614.

Medina, F., Suárez, F., Espíndola, J. M., 1989, Historic and Holocene volcanic centers in NW México: Bulletin of Volcanic Eruptions (Tokyo), 26, 91-93.

Menzies, M. A., 1989, Cratonic, circumcratonic and oceanic mantle domains beneath the western United States: Journal of Geophysical Research, 94, 7899-7915.

Mitre-Salazar, L. M., 1989, La megafalla laramídica de San Tiburcio, estado de Zacatecas: Revista del Instituto de Geología, Universidad Nacional Autónoma de México, 8, 47-51.

Miyashiro, A., 1974, Volcanic rock series in island arcs and active continental margins: American Journal of Science, 274, 321-355.

Morán-Zenteno, D. J., 1994, Geology of the Mexican Republic: Tulsa, Oklahoma, American Association of Petroleum Geologists Studies in Geology, 39, 160 p.

Nick, K., 1988, Mineralogische, geochemische und petrographische untersuchungen in der Sierra de San Carlos (Mexiko): Karlsruhe, Geowissenschaften Universität Fakultät fur Biologie, Tesis doctoral, $167 \mathrm{p}$.

Nieto-Samaniego, A. F., Alaniz-Alvarez, S. A. Labarthe-Hernández, G., 1997, La deformación Cenozoica poslaramídica en la parte meridional de la Mesa Central, México: Revista Mexicana de Ciencias Geológicas, 14, 13-25.

Nimz, G. J., 1989, The geochemistry of the mantle xenolith suite from La Olivina, Chihuahua, Mexico: Santa Cruz, California, University of California, Tesis doctoral, $315 \mathrm{p}$.

Nimz, G. J., Cameron, K. L., Cameron, M., Morris, S. L., 1986, The petrology of the lower crust and upper mantle beneath southeastern Chihuahua, Mexico: a progress report: Geofísica Internacional, 25(1), 85-116.

Nimz, G. J., Cameron, K. L., Niemeyer, S., 1993, The La Olivina pyroxenite suite and the isotopic compositions of mantle basalts parental to midCenozoic arc volcanism of northern Mexico: Journal of Geophysical Research, 98(B4), 6489-6509.

Nimz, G. J., Cameron, K. L., Niemeyer, S., 1995, Formation of mantle lithosphere beneath northern Mexico: Chemical and Sr-Nd-Pb isotopic systematics of peridotite xenoliths from La Olivina: Journal of Geophysical Research, 100(B3), 4181-4196.

Orozco-Esquivel, M. T., Ferrari, L., Eguchi, M., Tagami, T., Petrone, C., Albarran, J., 2003, The eastern alkaline province (Mexico) revised: geology, geochronology and geochemistry of Neogene volcanism in Veracruz state, en $99^{a}$ Reunión Anual, Geological Society of America, Cordilleran Section, Puerto Vallarta, Jal., 1 a 3 de abril de 2003, Libro de resúmenes: México, Geological Society of America; Universidad Nacional Autónoma de México, Instituto de Geología, 58.

Ortega-Gutiérrez, F., González-González, R., 1980, Nódulos de peridotita en la Isla Isabel, Nayarit: Revista del Instituto de Geología, Universidad Nacional Autónoma de México, 4(1), 82-83.

Ortega-Gutiérrez, F., Mitre-Salazar, L. M., Roldán-Quintana, J., Aranda-Gómez, J. J., Morán-Zenteno, D., Alaníz-Álvarez, S. A., Nieto-Samaniego, A. F., 1992, Carta geológica de la República Mexicana, escala 1:2.000.000. $5^{\mathrm{a}}$ ed.: México, Universidad Nacional Autónonoma de México, Inst. Geología; Secretaría de Energía, Minas e Industria Paraestatal, Consejo de Recursos Minerales, 1 mapa.

Padovani, E. R. Carter, J. L., 1977, Aspects of the deep crustal evolution beneath south central New Mexico, en Heacock, J.G. (ed.), The earth's crust; its nature and physical properties: Washington, D.C., American Geophysical Union, Monograph, 20, 19-55.

Paz-Moreno, F., Demant, A., Ornelas-Solís, R. E., 2000, Las ignimbritas hiperalcalinas neógenas de la región de Hermosillo, Sonora, México: mineralogía y geoquímica, en Calmus, T., Pérez-Segura, E. (eds.), Cuarta Reunión sobre la Geología del Noroeste de México y Áreas Adyacentes, Libro de resúmenes: Hermosillo, Sonora, Universidad 
Nacional Autónoma de México, Instituto de Geología, Estación Regional del Noroeste; Universidad de Sonora, Departamento de Geología, 90-91.

Paz-Moreno, F. A., Demant, A., Cochemé, J. J., Dostal, J., Montigny, R., 2003, The Quaternary Moctezuma volcanic field: a tholeiitic to alkali basaltic episode in the central Sonoran Basin and Range Province, México, en Johnson, S. E., Patterson, S. R., Fletcher, J. M., Girty, G. H., Kimbrough, D. L., Martín-Barajas, A. (eds.), Tectonic evolution of northwestern México and the southwestern USA: Boulder, Colorado, Geological Society of America Special Paper, 374, 439-455.

Perry, F. V., Baldridge, W. S., DePaolo, D. J., 1987, Role of asthenosphere and lithosphere in the genesis of late-Cenozoic basaltic rocks from the Rio Grande Rift and adjacent regions of the southwestern United States: Journal of Geophysical Research, 92(B9), 9193-9213.

Pettus, D. S., 1979, Ultramafic xenoliths from Llera de Canales, Tamaulipas, Mexico: Houston, Texas, University of Houston, Tesis de maestría, $65 \mathrm{p}$.

Pier, J. G., Podosek, F., Luhr, J. F., Brannon, J., Aranda-Gómez, J. J., 1989, Spinel-lherzolite-bearing, Quaternary volcanic centers in San Luis Potosí, México. II. Sr and Nd isotopic systematics: Journal of Geophysical Research, 94(B6), 7941-7951.

Pier, J. G., Luhr, J. F., Podosek, F. A., Aranda-Gómez, J. J., 1992, The La Breña-El Jaguey maar complex, Durango, Mexico: II. Petrology and geochemistry: Bulletin of Volcanology, 54, 405-428.

Ramírez-Fernández, J. A., 1996, Zur petrogenesse des alkalikomplex der Sierra de Tamaulipas, NE-Mexiko: Freiburg,Universität de Freiburg, Tesis doctoral, $317 \mathrm{p}$.

Ramírez-Fernández, J. A., 1997, Volcanismo intraplaca típico de la planicie costera del Golfo de México; Sierra de Tamaulipas: Actas INAGEQ, 3, 232

Ramírez-Fernández, J. A., Keller, J., Hubberten, H. W., 2000, Relaciones genéticas entre las carbonatitas y las rocas nefelíniticas del complejo El Picacho, Sierra de Tamaulipas, NE de México: Revista Mexicana de Ciencias Geológicas, 17(1), 45-55.

Ramírez-Fernández, J. A., Rodríguez-Saavedra, P., Jiménez-Boone, I., Cossío-Torres, T., 2002, El complejo magmático Terciario de la sierra de San Carlos-Cruillas, estado de Tamaulipas: Geos, 22(2), 250.

Richards, A. F., 1959, Geology of the Islas Revillagigedo, Mexico 1. Birth and development of Volcan Barcena, Isla San Benedicto: Bulletin of Volcanology, 22, 73-124.

Richards, A. F., 1965, Geology of the Islas Revillagigedo, 3. Effects of erosion on Isla San Benedicto 1952-61 following the birth of Volcan Barcena: Bulletin of Volcanology, 28, 381-403.

Richards, A. F., 1966, Geology of the Islas Revillagigedo, Mexico, 2. Geology and petrography of Isla San Benedicto: Proceedings of the California Academy of Sciences, 33, 361-414.

Righter, K., Carmichael, I. S. E., 1993, Mega-xenocrysts in alkali basalts: fragments of disrupted mantle assemblages: American Mineralogist, $78,1230-1245$.

Robin, C., 1976, El vulcanismo de las planicies de la Huasteca (este de México): datos geoquímicos y petrográficos: Boletín del Instituto de Geología, Universidad Nacional Autónoma de México, 96, 55-92.

Robin, C., 1982. Relations volcanologie-magmatologie-geodynamique: application au passage entre volcanismes alcalin et andesitique dans le sud Mexicain (Axe Trans-Mexicain et Province Alcaline Oriental): Clermont-Ferrand, Francia, Université Clermont-Ferrand II.; U.E.R. de Recherche Scientifique et Technique, Annales Scientifiques de l'Universite' de Clermont-Ferrand II, Géologie, Minéralogie, Tesis doctoral, 70, $503 \mathrm{p}$.

Rodríguez-Saavedra, P., 2003, Petrografía y geoquímica de las rocas magmáticas de la Sierra de San Carlos-Cruillas: Linares, Nuevo León, Universidad Autónoma de Nuevo León, Facultad de Ciencias de la Tierra, Tesis profesional, $134 \mathrm{p}$.

Rogers, G., Saunders, A. D., Terrell, D. J., Verma, S. P., Marriners, G. F., 1985, Geochemistry of Holocene volcanic rocks associated with ridge subduction in Baja California, Mexico: Nature, 315, 389-392.

Romer, R., Heinrich, W., 1999, Transport of $\mathrm{Pb}$ and $\mathrm{Sr}$ in leaky aquifers of the Bufa del Diente contact metamorphic aureole, northeast Mexico:
Contributions to Mineralogy and Petrology, 131, 155-170.

Rudnick, R. L., Cameron, K. L., 1991, Age diversity of the deep crust in northern Mexico: Geology, 19, 1197-1200.

Saunders, A. D., Rogers, G., Marriner, G. F., Terrell, D. J., Verma, S. P., 1987, Geochemistry of Cenozoic volcanic rocks, Baja California, Mexico: implications for the petrogenesis of post-subduction magmas: Journal of Volcanology and Geothermal Research, 32, 223-245

Sawlan, M. G., 1986, Petrogenesis of late Cenozoic volcanic rocks from Baja California Sur, Mexico: Santa Cruz, California, University of California, Tesis doctoral, $174 \mathrm{p}$.

Sawlan, M. G., 1991, Magmatic evolution of the Gulf of California rift, en Dauphin, J. P., Simoneit, B. A. (eds.), The Gulf and peninsular province of the Californias: Tulsa, Oklahoma, American Association of Petroleum Geologists, Memoir, 47, 301-369.

Schaaf, P., Heinrich, W., Besch, T., 1994, Composition and Sm-Nd isotopic data of the lower crust beneath San Luis Potosí, central Mexico: evidence from a granulite-facies xenolith suite: Chemical Geology, 118, 63-84.

Seager, W. R., Morgan, P., 1979, Rio Grande Rift in southern New Mexico, west Texas, and northern Chihuahua, en Riecker, R. E. (ed.), The Rio Grande Rift-Tectonics and magmatism: Washington, D.C., American Geophysical Union, 87-106.

Sedlock, R. L., Ortega-Gutiérrez, F., Speed, R. C., 1993, Tectonostratigraphic terranes and tectonic evolution of Mexico: Boulder, Colorado, Geological Society of America, Special Paper, 278, $153 \mathrm{p}$.

Seibertz, E., 1990, El desarrollo cretácico del Archipiélago de Tamaulipas. II. Génesis y datación de un dique de basalto y su efecto en el ambiente deposicional medio-Cretácico de la Sierra de Tamaulipas (Cenomaniano-Turoniano): Actas de la Facultad de Ciencias de la Tierra, Universidad Autónoma de Nuevo León, 4, 99-123.

Siebe, C., Komorowski, J. C., Navarro, C., McHone, J. F., Delgado, H., Cortes, A., 1995, Submarine eruption near Socorro Island, Mexico; geochemistry and scanning electron microscopy studies of floating scoria and reticulite: Journal of Volcalogy and Geothermal Research, 68, 239-271.

Siebert, L., Calvin, C., Kimberly, P., Luhr, J. F., Kysar, G., 2002, Volcanoes of México: Washington, D.C., Smithsonian Institution, 1 disco compacto.

Smith, J. A., 1989, Extension-related magmatism of the Durango volcanic field, Durango, Mexico: Saint Louis, Missouri, Washington University, Tesis de maestría, 290 p.

Smith, R. D., 1993, The Agua de Mayo mid-Cenozoic volcanic group and related xenoliths from La Olivina SE Chihuahua, Mexico: Santa Cruz, California, University of California, Tesis de maestría, $112 \mathrm{p}$.

Storey, M., Rogers, G., Saunders, A. D., Terrell, D. J., 1989, San Quintin volcanic field, Baja California, Mexico: "within plate" magmatism following ridge subduction: Terra Nova, 1, 195-202.

Sun, S. S., McDonough, J. D., 1989, Chemical and isotopic systematics of oceanic basalts: implications for mantle compositions and process, en Saunders, A. D. Norry, M. J. (eds.), Magmatism in the ocean basins: London, Geological Society, Special Publication, 42, 313-345.

Suter, M., 1991, State of stress and active deformation in Mexico and western Central America, en Slemmons, D. B., Engdahl, E. R., Zoback, M. D., Blackwell, D. D., (eds.), Neotectonics of North America: Boulder, Colorado, Geological Society of America, Decade map, 1, 401-421.

Treviño-Cázares, A., 2001, Xenolitos del manto en la planicie costera del Golfo de México: Linares, Nuevo León, Universidad Autónoma de Nuevo León, Facultad de Ciencias de la Tierra, Tesis profesional, 113 p.

Umhoefer, P., Mayer, L., Dorsey, B., 2002, Evolution of the margin of the Gulf of California near Loreto, Baja California peninsula, Mexico: Geological Society of America Bulletin, 114(7), 849-868.

Valdez-Moreno, G., 2001, Geoquímica y petrología de los campos volcánicos Las Esperanzas y Ocampo, Coahuila, México: México, Universidad Nacional Autónoma de México, Instituto de Geología, Tesis de maestría, $104 \mathrm{p}$.

van der Lee, S., Nolet, G., 1997, Upper mantle S velocity structure of North 
America: Journal of Geophysical Research, 102, 22815-22838.

Vasconcelos, M., Ramírez-Fernández, J. A., Viera-Décida, F., 2002, Petrología del vulcanismo traquítico del complejo volcánico de Villa Aldama, Tamps.: Geos, 22(2), 250-251.

Vidal-Solano, J. R., Paz-Moreno, F.A., Demant, A., 2000, Estudio mineralógico y geoquímico de la fase volcánica hiperalcalina del evento miocénico pre-Pinacate, campo volcánico el Pinacate (NW Sonora, México), en Calmus, T., Pérez-Segura, E. (eds.), Cuarta Reunión sobre la Geología del Noroeste de México y Áreas Adyacentes: Hermosillo, Sonora, Universidad Nacional Autónoma de México, Instituto de Geología, Estación Regional del Noroeste; Universidad de Sonora, Departamento de Geología, 142-143.

Viera-Décida, F., 1998, Delimitación, petrografía y geoquímica de los cuerpos intrusivos del Rancho El Salvador, Sierra de Tamaulipas: Linares, Nuevo León, Universidad Autónoma de Nuevo León, Facultad de Ciencias de la Tierra, Tesis profesional, $96 \mathrm{p}$.

Williams, W. J. W., 1999, Evolution of Quaternary intrplate mafic lavas detailed using ${ }^{3} \mathrm{He}$ surface exposure and ${ }^{40} \mathrm{Ar} /{ }^{39} \mathrm{Ar}$ dating, and elemental and $\mathrm{He}, \mathrm{Sr}, \mathrm{Nd}$, and $\mathrm{Pb}$ isotopic signatures; Potrillo volcanic field, New Mexico, U.S.A. and San Quintin volcanic field, Baja California Norte, Mexico: El paso, Texas, University of Texas at El Paso, Tesis doctoral,195 p.

Williams, W. J. W., 2002, Quaternary maar volcanism in the southern Rio Grande Rift, New Mexico, en Geological Society of America, 36th Annual Meeting, South-Central Section, Abstracts: http://gsa.confex. com/gsa/2002SC/finalprogram/abstract_32966.htm. (Consultado 29 de agosto del 2005)
Wood, D. A., Tarney, J., Varet, J. J., Saunders, A. D., Bougault, H., Joron, J. L., Treuil, M., Cann, J. R., 1979, Geochemistry of basalts drilled in the North Atlantic by IPOD Leg 49: implications for mantle heterogeneity: Earth and Planetary Science Letters, 42, 77-97.

Zindler, A. Hart, S., 1986, Chemical geodynamics: Annual Review of Earth and Planetary Sciences, 14, 493-571.

Zoback, M. D., Zoback, M. L., 1991, Tectonic stress field of North America and relative plate motions, en Slemmons, D. B., Engdahl, E. R., Zoback, M. D., Blackell, D. D. (eds.), Neotectonics of North America: Boulder, Colorado: Geological Society of America, Decade Map, 1, 339-366.

Manuscrito recibido: Agosto 24, 2004

Manuscrito corregido recibido: Agosto 19, 2005

Manuscrito aceptado: Agosto 22, 2005 